\title{
Indicators for optical oxygen sensors
}

\author{
Michela Quaranta • Sergey M. Borisov • Ingo Klimant
}

Received: 28 June 2012 / Accepted: 27 October 2012 /Published online: 24 November 2012

(C) The Author(s) 2012. This article is published with open access at Springerlink.com

\begin{abstract}
Continuous monitoring of oxygen concentration is of great importance in many different areas of research which range from medical applications to food packaging. In the last three decades, significant progress has been made in the field of optical sensing technology and this review will highlight the one inherent to the development of oxygen indicators. The first section outlines the bioanalytical fields in which optical oxygen sensors have been applied. The second section gives the reader a comprehensive summary of the existing oxygen indicators with a critical highlight on their photophysical and sensing properties. Altogether, this review is meant to give the potential user a guide to select the most suitable oxygen indicator for the particular application of interest.
\end{abstract}

Keywords Bioanalysis · Oxygen indicators $\cdot$ Luminescence · Metal complexes · Quenching

\section{Introduction}

Oxygen is by far one of the most important chemical species on earth since it is essential for life. Measurements of its concentration are of extreme importance in many different research fields such as: medicine, chemistry, environmental and marine analysis, molecular biotechnology, bioprocess control, food packaging, and industrial production monitoring. In the majority of the cases, it would be ideal to monitor oxygen concentration continuously which implies the use of oxygen sensors: a class of chemical sensors and by definition "a miniaturized device that can deliver real-time and on-line

M. Quaranta $(\bowtie) \cdot$ S. M. Borisov $\cdot$ I. Klimant Institute of Analytical Chemistry and Food Chemistry, Graz University of Technology, Graz, Austria

e-mail: quaranta.michela@gmail.com information on the presence of specific compounds or ions in even complex samples" [234].

Several methods for oxygen detection exist and can be classified on the basis of the principle used in electrochemical (amperometric, potentiometric, or conductometric), optical (absorption changes or photoluminescence), and chemical (Winkler titration).

Since its development, the Clark electrode has been considered the conventional method for the measurement of oxygen concentration because it is quite robust and reliable. However, in the last three decades, optical sensor technology has received increasing attention due to the fact that optical oxygen sensors can be rather inexpensive, are easy to miniaturize, can be used remotely, are virtually noninvasive or minimally invasive and, most of all, do not suffer from electrical interference nor consume oxygen [3].

Optical chemical sensors can be divided in several subgroups depending on the working principle applied; practically all spectroscopic methods have been used (absorption spectroscopy, reflectometry, luminescence, infrared and Raman spectroscopies, interferometry, and surface plasmon resonance). The majority of the optical sensors developed for oxygen detection rely on quenching of the luminescence of an indicator dye by molecular oxygen [153].

Typical layouts consist of a luminescent dye, whose optical properties are reversibly influenced by the presence of molecular oxygen, which is usually incorporated into a polymeric matrix and deposited on a solid support (planar waveguide, microtitre plate, or optical fiber). Nano- and microparticle-based oxygen probes have also proved to be important analytical tools.

The field of application plays an important role in the choice of the indicator dye and, as a consequence, of the matrix material and detection method. For example, when measuring oxygen in live cells or in tissues, it is necessary to take into account the autofluorescence generated by the 
presence of biological substances such as proteins, DNA, and melanin. In such cases, in order to minimize absorption and scattering of the excitation and emission light in the tissue, it is preferable to employ indicators that show longwave-shifted absorption (590-650 nm) and emission $(730-900 \mathrm{~nm})$ bands $[63,223]$. On the other hand, when measuring ultrafast oxygen dynamics, for example in breath monitoring application [33], it is crucial to use optodes with a very fast response time which can be achieved by employing very thin sensing layers and indicator dyes possessing exceptional brightness.

The scope of this review is not only to provide the reader with a selection of recently developed oxygen indicators but also to give a feeling about the area of applicability with a special focus on bioanalysis.

\section{Photoluminescence and oxygen quenching schemes}

Photoluminescence is the emission of photons produced in certain molecules during de-excitation and is one of the possible physical effects resulting from the interaction between light and matter.

When a luminescent molecule absorbs a photon, it is excited from its ground state $\left(S_{0}\right)$ to some higher vibrational level of either the first or second electronic state $\left(S_{1}\right.$ or $\left.S_{2}\right)$. This transition occurs in about $10^{-15} \mathrm{~s}$ and the subsequent possible de-excitation processes can be visualized by the Perrin-Jablonski diagram in Fig. 1.

The first process to occur, after absorption, is the internal conversion from the excited vibrational level to the lowest vibrational level of $S_{1}$, which takes typically $10^{-12} \mathrm{~s}$ or less. Internal conversion is a nonradiative transition and it is generally complete prior emission. From $S_{1}$, two major radiative de-excitation processes are possible; the first one is fluorescence emission which is a spin-allowed transition (it happens with no changes in multiplicity) that has a high probability of occurrence; fluorescence lifetimes are typically near $10^{-8} \mathrm{~s}$. The second possible process is phosphorescence emission

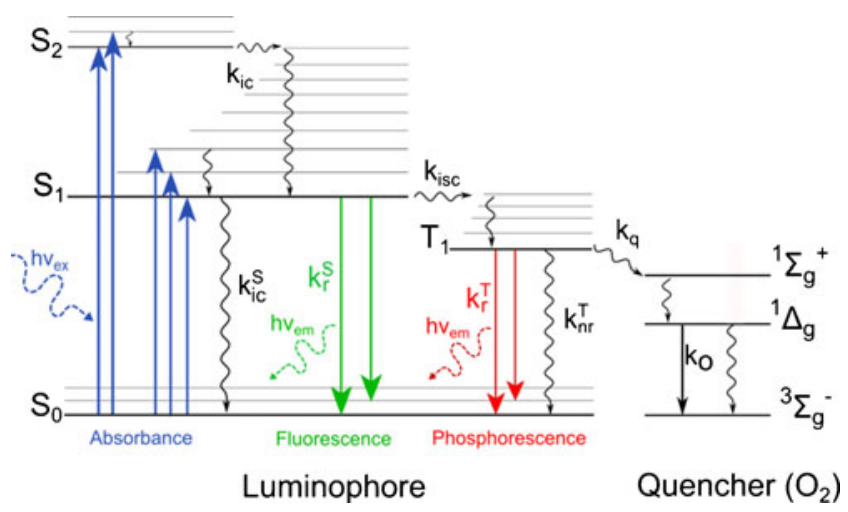

Fig. 1 Perrin-Jablonski diagram from the lowest excited triplet state $T_{1}$ which requires nonradiative intersystem crossing between two isoenergetic vibrational levels belonging to electronic states of different multiplicities $\left(S_{1} \rightarrow T_{1}\right)$ and therefore has a lower probability of occurrence. Transition from $T_{1}$ to the singlet ground state is forbidden; therefore, the rate constants for triplet emission are several orders of magnitude smaller than those of fluorescence and the lifetimes usually vary from $10^{-6}$ to several seconds. The presence of heavy atom within the indicator, either as the central atom or as a substituent in the ligand, usually greatly increases the probability of intersystem crossing (up to unity). This result can promote highly efficient phosphorescence and shortens the phosphorescent decay time.

When an excited molecule returns to the ground state, it emits light at a longer wavelength and lower energy compared to the absorbed light (Stokes' shift); this phenomenon is more pronounced for phosphorescence emission since it occurs from a lower energy state.

In the presence of molecular oxygen, the photoluminescence of such molecules is quenched via a radiationless deactivation process which involves molecular interaction between the quencher and the luminophore (collisional quenching) and it is therefore diffusion limited. The mechanism by which oxygen quenches luminescence is not yet completely clear, one of the proposed mechanisms suggests that the paramagnetic oxygen causes the luminophore to undergo intersystem crossing to the triplet state while molecular oxygen goes to the excited state (either ${ }^{1} \Delta_{g}$, the first excited state or ${ }^{1} \Sigma_{g}{ }^{+}$, the second excited state) and then returns to ground state $\left({ }^{3} \Sigma_{g}^{-}\right.$, the triplet state; Fig. 1) [124]. The formation of singlet oxygen $\left({ }^{1} \mathrm{O}_{2}\right)$ is a direct evidence of the energy transfer mechanism and often the quantum yield of singlet oxygen formation approaches unity. However, quenching mechanism can also occur via electron transfer which was demonstrated to be rather efficient for example in the case of iridium cyclometallated complexes [56].

Independent from the predominant mechanism (energy or electron transfer), the kinetics of collisional quenching by oxygen is very well described by the Stern-Volmer equation (Eq. 1)

$$
\frac{I_{0}}{I}=\frac{\tau_{0}}{\tau}=1+k_{q} \tau_{0} p O_{2}=1+K_{s v} p O_{2}
$$

Where $I$ and $I_{0}$ are the luminescence intensities in the presence and absence of the quencher, $\tau$ and $\tau_{0}$ are the lifetimes of the luminophore in the presence and absence of the quencher, $k_{q}$ is the bimolecular quenching constant, and $K_{\mathrm{sv}}$ is the Stern-Volmer quenching constant.

It is often the case that in microheterogeneous environment (e.g., in polymers) Eq. 1 does not adequately describe the quenching mechanism; in such cases, it is preferable to 
use a second equation from the so-called two-site model [35] (Eq. 2)

$$
\frac{I}{I_{0}}=\frac{f}{1+\mathrm{K}_{\mathrm{sv}}^{1} \mathrm{pO}_{2}}+\frac{1-f}{1+\mathrm{K}_{\mathrm{sv}}^{2} \mathrm{pO}_{2}}
$$

where $f$ represents the fraction of the total emission for the first site and $K_{\mathrm{sv}}{ }^{1}$ and $K_{\mathrm{sv}}{ }^{2}$ are the Stern-Volmer quenching constants for the two sites. The two-site model assumes the existence of two different environments with substantially different accessibility for oxygen. Although this model is physically meaningful only for luminescence intensities, in most cases it can also be used to fit decay times dependences.

Apart from the two-site model, other models exist that are able to describe the degree of heterogeneity of a sensor; for example the log-Gaussian distribution in $\tau_{0}$ and $k_{q}$ [161]. The model assumes that the heterogeneity of an optical oxygen sensor is manifested as a log-Gaussian distribution in rate and therefore is controlled by two kinetic processes: the intramolecular deactivation of the excited state of the luminophore $\left(1 / \tau_{0}\right)$ and the intermolecular quenching of the excited state by oxygen $\left(k_{\mathrm{q}} \cdot p \mathrm{O}_{2}\right)$. Such model is able to generate model parameter values which are physically plausible and consistent at all partial pressures of oxygen.

\section{Sensing methodologies}

Although some of the oxygen sensors in use rely on absorption-based measurements, the majority make use of the luminescence quenching of an indicator dye. Luminescence sensing requires a change in the spectral properties of the indicator in the presence of oxygen. Changes can occur in the form of emission spectrum, luminescence intensity, anisotropy, or lifetime of the sensing probe [124].

The most direct sensing method entails the measurement of changes in luminescence intensity in response to the presence of an analyte. Unfortunately, it is often inconvenient to rely on intensity changes since they can be influenced by a wide variety of factors (e.g., luminophore concentration, photobleaching, light source intensity, scattering, coloration of the probe, etc.) and therefore alter the results of a measurement. Hence, it is important to use alternative methodologies that are independent on these factors, such as ratiometric or lifetimebased measurements. Usually, the choice depends on the cost of the equipment, the availability of indicator dyes, and the field of application.

Ratiometric methods are often preferable for imaging application and typically the sensors contain both an oxygen-sensitive indicator and a reference dye usually incorporated in the same matrix. The latter has to be unquenchable by oxygen and photostable in its presence; the emission spectrum of the reference dye should have little or no overlap with the one of the indicator dye and there should be no energy transfer between the two dyes. Oxygen concentration can then be determined from the ratio of the luminescence intensities of the indicator and the reference dye measured at two different emission wavelengths. This is usually done by using bandpass filters or, alternatively, by attributing the emissions of the components to different color channels of an RGB camera [128, 212, 228]. A more elegant solution is an application of tailor-made indicators which possess dual emission (oxygen-sensitive phosphorescence and oxygen-insensitive fluorescence) but very few examples have been reported so far [244, 254, 256, 258].

Ratiometric oxygen sensors can be applied, for example, for in vitro measurements to image $\mathrm{O}_{2}$ concentration in cells [43] or for noninvasive real-time monitoring of oxygen levels in live cancer cells under normal and hypoxic conditions [135]. It should be mentioned here that ratiometric imaging is still affected by light scattering because this effect is wavelength dependent.

An alternative property that can be used to monitor oxygen concentration is luminescence lifetime $(\tau)$. The lifetime is the average amount of time a luminophore remains in the excited state following excitation and it can be measured either in time domain or in frequency domain [124]. In time domain, the sample is excited with a pulse of light and then the time-dependent intensity is measured; the decay time is calculated from the slope of the a plot of $\log I(\mathrm{t})$ versus $t$ (slope $=-1 / \tau)$. A short delay between the excitation pulse and the measurement allows the complete elimination of short-lived background fluorescence.

In the frequency domain method, the sample is excited with intensity-modulated light. The emission of a luminophore is delayed in time relative to the excitation; the delay is measured as a phase shift $(\varphi)$ and can be used to calculate the decay time:

$\tau=\tan \varphi / 2 \pi f$

where $f$ is the modulation frequency.

A two-frequency phase modulation technique can be very practical when measuring intracellular oxygen concentration in plant tissue since it allows discrimination between the luminescent lifetime of the autofluorescence of the plant tissue and the phosphorescence of the indicator dye [198].

Pulse and phase techniques are theoretically equivalent and provide the same kind of information; each has its own advantages and drawbacks. As mentioned earlier, lifetime measurements overcome the disadvantages of the intensitybased measurements. Luminescence lifetime, for example, is an ideal parameter to measure in biological system where the exact concentration of dye after cellular uptake is difficult to determine and replicate accurately [171].

Imaging of oxygen distribution has become a popular technique in different fields of application such as biomedicine $[158,257]$, marine microbiology [75, 86], and biological systems (intra- and extracellular oxygen distribution) $[57,130]$. 
Luminescence imaging can be performed either through intensity- or lifetime-based measurements. One of the first works on intensity-based phosphorescence imaging was published in 1988 and used to measure oxygen distribution in perfused tissue [192]. Lifetime imaging techniques were developed for the first time two decades ago, and both timedomain (pulsed) [229] and frequency-domain (phase-resolved) [125] have been described; in 1997, the first noninvasive technique to measure oxygen concentration on nonplanar surfaces (e.g., human skin) was described [92].

Lifetime imaging has two major advantages over intensity-based imaging: it consents the enhancement of contrast and it allows the suppression of background fluorescence; also, lifetime imaging does not depend on intensity variation that can derive, for example, from photobleaching or variable indicator concentrations and calibration-free sensing applications are feasible [96]. A frequently used pulsed technique for the determination of fluorescence lifetime is the time-correlated single-photon counting in which the decay time curve is obtained from the integration of many pulses recorded over time [196]. This technique requires complex instrumentation and is less feasible for phosphorescence lifetime imaging because of much longer acquisition times; therefore, a second methodology called rapid lifetime determination (RLD) became rather popular [95, 96, 238].

The principle for image acquisition in RLD is briefly the following: the measurement starts by switching on the excitation source which illuminates the sensing material, the luminescence intensity increases until equilibrium between absorbed and emitted energy of the indicator dye is reached. Then, the light source is switched off and the shutter of the camera is opened to allow luminescence and ambient light to reach the charge-coupled device (CCD) chip at two different time gates $\left(t_{1}\right.$ and $\left.t_{2}\right)$ of identical period $(\Delta t)$; the lifetime is therefore proportional to the ratio of the integrated photon counts $D_{1}$ and $D_{2}$ (Eq. 4 in Fig. 2) [139].

In recent years, another technique appeared and became rather popular: multiphoton microscopy, which is based on

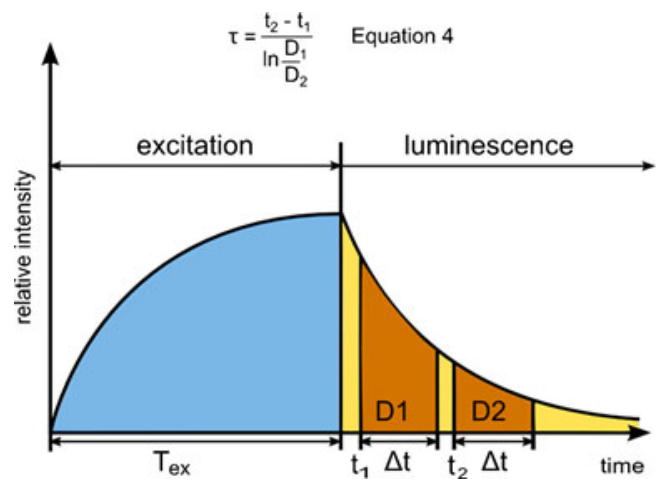

Fig. 2 Schematic representation of RDL measurement excitation of the dye by simultaneous absorption of two or more photons. It is usually used with fluorescence dyes to visualize either tissues or cells with high resolution. The advantages of this method rely on the fact that the nearinfrared (NIR) light used for excitation penetrates deeply into tissues for which is not harmful, the background fluorescence is absent, the spatial resolution is significantly higher, and the photobleaching is lower than for other techniques such as confocal spectroscopy. As a consequence, some probes using this methodology have been recently developed [74, 131, 195]. Unfortunately, the state-of-theart luminescence indicators possess very low two-photon absorption cross-sections and that is why rather sophisticated design of new probes is necessary.

\section{Application of oxygen sensors in bio-analysis}

Optical oxygen sensors have been developed for a wide variety of applications and in this section of the review, the ones inherent to bioanalysis will be highlighted and briefly described. We will focus on the following bioanalytical applications: oxygen content measurements in blood (diagnostics), measurements in bioreactors or in cell cultivating flasks, imaging intra or extracellular oxygen distribution, applications in marine biology, and measurements of photosynthetic and respirometric activity [16]. Finally, the role of oxygen as a transducer for enzymatic biosensors (e.g., for glucose sensors) will be discussed.

\section{Medical diagnostics}

Assessing a patient's need of oxygen is of extreme importance in critical situations such as during surgery, recovery, or while a patient is under intensive care treatment. Sampling of arterial blood and the subsequent analysis suffers from the main disadvantage of not being a continuous method: it is not feasible to sample more than two or three times a minute and oxygen content can fluctuate widely during periods of few seconds.

Back in 1942, Millikan [160] developed the first original oximeter which in concept was very similar to the modern pulse oximeters but suffered from the inability to effectively compensate for the pulsatile variations of the arterial blood. Pulse oximetry was developed by Aoyagi in 1972 [203], who had the idea to measure only the pulsatile changes in light transmission through living tissue to compute the arterial saturation.

The role of a pulse oximeter is to determine the "oxygen saturation" in blood which is defined as the ratio of concentrations between oxyhemoglobin and the total hemoglobin; the method is noninvasive and as a typical intrinsic optical sensor, it does not require any indicator. Light at two 
different wavelengths is allowed to pass through a part of the patient's body (usually the fingertip or the earlobe) to be then measured by a photodetector. Today's oximeters use a pair of light-emitting diodes (LEDs): a red $(660 \mathrm{~nm})$ and an infrared (910 or $940 \mathrm{~nm}$ ) one; at this two wavelengths, hemoglobin and oxyhemoglobin exhibit a very different absorption, therefore, their concentration's ratio can be calculated from the ratio of the absorptions of the red and infrared lights.

Luminescent oxygen sensors have also been applied in medical diagnostics: for example back in 1994, a portable system for in vitro test blood analysis (OPTI system) was developed and commercialized. The system consists of a disposable cassette containing six different optodes for measurement of $\mathrm{pH}$, oxygen and carbon dioxide partial pressure, sodium, potassium, and calcium, all by fluorescence. Additional cassettes are available for determinations of chloride, glucose, and urea [219].

More recently, additional applications of luminescent oxygen sensor for diagnostics have been emerging such as the control of wound healing processes [200], the measurement of transcutaneous $\mathrm{pO}_{2}$ [17], and of tumor hypoxia [258], to mention only some.

\section{Bioreactor and cell cultivating flasks}

Continuous measurements of dissolved oxygen (DO) during cell culture are very important not only to control cellular differentiation, viability, and proliferation [79, 215, 248] but also when designing the scale-up from small-scale culture to mass production $[89,255]$. DO measurement is particularly important in shake flasks for cell cultivation since, for example, in such devices the oxygen transfer rate is lower than in stirred bioreactors; therefore, accurate measurements are essential to avoid biological misinterpretation [199].

Luminescence-based oxygen sensors are very attractive for biotechnological application for a number of different features such as the fact that they are noninvasive and generally nontoxic since they can be easily incorporated in matrices that are not only biocompatible but also nonreactive and non-irritant to culture media [110].

There are many biotechnological processes such as the synthesis of penicillin or yeast fermentation, which require a sterile environment; therefore, the optical sensor used to continuously measure the oxygen concentration in those bioreactors needs to be autoclavable and to withstand sterilization (e.g., high temperature and humidity). Voraberger et al. [224] developed such sensor which was used to measure oxygen concentration in a fermenter; the results showed good comparison with the ones obtained with a Clark-type electrode, which has the disadvantage to suffer from inadequate signal stability, slow response time, and electrical interferences.
Optical oxygen sensors were also developed for online measurement of the biocatalytic activity of enzymes in microtiter plates by integrating the sensing layer into the bottom of each plate [80]; such devices are of potential interest for the screening of aerobic cell activities, biological degradation of pollutants, and for toxicity tests.

Intra and extracellular $\mathrm{O}_{2}$ imaging and $\mathrm{DO}$ in tissue

The application of optical oxygen sensors in the measurement of oxygen concentration, particularly in living tissue, has the advantage of being noninvasive and it can be used remotely.

Inter- and intracellular measurements of dissolved oxygen can be potentially performed with the use of a ratiometric fiber optic sensor which was developed and characterized by Park et al. [180]. The described sensor exhibited excellent reversibility, minimal photobleaching, and fast response time which are fundamental qualities to measure oxygen in biological samples. On the other hand, the size of the fibers, with tips ranging from 40 to $200 \mu \mathrm{m}$, is too big for noninvasive intracellular measurements. Apart from the size, another disadvantage in using optical fibers is that they allow only singlepoint acquisition and are therefore unsuitable for microscopic imaging. As previously mentioned, ratiometric methods are often preferable for imaging applications and have been applied to measure oxygen concentration inside cells [43].

Different kinds of sensing probes have been developed for extra- and intracellular microscopic imaging such as dendrimers, dye conjugates, and dyes (non)covalently entrapped in polymeric nanoparticles, which have the characteristic of being small enough to be introduced directly into the medium of interest (e.g., blood or interstitial fluid).

When measuring in biological systems, phototoxicity is a potential concern. The byproduct of the quenching reaction is singlet oxygen which is highly reactive and capable of damaging biological tissue. Several solutions to this problem are currently under investigation some of which are already employed, for example the use of PEGylated dendritic "jackets" to regulate the sensitivity and dynamic range of measurements by controlling the oxygen quenching constant [37]. PEG residues are used to modify dendrimers in order to enhance their solubility, to reduce their toxicity, and to help to prevent interactions between the probe and the biological environment. Such probe was tested for high-resolution microscopic in vivo microscopy of vascular $\mathrm{pO}_{2}$ in rat's brain [130]. Another approach consists in the encapsulation of an indicator inside an inert nanoparticle, often referred to as probes encapsulated by biologically localized embedding (PEBBLE) [46]; such nano-spheres can have radii as small as $10 \mathrm{~nm}$ and therefore occupy only circa $1 \mathrm{ppb}$ of an average mammalian cell's volume which has the advantage of causing a rather negligible mechanical perturbation. 
Nanosensors have been successfully used to monitor dissolved oxygen in human plasma [34], to monitor cellular respiration [113], and to measure the real-time oxygen concentration inside tumor cells under normal and hypoxic conditions [135].

Nanosensors can be delivered into cells by different techniques such as pico-injectors, gene guns, liposomal incorporation, and endocytosis. Some oxygen nanosensors can spontaneously penetrate cell's membranes thanks to the presence of positively charged groups on the surface of the particle [69].

Another class of cell-penetrating dyes which rely on an endocytic mechanism of cell entry is represented by the derivative of tetracarboxylic $\mathrm{Pt}(\mathrm{II})$-coproporphyrin I (PtCP) [58, 174]. Such conjugates were successfully tested to measure intracellular $\mathrm{O}_{2}$ concentration in live cells, giving informationrich data on cellular function and metabolism. The probe has recently being optimized in order to reduce nonspecific bindings and increase intracellular distribution [57].

Measurements of oxygen concentration in tissue entail additional requirements: the probe does not only have to be highly water soluble, but also to be impermeable to biological membranes so that penetration can be avoided. Another important characteristic is to possess an absorption band in the NIR region since the excitation light needs to penetrate the depths of tissue [130].

Accurate measurements of oxygen concentration in tissue not only give information about tissue oxygenation but also about local microcirculation; such information is of clinical interest for example in radiotherapy and chemotherapy of cancer. Continuous monitoring of oxygen partial pressure has also been realized with the use of an optochemical glass capillary oxygen sensor connected to a microdialysis catheter for the extraction of the biological fluid from a subcutaneous adipose tissue [23].

Two-dimensional $\mathrm{pO}_{2}$ distributions were measured over the cross-section of cultivated tissues which were, for this scope, immobilized on top of an optical sensor foil [101]. The experimental setup used by the authors allowed a continuous, noninvasive measurement of tissue oxygen distribution which correlated well with histological analysis and supports the hypothesis that tissue growth in vitro is limited by oxygen supply.

\section{Marine biology}

The accurate measurement of oxygen concentration in fresh and salty water environments has always solicited the interest of scientists in different fields since monitoring the level of DO is essential to clarify several biological processes. Along with oxygen microelectrodes [119], oxygen microoptodes have been extensively used in marine biology for over a decade $[105,127,184]$.

The study of two dimensional (spatial and temporal) distributions and the dynamics of oxygen in marine sediments is also very important, but it cannot be performed with a fiber optic micro-optode since it allows only single-point measurements and it would require a series of sensors (and recording devices) and therefore render the measurement expensive and impractical. Those problems were overcome with the introduction of planar optode to aquatic sciences [85]. Such systems can be based on either intensity (pure or ratiometric) or lifetime-based measurements and they have been developed and applied in many different habitats [121] like microbial mats [84], marine sediments [112, 202], coastal sands [86, 231], permeable sediments [49], rhizospheres [98], and endolithic algal communities [120].

Monitoring of oxygen on 3D surfaces and in tissues is not yet common in marine biology due to the fact that suitable sensing materials (oxygen-sensitive micro- and nanoparticles) became available only in recent years. A very recent work [67] though suggests that such new analytical tools developed by material chemists will become increasingly important in this field in the future. These tools can provide information which is not accessible by more conventional fiber-optic microsensors and planar optodes.

\section{Enzymatic biosensors}

Optical oxygen sensors can be used as transducers for biosensors when coupled with specific biorecognition elements such as enzymes, antibodies, or oligonucleotides [30]. True biosensors can be defined as analytical devices which comprise the following two elements in spatial proximity: a biological element, which is able to interact specifically with the target analyte and a transducer, which transforms the recognition event into a measurable signal. In addition, true biosensors do not need any additional processing steps such as reagent addition and therefore give a reading when exposed to the sample [214].

The most exploited biosensors that make use of optical oxygen sensors as transducer are glucose sensors since they have a wide application in life science, biotechnology, biology, clinical analysis, and food chemistry. In general, the significant interest in sensing glucose is driven by the fact that $4-5 \%$ of the world population suffers from diabetes mellitus which is a complex disorder and its main characteristic is the chronic shift in glucose concentration in blood [210]. There are several complications related to diabetes which are linked to the duration and severity of hyperglycemia (high blood glucose concentration); therefore, it is of extreme importance to maintain the glucose level near to normal values. This can only be provided by a device that continuously measures glucose concentration in the blood. Ideally, the ultimate implantable glucose sensor (used in artificial pancreas) would constantly monitor glucose concentration and automatically activate the release of insulin when needed; unfortunately, such device is still quite far from being fully developed. Many different types 
of optical glucose sensor have been successfully assembled and used, but since the focus of this review is on optical oxygen sensors, only those which rely on the measurement of oxygen consumption due to the enzymatic oxidation of glucose by glucose oxidase (GOx; Eq. 5) will be described.

$D-$ glucose $+\mathrm{O}_{2} \rightarrow \mathrm{D}-$ glucono $-1,5$ - lactone $+\mathrm{H}_{2} \mathrm{O}_{2}$

One of the first optical biosensor based on GOx immobilized on a nylon membrane was reported in 1988 [218]. Such sensor was based on the quenchability of decacyclene, allowed a continuous determination of glucose in the physiological range and it was in commercial use for more than 10 years. The sensor had been improved years later to obtain shorter response times within the range of 8-60 s [197].

Among the optical devices developed for continuous glucose detection and measurements in vivo, the miniaturized hybrid fiber optical biosensor presented by Klimant and coworkers $[181,182]$ should be mentioned. The design of this hybrid sensor allows its implantation in subcutaneous tissue and to compensate for the local $\mathrm{pO}_{2}$ changes. Two different optodes, one for the determination of glucose and the second one for the determination of local oxygen are placed in close proximity into a polyimide tube; therefore, the final readout which corresponds to glucose can be obtained by the difference between the local oxygen tension (measured by the reference optode) and the reduction of the oxygen level measured by the glucose optode due to the enzymatic reaction [181]. A similar setup has been tested in vitro in a 3-day continuous experiment in glucose-spiked plasma and once coupled with a flow-through cell and commercially available catheter; its ability to measure glucose in humans was also demonstrated in a $24 \mathrm{~h}$ test on healthy volunteers [182].

Another fiber-optic dual sensor for the continuous determination of oxygen and glucose was developed by $\mathrm{Li}$ et al. [137]. In this approach, the two sensing sites were placed at defined distance between each other on the distal end of an imaging fiber, the changes in fluorescence intensities were therefore captured with a CCD camera. Apart from the instrumental costs, the main drawback of the unit was the dependence of the signal intensity on the dye loading.

Different assemblies of thin film glucose biosensor based on a sol-gel matrix, which are capable of compensating the effect of variable oxygen background, have also been developed by Wolfbeis et al. [236].

Glucose has also been successfully measured online in animal cell cultures with the use of a flow injection analysis system based on fiber optic detection of oxygen consumption using immobilized glucose oxidase [62]. Such system has been tested to be stable for more than 4 weeks in continuous operation withstanding up to 20 analyses per hour and it has been successfully applied to the online monitoring of both glucose and lactate concentrations of an animal cell culture for the production of recombinant human antithrombine III.

Biosensors have also been developed to measure glucose concentration in beverage samples, where the enzyme was either immobilized in eggshell membrane [42] or entrapped in sol-gel [243] and in urine samples where GOx was immobilized in xerogel [240].

Continuous glucose monitoring is of course extremely important, especially for critically ill patients. Many people suffer from diabetes but only one third is aware of it, it is therefore fundamental to have a fast, easy, and cheap way to diagnose diabetes. Wang et al. [230] have developed a new optical biosensor characterized by short response time, lower detection limit, high sensitivity, and stability which can be potentially applied for the fast determination of glucose in human serum. The same group has recently assembled a novel direct readout colorimetric optical glucose sensor strip which can be easily read without instrumental assistance [225]. Such "glucose ruler" was constructed based on a three-layer film which includes a green-emitting $\mathrm{CdTe} / \mathrm{CdS}$ quantum dots layer as a stable background, a red-emitting platinum-porphyrin oxygen-sensitive layer and a glucose oxidase layer. Oxygen is consumed when the ruler is exposed to glucose and it results in a color change from green to red depending on the concentration.

Biosensors that make use of oxidase type enzyme combined with an optical oxygen transducer have been also designed for other compounds:

- Phenols in hydrophobic organic solvents (enzyme: tyrosinase) [242]

- Alcohols (methanol and ethanol-biosniffer) in watermiscible solvents and in hydrophobic organic solvents (enzyme: alcohol oxidase) [167, 241]

- Cholesterol, for the continuous detection either in aqueous micelle solution or in hydrophobic organic solvents (enzyme: cholesterol oxidase) [239]

- Aspartame in commercial products such as artificial sweeteners (enzymes: $\alpha$-chymotrypsin and alcohol oxidase) [247]

- Choline-containing phospholipids in serum samples (enzyme: phospholipase-D) [150]

- Bilirubin in serum samples (enzyme: bilirubin oxidase) [136]

- Glutamine in mammalian cells cultures (enzymes: glutaminase and glutamate oxidase) [36]

\section{Classification of indicators for oxygen sensors}

The scope of this review is to give the reader an overview on the state-of-the-art indicators available for optical oxygen 
sensing. Among the different indicators that have been synthesized and used in this area, one can classify them in two main groups: absorption- and luminescence-based indicators. Absorption-based indicators can be further divided in reversible and irreversible while luminescence-based indicators are only reversible.

\section{Absorption-based indicators}

Irreversible probes

In general, irreversible absorption-based indicators work by producing a visible color change which is caused by chromogenic chemistry that involves oxidation of the leuco dye by molecular oxygen. Only few of such indicators have been described and their main application can be found in the food and pharmaceutical industries where it is necessary to monitor the headspace gas within packages for meat/fish or for immune reagents, since oxygen is responsible for a variety of food spoiling processes. To be of use for the final consumer, ideal indicators should produce a discernible color change detectable by eyes and should not require specific analytical equipment. Also, an irreversible probe can be preferable to a reversible one in food packaging applications since it can reliably detect the event of the oxygen ingress during the package damage. On the other hand, a reversible probe may still indicate the absence of oxygen in a damaged package since oxygen, after penetration, can be consumed by growing bacterial species.

Indigo and thioindigo (1b and $\mathbf{2 b}$, respectively, Fig. 3) are vat dyes that can be easily reduced with a suitable reducing agent to become water soluble and colorless. They were incorporated in their reduced form in different polymeric matrices, either moderately or highly oxygen-permeable in order to increase the effective dynamic range [233]. Reaction with oxygen leads to a color change within a few minutes which is quite important when wanting to detect leaks in food packed under modified atmosphere. The authors reported on the possibility to regenerate the sensor immobilized on hydrogel by reduction under inert atmosphere.

Very recently, Mills et al. [162] used a redox dye, methylene blue (MB 3b, Fig. 3) in combination with a sacrificial electron donor, DL-threitol, and $\mathrm{TiO}_{2}$ particles to create an oxygen-sensitive pigment that was then incorporated into a thermoplastic polymer and used as an $\mathrm{O}_{2}$ smart plastic film. Once the blue-colored indicator is incorporated in the package, it needs to be activated by UVA light $\left(4 \mathrm{~mW} \mathrm{~cm}^{-2}\right)$ for less than $90 \mathrm{~s}$ which causes the MB to be converted to its colorless leuco form that will persist for long time provided that no oxygen is present. It was reported that the indicator can be regenerated in about 4 days. The authors also suggested that the response of the indicator could be increased by depositing Pt nanoparticles onto the $\mathrm{TiO}_{2}$ surface.

Methylene blue suffers from a slow reduction to its leuco form and a fast subsequent oxidation by oxygen present at low concentration; therefore, Hay et al. [187] have chosen indicators which showed a much faster reduction after UV exposure, namely 2,2'-dicyano-1-1'dimethy-4,4'-dipyridinium dimesylate and thionine (4b and $\mathbf{5 b}$, respectively, Fig. 3). This class of indicators shows a moderate sensitivity to oxygen and therefore can be used even when the level increases up to $4 \mathrm{kPa}$.

\section{Reversible probes}

In our body, oxygen is efficiently transported from the respiratory organs to the rest of the body by hemoglobin, a metalloprotein which binds oxygen reversibly. The association with oxygen generates a shift in the Soret absorption band of hemoglobin; this absorption change was exploited to build an optical sensor to measure $\mathrm{pO}_{2}$ from 2.6 to $13.4 \mathrm{kPa}$, based on immobilized hemoglobin [259]. The main shortcomings of this system are related to the fact that hemoglobin degrades within 2 days when stored at room temperature and 1 week when stored at $4{ }^{\circ} \mathrm{C}$. Therefore, a synthetic, more stable, alternative needed to be found. It is known that some organometallic compounds are able to reversibly bind molecular oxygen [65] and therefore once immobilized on an appropriate support be used as absorption-based oxygen sensors. Among the different organometallic compounds synthesized by Baldini et al. [19], bis(histidinato) cobalt(II) $\left[\mathrm{Co}(\mathrm{His})_{2}\right] 6$ (Fig. 4) was identified to be the best candidate to work as a transducer for oxygen sensing. Such indicator was adsorbed on a thin layer chromatographic plate which was then coated with a layer of silicon rubber; this additional layer is necessary not only to maintain a wet micro-environment but also to mechanically protect the sensitive layer [54]. The sensor was successfully tested in a series of oxygenation/deoxygenation cycles by monitoring the absorption peak at $\lambda=408 \mathrm{~nm}$. It was also found that the response of the indicator is influenced by the $\mathrm{pH}$ and it does not give any response at $\mathrm{pH}$ lower than 4 , since the histidine ligand can exist in different forms depending on $\mathrm{pH}$ and a change in the ligand is likely to affect the binding of oxygen.

Another complex that mimics hemoglobin in binding oxygen is the meso-tetra $(\alpha-\alpha-\alpha-\alpha-o$-pivalamidophenyl) porphyrinatocobalt(II) 7 [47] which was immobilized on either poly(octylmethacrylate-co-1-vinylimidazole) or poly $(2,2,3,3,4,4,5,5$-octafluoropentylmethacrylate-co-1vinylimidazole) [189]. The complex in the presence of oxygen forms an oxo-adduct (Fig. 4) at the cobalt center which causes a shift in the absorption spectra, monitored at $547 \mathrm{~nm}$. The sensing membranes are stable for 1-2 months and possess a useful response range between 0.1 and $100 \%$ of oxygen at atmospheric pressure. 
Fig. 3 Chemical structures of irreversible probes<smiles>[O-]C1C(=C2Nc3ccccc3C2O)Nc2ccccc21</smiles>

1a Reduced leuco form (colorless)<smiles>Cc1ccccc1SC1=CCCCC1[O-]</smiles>

2a Reduced leuco form (colorless)<smiles>[R20]C(Cl)(Cl)Cl</smiles>
leuco form (colorless)<smiles>CN1C=CC(=C2C=CN(C)C(C#N)=C2)C=C1C#N</smiles>

4a Reduced leuco form (colorless)

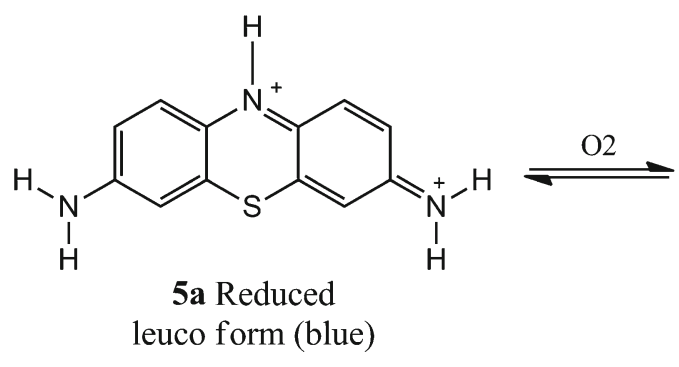<smiles></smiles>

1b Oxidised form indigo (blue)<smiles>O=C1/C(=C2\Sc3ccccc3C2=O)Sc2ccccc21</smiles>

2b Oxidised thioindigo (red) 3b Oxidised methylene blue (blue)<smiles>C[n+]1ccc(-c2cc[n+](C)c(C#N)c2)cc1C#N</smiles>

4b Oxidised 2,2'-dicyano-1-1'dimethy4,4'-dipyridinium dimesylate (blue)<smiles>Nc1ccc2nc3ccc(N)cc3[s+]c2c1</smiles>

5b Oxidised thionine (purple)
A fiber optic oxygen sensor for gaseous $\mathrm{O}_{2}$ measurements was successfully developed by Choi and Hawkins [40, 41]. The working principle of this sensor is based on the contact charge-transfer absorption of $N, N$-dimethyl- $p$-toluidine 8 (Fig. 4) at $400 \mathrm{~nm}$. The indicator is entrapped inside a poly(tetrafuoroethylene) tubing and inserted into a glass flow though cell. The described sensor can detect $\mathrm{O}_{2}$ from 4.3 to $100 \%$, it uses very inexpensive materials and its fabrication is quite simple and fast but it suffers from several drawbacks such as interference from $\mathrm{Cl}_{2}$ and $\mathrm{SO}_{2}$, long response time and recovery times (12-26 $\mathrm{min})$.

None of the absorption-based systems presented above became widespread in practice since the resolution provided is quite low as the spectral changes upon oxygen binding are relatively small. It should be mentioned here the existence of another technique for absorption-based oxygen sensors that relies on monitoring of the lifetime change of the triplet-triplet $\left(T_{1}-T_{n}\right)$ absorption [3]. The triplets of the indicators produced 
Fig. 4 Chemical structures of reversible absorption-based indicators

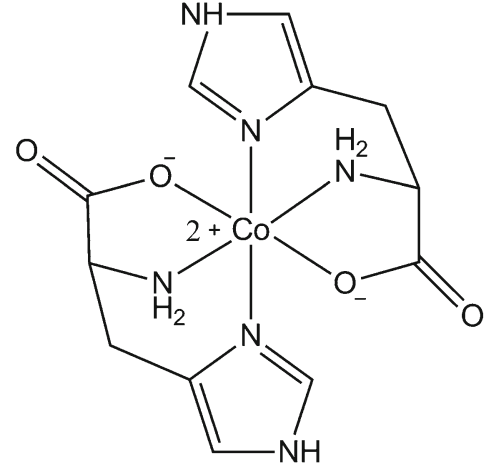

6 Bis(histidinato) cobalt (II)<smiles>[Y]CC(CC([Y])n1ccnc1)C(=O)O[R]</smiles><smiles>C=C</smiles><smiles>[Y]CC(CC([Y])n1cccn1)C(=O)O[R]</smiles>

$\mathbf{R}=\mathrm{PhNHCOC}\left(\mathrm{CH}_{3}\right)_{2}$

$\mathbf{R}^{\prime}=$ a) n-octyl or b) 2,2,3,3,4,4,5,5-octafluoropenyl

7 meso-tetra(a- a- a- a-o- pivalamidophenyl) porphyrinatocobalt(II) immobilized on poly(metacrylate-co-1-vinylimidazole) (a) or on poly $(2,2,3,3,4,4,5,5$-octafuoropentylmethacrylate-co-1-vinylimidazole (b)

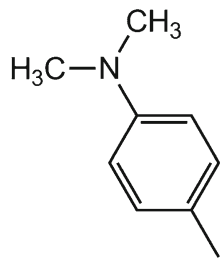

$8 N, N$-dimethyl - $p$-toluidine

during excitation are dynamically quenched by molecular oxygen. Theoretically, the number of oxygen indicators can be greatly extended since any luminescent or nonluminescent molecule possessing efficient intersystem crossing is suitable. In practice though, the use of this technique is severely limited by the need of a quite complicated setup and high power light sources to allow an efficient population of triplet states. Two classes of indicators have been reported so far, $\mathrm{Zn}^{2+}$ porphyrins, which have a long lifetime of photoexcited triplet state $(\sim 100 \mu \mathrm{s})$ and fullerene $\left(\mathrm{C}_{60}\right.$ and $\left.\mathrm{C}_{70}\right)$ which have a longer photoexcited triplet state $(\sim 20 \mathrm{~ms})$ that is efficiently quenched by oxygen [3].

\section{Luminescence-based indicators}

To date, the most common and useful types of optical oxygen sensors are those based on the quenching of 
luminescence of appropriate indicators by molecular oxygen. The ability of oxygen to decrease the luminescence of dyes adsorbed on inorganic surfaces was first observed and published by Kautsky back in 1939 [100] who immobilized organic dyes such as trypaflavin, chlorophyll, porphyrins, eosin, erythrosine on either solid silica gel or aluminum oxide gel and observed that both the fluorescence and the phosphorescence of the adsorbates are reversibly quenched by oxygen.

Since then, different analytical applications of luminescence quenching for the determination of oxygen partial pressure have been reported. In 1944, Pollack et al. [185] described a method to measure oxygen production by exploiting the quenching of phosphorescence of an unspecified dye adsorbed in silica gel. Shaw [204] applied the ability of $\mathrm{O}_{2}$ to quench the phosphorescence emission of phenanthrene and triphenylene immobilized in acrylic media as a method to measure the diffusion coefficients of oxygen through the polymeric media.

Jones [99] determined the oxygen permeability in thin acrylic films by measuring the quenching rate of the phosphorescence lifetime of naphthalene which was added to the film as an additive. A prototype to measure the atmospheric oxygen tension based on the quenching of fluorescence of fluoranthene adsorbed on porous glass was developed by Bergman in 1967 [22].

The number of luminescent indicators synthesized and exploited in optical oxygen sensing has of course largely increased as researchers started recognizing their potential to measure oxygen concentration in different fields of science as previously described.
The reader will now find the description of luminescent indicators classified in the following groups: polycyclic aromatic hydrocarbons, polypyridyl complexes, metal porphyrins, cyclometallated complexes, and complexes with rarely used central atoms. Indicators for oxygen sensing not belonging to any of these categories can be found in the section called "Miscellaneous".

\section{Polycyclic aromatic hydrocarbons}

Polycyclic aromatic hydrocarbons (PAHs), especially pyrene and its derivatives (Fig. 5), have been used as fluorescent indicators as they possess a relative long excitedstate lifetimes and can be quenched by oxygen in the 0 $40 \mathrm{kPa}$ range (Table 1).

Pyrene (9) has a relatively high quantum yield $(\Phi)$ of circa 0.7 , good pressure sensitivity, and low temperature coefficient at ambient temperature; characteristics that can make it a suitable fluorophore for pressure sensitive paint (PSP). On the other hand, studies have demonstrated lack of stability of this indicator which tends to diffuse out of the support and evaporate [20]. Also, low solubility of planar PAHs and their tendency to aggregate in polymer represent another hindrance. Therefore, a number of pyrene derivatives bearing long lipophilic chains were prepared to overcome the above disadvantages. For example, Basu et al. [21] synthesized a pyrene derivative: 1-decyl-4-(1-pyrenyl) butanoate 12 which has a high oxygen quenching sensitivity and lower diffusion coefficient in silicone polymer. Perylene dibutyrate $\mathbf{1 3}$ has been incorporated in an organic polymer adsorbent (amberlite) and deposited on an optical fiber for in vivo oxygen concentration measurements [183].
Fig. 5 Chemical structures of polycyclic aromatic hydrocarbons

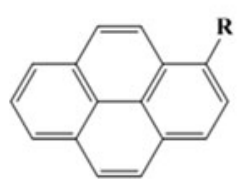

9 pyrene
$\mathbf{R}=$<smiles>CCCC(=O)O</smiles>

101 -pyrenebutyric acid

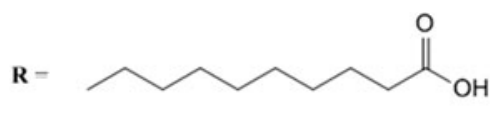

11 1-pyrenedecanoic acid

$\mathbf{R}=$<smiles>CCCCCCCCCCOC(=O)CCC</smiles>

12 1-decyl-4-(1-pyrenyl) butanoate

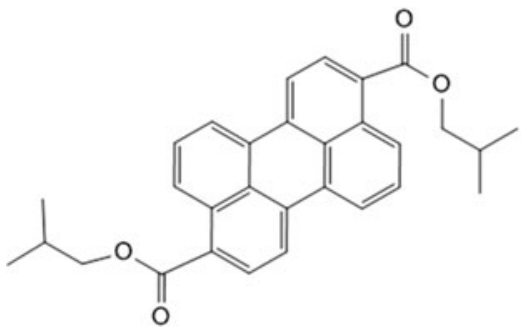

13 perylene dibutyrate

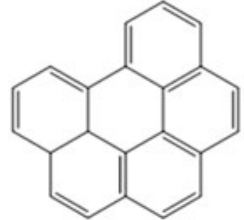

14 benzo[ghi]perylene<smiles></smiles>

15 decacyclene 
Table 1 Photophysical properties of polycyclic aromatic hydrocarbons

\begin{tabular}{|c|c|c|c|c|c|c|}
\hline Dye & $\lambda_{\max }^{\text {abs }}(\mathrm{nm})$ & $\lambda_{\max }^{\mathrm{em}}(\mathrm{nm})$ & Medium & $\Phi$ & $\tau(\mathrm{ns})$ & References \\
\hline 9 Pyrene & $305 / 319 / 335$ & $381 / 390$ & Cyclohexane & 0.65 & 450 & {$[252]$} \\
\hline 10 1-Pyrenebutyric acid & 365 & $376 / 396 / 447$ & Toluene & - & 200 & {$[3,176]$} \\
\hline 11 1-Pyrenedecanoic acid & 340 & $376 / 396$ & Alumina plate & & & {$[78]$} \\
\hline 12 1-Decyl-4-(1-pyrenyl) butanoate & 345 & 480 & Toluene & - & - & {$[21]$} \\
\hline 13 Perylene dibutyrate & 468 & 514 & Toluene & - & - & [183] \\
\hline 14 Benzo[ghi]perylene & 386 & 419 & Methanol & $0.26^{\mathrm{a}}$ & 110 & {$[97]$} \\
\hline 15 Decacyclene & 385 & 510 & Toluene & 0.29 & - & {$[218,237]$} \\
\hline
\end{tabular}

a Taken from [53]

Among the different PAHs, 1-pyrenebutyric acid 10 possesses longer fluorescence lifetime $(0.2 \mu \mathrm{s})$ and therefore it is suitable for optical oxygen sensing devices; it has been demonstrated that isolated rat liver cells easily take up 1pyrenebutyric acid in concentrations up to $0.8 \mathrm{mM}$ and the fluorescence probe can be used to measure intracellular oxygen concentration [108]. In general, PAHs are not very soluble in polymeric matrices; to overcome this problem, Amao et al. [13] fabricated a probe for oxygen sensing based on 1-pyrenebutyric acid adsorbed on the surface of an alumina plate.

1-Pyrenedecanoic acid $\mathbf{1 1}$ can also be chemisorbed onto alumina plate through its carboxyl group and the resulting sensor film has rapid response and recovery times. The fluorescence lifetime of benzo[ghi]perylene $\mathbf{1 4}$ is longer than $100 \mathrm{~ns}$ and its absorption maximum coincided with the wavelength of the second-harmonic emission from a near-infrared semiconductor laser which was used as the light source in an optical fiber setup for the determination of oxygen concentrations [175].

Decacyclene $\mathbf{1 5}$ has been used for more than 10 years as the oxygen indicator in a glucose biosensor [218] and it was the indicator of choice in a dual sensor for oxygen and halothane [237]; it can be excited by a blue LED and it has the advantage of not producing singlet oxygen when quenched.

This class of dyes in general suffers from many disadvantages which has limited their application as indicators for oxygen sensors. They have short excitation wavelength (300-390 nm) which causes components of biological media, optical components or polymers to display strong background fluorescence which is emphasized by small Stokes' shifts; despite good emission quantum yields the molar absorption coefficients are rather low which results in moderate brightness; the fluorescence decay times do not exceed several hundred nanoseconds so that sufficient sensitivity can be achieved only in highly gas-permeable polymers; finally, the majority of PAHs is not well soluble in polymeric matrices and therefore suffers from lack of stability due to aggregation.
It can be summarized here that PAHs and other fluorescent oxygen indicators which have been of importance in the early stage of sensor development are nowadays almost completely substituted by more advanced indicators which will be described below.

\section{Transition metal polypyridyl complexes}

Many luminescent transition metal polypyridyl complexes have been synthesized and some have been used as indicators for oxygen sensing. Within this group of indicators, transition metals used are Ru(II) and Os(II). In general, their complexes are characterized by large Stokes' shifts, possess excitation and emission maxima in the visible region, show good photostability, and their luminescent properties can be tuned as a function of the ligands.

Within this group, $\mathrm{Ru}(\mathrm{II})$ polypyridyl complexes have been used more frequently due to their relatively high brightness and relatively long lifetimes; this is especially true for the tris(4,7-diphenyl-1,10-phenanthroline) ruthenium(II) complex $\left[\mathrm{Ru}(\mathrm{dpp})_{3}\right]^{2+} \mathbf{2 0}$ (Fig. 6) which has a luminescence lifetime up to $6.4 \mu$ s and a quantum yield of 0.3 [2]. Despite the disadvantages which will be described below, this dye is still one of the most popular oxygen indicators in use.

The luminescence of $\mathrm{Ru}(\mathrm{II})$ polypyridyl complexes is dominated by the metal to ligand charge transfer (MLCT) process that involves the promotion of an electron from a metal $d$ orbit to a ligand $\pi^{*}$ orbit; and therefore has been shown to be dependent on the polarity of the microenvironment and on the donor/acceptor character of the surrounding medium because of the significant changes produced on the electronic charge distribution of the molecule upon photoexcitation [166]. Also, both the excitation and the emission bands of the MLCT complexes are very broad which can be viewed as a positive property (higher flexibility in the choice of the excitation sources) but can also be a disadvantage (lower molar absorption coefficients and difficulties in isolating the emission in multi-analyte systems).

Luminescence lifetimes of several microseconds result in rather low oxygen sensitivity in common polymeric 


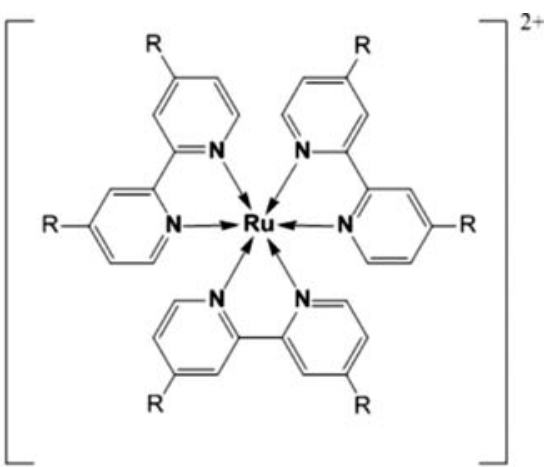

$16 \mathrm{R}=\mathrm{H}$, Tris(bipyridine) ruthenium(II) $\left[\mathrm{Ru}(\mathrm{bpy})_{3}\right]^{2+}$

$17 \mathrm{R}=\mathrm{Ph}$, Tris(4,4-diphenyl-2,2-bipyridine) ruthenium(II) $\left[\mathrm{Ru}(\mathrm{dpb})_{3}\right]^{2+}$

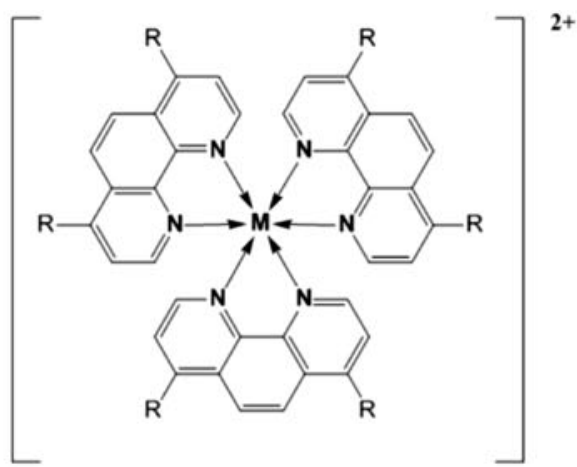

$19 \mathbf{M}=\mathbf{R u}, \mathrm{R}-\mathrm{H}$, Tris(1,10-phenanthroline) ruthenium(II) $\left.[\text { Ru(phen })_{3}\right]^{2+}$

$24 \mathbf{M}=\mathbf{O s}, \mathbf{R}=\mathrm{H}$, Tris(1,10-phenanthroline) osmium(II) $\left.[\mathrm{Os} \text { (phen })_{3}\right]_{2+}$

$20 \mathbf{M}=\mathbf{R u}, \mathbf{R}=\mathrm{Ph}$, Tris(4.7-diphenyl-1,10-phenanthroline) ruthenium(II) $\left[\mathrm{Ru}(\mathrm{dpp})_{3}\right]^{2+}$

$25 \mathbf{M}=\mathbf{O s}, \mathrm{R}=\mathrm{Ph}$, Tris(4.7-diphenyl-1,10-phenanthroline) osmium(II) $\left[\mathrm{Os}(\mathrm{dpp})_{3}\right]^{2+}$

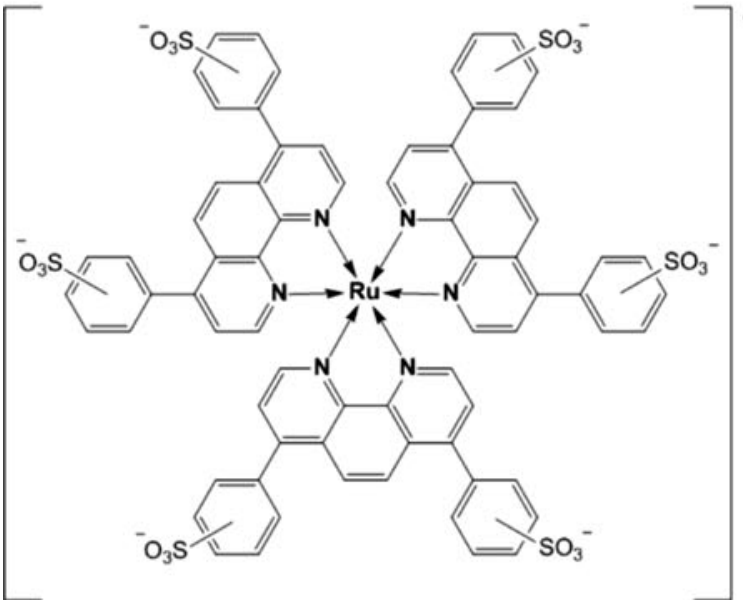

21 Tris(1,10-phenanthroline-4.7-bis(phenylsulphonate)) ruthenium(II) $\left[\mathrm{Ru}(\mathrm{s} 2 \mathrm{~d})_{3}\right]^{2-}$

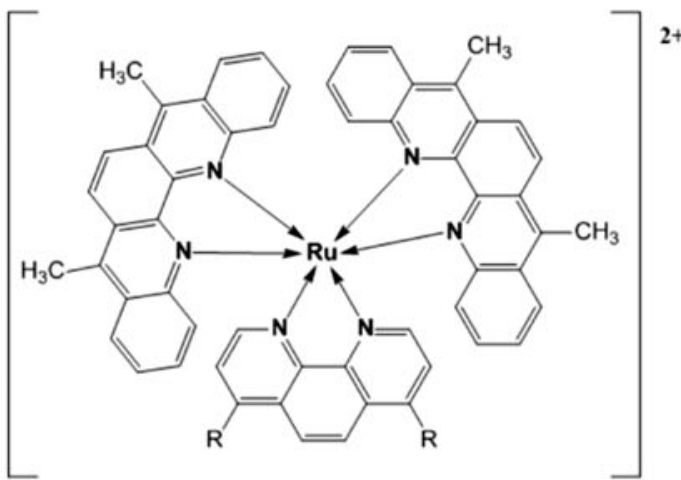

$23 \mathrm{R}=\mathrm{Ph},((4,7$-diphenyl-1,10-phenanthroline)bis(6.7-dihydro5,8-dimethyl-dibenzo-[i,j][1,10]penanthroline)) ruthenium(II) $\left[\mathrm{Ru}(\mathrm{ddp})(\mathrm{DMCH})_{2}\right]^{2-}$

Fig. 6 Chemical structures of Ru(II) and Os(II) polypyridyl complexes

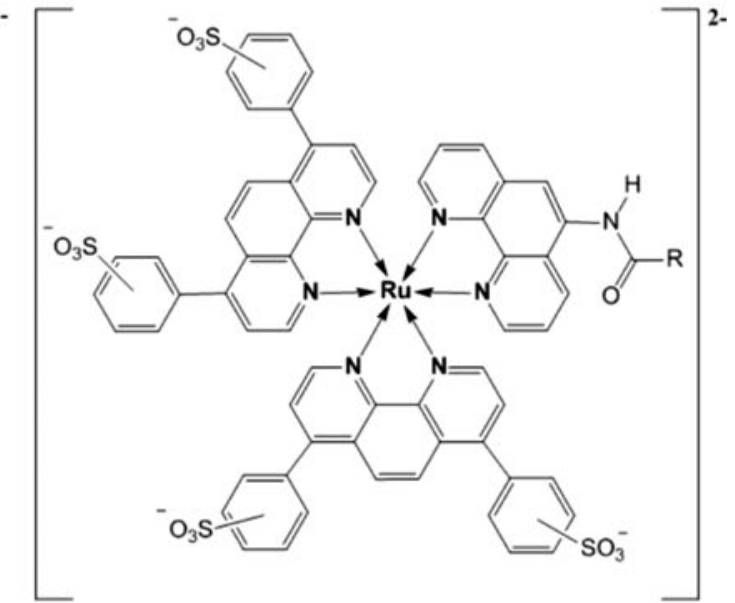

22a $\mathrm{R}-\mathrm{CH}_{3}$, (s2d) $)_{2}$ (5-acetamide-1,10-phenanthroline) ruthenium(II) $\left[\mathrm{Ru}(\mathrm{s} 2 \mathrm{~d})_{2} \text { (acap) }\right]^{2-}$

22b $\mathrm{R}=\mathrm{C}_{13} \mathrm{H}_{27},(\mathrm{~s} 2 \mathrm{~d})_{2}$-(5-tetradecanamide-1,10-phenanthroline) ruthenium(II)

$\left[\mathrm{Ru}(\mathrm{s} 2 \mathrm{~d})_{2}(\mathrm{tdap})\right]^{2 \cdot}$ 
matrices such as polystyrene [91]; the resolution of such sensors in the range of $0-21 \mathrm{kPa} \mathrm{O}_{2}$ is often not sufficient for practical applications. To overcome this problem, the ruthenium(II) polypyridyl complexes have been immobilized in highly oxygen-permeable matrices such as silicon rubbers or organically modified silica (Ormosil). Unfortunately, $\left[\mathrm{Ru}(\mathrm{dpp})_{3}\right]^{2+}$, just like the majority of the other ruthenium polypyridyl complexes, is ionic and therefore it displays very poor solubility in silicon rubber which is one of the most common matrices for optical oxygen sensors as it has a high permeability for oxygen, good adhesion to glass fibers, inertness to biological samples, optical transparency, and excellent chemical and mechanical stability. Klimant and Wolfbeis [107] replaced the inorganic counter ion with an organic one to render the dye silicone soluble. Dodecyl sulfate $\left(n-\mathrm{C}_{12} \mathrm{H}_{25} \mathrm{SO}_{3}{ }^{-} / \mathrm{DS}\right)$ or trimethylsilylpropanesulfonate $\left(\left(\mathrm{CH}_{3}\right)_{3} \mathrm{SiCH}_{2} \mathrm{CH}_{2} \mathrm{CH}_{2} \mathrm{SO}_{3}{ }^{-}\right.$/TSPS $)$were used. They demonstrated that, thanks to the enhanced solubility, the modified indicators could be used as indicators for oxygen sensors in high concentrations so that very thin but highly luminescent layers could be prepared.

In the same way, Mills [164] incorporated the fluorophore cation into a variety of different plasticized polymeric films (e.g., polymethylmethacrylate (PMMA)/tri$n$-buthylphospate (TBP)) using a tetraphenylborate anion.

Alternative matrices have been used to immobilize [Ru $\left.(\mathrm{dpp})_{3}\right]^{2+}$ to construct a feasible optical oxygen sensor. Examples are sol-gel [147, 152, 154, 249], ethyl cellulose or PVC membranes [61], different types of ORMOSILs [39, 94, 106], polystyrene [91], polysulfones [11, 18], poly (dimethylsiloxane) alone [251] or with different amounts of pendant acrylate groups [168], and a blended fluoropolymer matrix consisting of Nafion ${ }^{\circledR}$ and Aflas $^{\circledR}$ [83]. In another approach, the $\left[\mathrm{Ru}(\mathrm{dpp})_{3}\right]^{2+}$ complex was adsorbed onto silica and then dispersed in a silicone rubber support $[38,93]$. Finally, the ruthenium indicator can be cross-liked with isobutyl methacrylate and 2,2,3,3-tetrafluoropropyl methacrylate to obtain a porous plastic probe which can be easily coupled with common optic fibers [87].

Optical oxygen sensors have been developed using various $\mathrm{Ru}(\mathrm{II})$ polypyridyl complexes such as $\left[\mathrm{Ru}(\mathrm{bpy})_{3}\right]^{2+} \mathbf{1 6}$ (bpy=bipyridyl) $[142,159,235],\left[\mathrm{Ru}(\mathrm{dpb})_{3}\right]^{2+} \mathbf{1 7}(4,4-$ diphenyl-2,2-bipyridine) [232], $\left[\operatorname{Ru}(5 \text {-odap })_{3}\right]^{2+} \mathbf{1 8}(5$ odap $=5$-octadecanamide-1,10-phenanthroline) [166], [Ru $\left.(\text { phen })_{3}\right]^{2+} 19$ (phen=phenanthroline) [227], $\left[\mathrm{Ru}(\mathrm{s} 2 \mathrm{~d})_{3}\right]^{4-}$ 21 (s2d=1,10-phenanthroline-4,7-bis(phenylsulfonate)) also modified with 5 -acetamide-1,10-phenanthroline (acap) 22a or 5-tetradecanamide-1,10-phenanthroline (tdap) 22b [245] (Fig. 6, Table 2). These indicators have not been as widely used as $\left[R u(d p p)_{3}\right]^{2+}$ due to their lower quantum yield and shorter luminescent lifetime.

In general, one advantage of $\mathrm{Ru}(\mathrm{II})$ polypyridyl complexes is that they are fairly easy to prepare, reason why they are quite popular as indicators for early optical oxygen sensors; on the other hand, though they present many disadvantages they show only moderate molar absorption coefficients and therefore brightness, they possess relatively short lifetimes, their absorption and emission spectra are usually very broad which implies the use of specific filters and more expensive instrumentation and they suffer from pronounced cross talk to temperature since their triplet states are subjected to severe thermal quenching [140].

The absorption of the of $\mathrm{Ru}$ (II) complexes is located in the blue part of the spectrum (Table 2) which can be a severe limitation for many applications (particularly for in vivo measurements); thus, Klimant et al. [103] used Ru(II) complexes based on $\pi$-extended polypyridyl ligands ([Ru $\left.\left.(\mathrm{ddp})(\mathrm{DMCH})_{2}\right]^{2+} \mathbf{2 3}\right)$, whose absorption and emission bands were bathochromically shifted of about $100 \mathrm{~nm}$ compared to the conventional $\mathrm{Ru}$ (II) complexes. Unfortunately, the brightness of the new indicators was too low ( $\Phi$ did not exceed $1 \%)$ and the decay times too short ( $<700 \mathrm{~ns})$.

In an alternative approach, Demas et al. [250] focused their attention on Os(II) complexes which are analogous to the $\mathrm{Ru}$ (II) but can be excited in the red part of the spectrum and are therefore compatible with red LEDs and low-cost red lasers diodes. It has also been argued that the Os(II) complexes should be even more photostable and robust than the $\mathrm{Ru}(\mathrm{II})$ complexes as they present a larger energy gap between the emitting state and the photochemically destructive upper $d d$ states [109]. Optical oxygen sensors have been developed using mainly two indicators: $\left[\mathrm{Os}(\mathrm{phen})_{3}\right]^{2+} \mathbf{2 4}$ and $\left[\mathrm{Os}(\mathrm{dpp})_{3}\right]^{2+} \mathbf{2 5}$ (Fig. 6) immobilized in poly(dimethylsiloxane) (PDMS) and in Gp-163 (an acrylate-modified PDMS). The luminescence lifetimes of such indicators in dichloromethane are in the nanosecond range which is much shorter when compared to the $\mathrm{Ru}(\mathrm{II})$ analogs; thus, only very highly oxygen-permeable materials can be adequate to obtain measureable responses. It should also be mentioned here that the luminescence quantum yields of the $\mathrm{Os}(\mathrm{II})$ are much lower than for the $\mathrm{Ru}$ (II) analogs (Table 2) which is a severe disadvantage.

Other two osmium polypyridyl complexes have been used by Bawendi et al. [155] in conjunction with nanocrystals as two-photon oxygen sensors for application in biological microenvironments; namely bis (2,2'-bipyridine) $(N-(6$ aminohexyl)-4'-methyl-2,2'-bipyridine-4-carboxamide) osmium(II), $\left[\mathrm{Os}(\mathrm{bpy})_{2}(\mathrm{Nbpy})\right]^{2+} \mathbf{2 6}$ and bis(4,7-diphenyl-1,10phenanthroline)( $N$-(6-aminohexyl)-4'-methyl-2,2'-bipyridine4-carboxamide) osmium(II), $\left[\mathrm{Os}(\mathrm{dpp})_{2}(\mathrm{Nbpy})\right]^{2+} 27$ (Fig. 7). The free amine groups of the modified polypyridynes were linked to a carboxylic acid functionality of a semiconductor nanocrystal (NC) to afford a biologically stable amide bond; the resulting compounds possess absorption profiles that extend well into the red spectral region, leading therefore to a good overlap with the emission band of the NCs donors and 
Table 2 Photophysical properties of transition metals polypyridyl complexes

\begin{tabular}{|c|c|c|c|c|c|c|}
\hline Dye & $\lambda_{\max }{ }^{\mathrm{abs}}\left(\mathrm{nm} ; \varepsilon \times 10^{-4} \mathrm{M}^{-1} \mathrm{~cm}^{-1}\right)$ & $\lambda_{\max }^{\mathrm{em}}(\mathrm{nm})$ & Medium & $\Phi$ & $\tau$ & References \\
\hline $16\left[\operatorname{Ru}(\mathrm{bpy})_{3}\right]^{2+}$ & $450(1.43)$ & 630 & EtOH-MeOH $(4: 1 v / v)$ & 0.089 & $1.15 \mu \mathrm{s}^{\mathrm{a}}$ & {$[48]$} \\
\hline $17\left[\mathrm{Ru}(\mathrm{dpb})_{3}\right]^{2+}$ & $473(2.80)$ & 635 & EtOH-MeOH $(4: 1 v / v)$ & 0.306 & $1.95 \mu \mathrm{s}$ & {$[48]$} \\
\hline $18\left[\operatorname{Ru}(5 \text {-odap })_{3}\right]^{2+}$ & $449(1.75)$ & 600 & $\mathrm{MeOH}$ & 0.027 & $0.50 \mu \mathrm{s}$ & {$[166]$} \\
\hline $19\left[\mathrm{Ru}(\text { phen })_{3}\right]^{2+}$ & $444(2.00)$ & 596 & $\mathrm{MeOH}$ & 0.019 & $0.28 \mu \mathrm{s}$ & {$[166]$} \\
\hline $20\left[\operatorname{Ru}(\mathrm{dpp})_{3}\right]^{2+}$ & $463(2.86)$ & 618 & EtOH-MeOH $(4: 1 v / v)$ & 0.366 & $6.40 \mu \mathrm{s}$ & {$[2]$} \\
\hline $21\left[\operatorname{Ru}(\mathrm{s} 2 \mathrm{~d})_{3}\right]^{4-}$ & 475 & 620 & $\mathrm{MeOH}$ & - & $0.31 \mu \mathrm{s}$ & [245] \\
\hline 22a $\left[\operatorname{Ru}(\mathrm{s} 2 \mathrm{~d})_{2}(\text { acap })\right]^{2-}$ & 475 & 616 & $\mathrm{MeOH}$ & - & $0.32 \mu \mathrm{s}$ & {$[245]$} \\
\hline 22b $\left[\operatorname{Ru}(\mathrm{s} 2 \mathrm{~d})_{2}(\mathrm{tdap})\right]^{2-}$ & 475 & 605 & $\mathrm{MeOH}$ & - & $0.30 \mu \mathrm{s}$ & {$[245]$} \\
\hline $23\left[\mathrm{Ru}(\mathrm{ddp})(\mathrm{DMCH})_{2}\right]^{2+}$ & 563 & 738 & $\mathrm{EtOH}$ & 0.009 & $650 \mathrm{~ns}$ & [103] \\
\hline $24\left[\mathrm{Os}(\mathrm{Phen})_{3}\right]^{2+}$ & $432 / 478 / 660$ & 691 & $\mathrm{CH}_{2} \mathrm{Cl}_{2}$ & - & $6.0 \mathrm{~ns}$ & {$[250]$} \\
\hline $25\left[\mathrm{Os}(\mathrm{dpp})_{3}\right]^{2+}$ & $454 / 500 / 580 / 650$ & 729 & $\mathrm{CH}_{2} \mathrm{Cl}_{2}$ & - & $4.6 \mathrm{~ns}$ & {$[250]$} \\
\hline $26\left[\mathrm{Os}(\mathrm{bpy})_{2}(\mathrm{Nbpy})\right]^{2+\mathrm{b}}$ & 490 & 800 & Water & 0.0096 & $12 \mathrm{~ns}$ & {$[155]$} \\
\hline $27\left[\mathrm{Os}(\mathrm{dpp})_{2}(\mathrm{Nbpy})\right]^{2+}$ & 450 & 795 & Water & 0.013 & $15 \mathrm{~ns}$ & [155] \\
\hline $28\left[\operatorname{ReL}(\mathrm{CO})_{3} \mathrm{CNR}\right]^{+\mathrm{c}}$ & $\begin{array}{l}\text { a } 338(0.43) \\
\text { b } 386(0.7)\end{array}$ & $\begin{array}{l}\text { a } 448 \\
\text { b } 496\end{array}$ & $\mathrm{CH}_{2} \mathrm{Cl}_{2}$ & $\begin{array}{l}\text { a } 0.59 \\
\text { b } 0.60\end{array}$ & $\begin{array}{l}\text { a } 1.97 \mu \mathrm{s} \\
\text { b } 44.4 \mu \mathrm{s}\end{array}$ & [194] \\
\hline $29 \mathrm{Pt}(\mathrm{ddp})(\mathrm{CN})_{2}$ & $293(41.3) / 375(5.9) / 357(7.5)$ & 630 & Polyethylene glycol & - & $1 \mu \mathrm{s}$ & {$[122]$} \\
\hline
\end{tabular}

${ }^{\text {a }}$ Taken from [141]

${ }^{\mathrm{b}} \mathrm{Nbpy}=N$-(6-aminohexyl)-4'-methyl-2,2'-bipyridine-4-carboxamide

${ }^{\mathrm{c}} \mathrm{L}=2$,2-bipyridine (a) or 1,10-phenanthroline (b) and $\mathrm{R}=$ tert-butyl

allowing fluorescence resonance energy transfer from the semiconductor to the osmium complex. Since the $\mathrm{NC}$ emission is insensitive to oxygen, it can be used as an internal reference while the enhanced Os(II) emission can be exploited for sensing. However, the aforementioned disadvantages of the Os(II) complexes are also valid for these indicators.

Also, $\operatorname{Re}(\mathrm{I})$ complexes have been used as oxygen indicators, however, their structure is different from the $\mathrm{Ru}(\mathrm{II})$ and Os(II) complexes since they contain only a single polypyridyl ligand and additional carbonyl ligands are necessary to obtain sufficient luminescence. $\left[\mathrm{Re}(\mathrm{bpy})(\mathrm{CO})_{3} \mathrm{CNR}\right]^{+} \mathbf{2 8 a}$ and $\left[\operatorname{Re}(\mathrm{dpp})(\mathrm{CO})_{3} \mathrm{CNR}\right]^{+} \mathbf{2 8 b}$ (Fig. 7) can be mentioned as an example. These dyes possess very high quantum yields $(\sim 0.7)$ and long lifetimes ( $>40 \mu \mathrm{s})$ but they lack significant absorption above $400 \mathrm{~nm}$ and their molar absorption coefficients are quite low $\left(<7,000 \mathrm{M}^{-1} \mathrm{~cm}^{-1}\right)[193,194]$.

Recently, Telfer et al. [156] reported the first $\operatorname{Re}(\mathrm{I})-$ dipyrrinato complexes $(\mathbf{2 8 c})$ which in comparison with $\mathbf{2 8 a}$ and $\mathbf{b}$, have higher molar absorption coefficients $(2.5-4.2 \times$ $10^{4} \mathrm{M}^{-1} \mathrm{~cm}^{-1}$ ) but much lower quantum yields ( $>0.01$; Fig. 7$)$.

Even though platinum complexes do not need extra ligands to increase their luminescence, a Pt(II) complex with a structure similar to $\mathbf{2 8}$ has been reported. $\mathrm{Pt}(\mathrm{ddp})(\mathrm{CN})_{2} 29$ is of interest since it is very soluble and stable in silicone rubber and shows no photochemical degradation (photophysical properties are shown in Table 2) [122]. Complex 29 being neutral can be mixed with silicone rubber quite easily and it does not leach into aqueous solutions. Moreover, $\mathrm{Pt}$
$(\mathrm{ddp})(\mathrm{CN})_{2}$ forms excimer upon irradiation and its emission can be easily monitored, therefore $\mathbf{2 9}$ can be used as spectroscopic probe of microenvironments inside polymers.

\section{Metalloporphyrins}

Among all the indicators that have been used for optical oxygen sensors, Pt(II) and $\mathrm{Pd}(\mathrm{II})$ porphyrins are the most popular luminophores since they possess strong phosphorescence at room temperature, moderate to high molar absorption coefficients and large Stokes' shifts. Additionally, phosphorescence lifetimes are rather long (microsecond to millisecond) and can be tuned by varying the nature of the central atom. As it can be noted from Table 3, in general, for each pair of metalloporphyrin complex the one in which $M=\mathrm{Pd}(\mathrm{II})$ shows much longer lifetimes with respect to the $\mathrm{Pt}(\mathrm{II})$ analog, this can be related to the increase in spin-obit coupling expected in the heavier metal [64]; on the other hand, platinum(II) complexes possess approximately two to three times higher emission quantum yields than the respective palladium (II) derivatives.

A large number of Pt(II) and Pd(II) pophyrin complexes have been synthesized and many have been modified during the years to improve the photophysical properties such as brightness, lifetime, photostability, and to tune the wavelength of absorption, in order to make the indicators suitable for oxygen sensing in different conditions and media.

Platinum and palladium complexes with octaethylporphyrin (PtOEP 30, PdOEP 31) remain popular indicators due to their strong room temperature phosphorescence with 


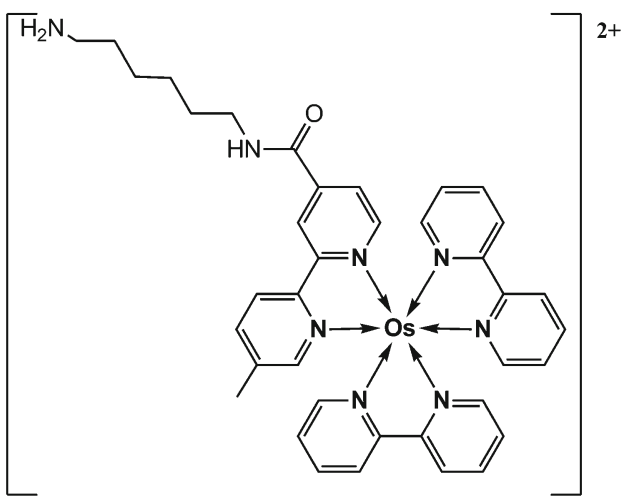

$26 \operatorname{Bis}\left(2,2^{\prime}\right.$-bipyridine)( $N$-(6-aminohexyl)-4'-methyl-2,2'bipyridine-4-carboxamide) osmium(II) $\left[\mathrm{Os}(\mathrm{bpy})_{2}(\mathrm{Nbpy})\right]^{2+}$

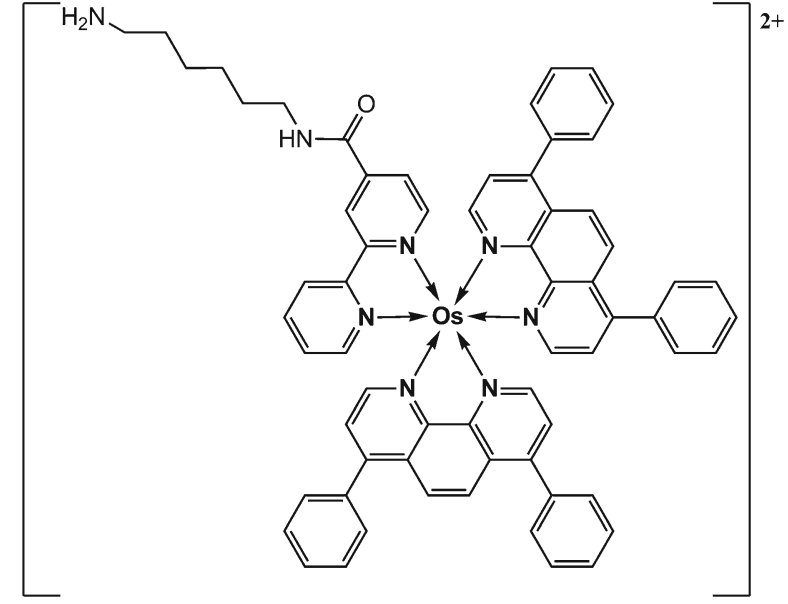

27 Bis(4,7-biphenyl-1,10-phenanthroline)( $N$-(6-aminohexyl)-4'-methyl2,2'-bipyridine-4-carboxamide) osmium(II) $\left[\mathrm{Os}(\mathrm{dpp})_{2}(\mathrm{Nbpy})\right]^{2+}$

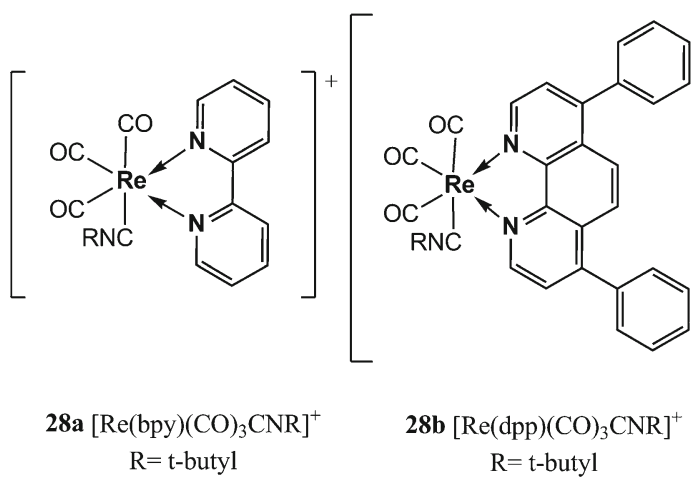

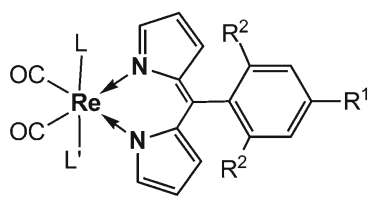<smiles>N#CP1C2=C3C4=C(c5ccccc5)C=CN1C3N(C=C4)C(c1ccccc1)C=C2</smiles>

28c $\operatorname{Re}(\mathrm{I})$ dipyrrinato complexes $\mathrm{L}$ or $\mathrm{L}^{\prime}=\mathrm{CO}, \mathrm{PPh}_{3}, \mathrm{PBu}_{3}$ $\mathrm{R}^{1}=\mathrm{H}, \mathrm{Me}, \mathrm{OMe}, \mathrm{CO}_{2} \mathrm{Me}, \mathrm{NPh}_{2}$ $\mathrm{R}^{2}=\mathrm{H}, \mathrm{Me}$
$29 \mathrm{Pt}(\mathrm{ddp})(\mathrm{CN})_{2}$ ddp $=$ 4,7-diphenyl-1,10phenantroline

Fig. 7 Chemical structures of Os(II), Re(I), and Pt(II) polypyridyl complexes

quantum yields of about 0.5 and 0.2 , respectively, and long lifetimes under anoxic conditions (ca. $91 \mu$ s and ca. $990 \mu$ s, respectively) [177]. These indicators have been widely used as optical oxygen sensors and have been immobilized in various oxygen-permeable polymeric matrices such as polystyrene [104, 178], sol-gels [132, 133], poly(aryl ether ketone) [14], ethyl cellulose, cellulose acetate butyrate and polyvinylchloride [60], styrene-pentafuorostyrene copolymer film [9], and poly(1-trimethylsilyl-1-propyne) [6]. A general disadvantage of these indicators is their rather low photostability.

Platinum tetrakis(pentafuorophenyl)porphyrin (PtTFPP 32) has received much attention and mostly replaced PtOEP because it shows much less photodeterioration [186]. The higher photostability of $\mathbf{3 2}$ compared to $\mathbf{3 0}$ is explained by the electron-withdrawing character of the perfluorophenyl substituents which reduces the electron density on the porphyrin ring thus rendering the PtTFPP less reactive toward oxidation by singlet oxygen [134]. PtTFPP possesses similarly long decay time $(60 \mu \mathrm{s})$ and acceptable brightness when excited in the visible rage; it has been widely used as oxygen indicator in different types of matrices such as polystyrene [5, 134], fluoroacrylic polymer as a component of a pressure-sensitive paint [51, 186], in sol-gel [44, 45], poly(norobornene)s [213], and many other matrices. PtTFPP was also modified to be able to be polymerized and cross-linked with hydrophilic poly(2-hydroxyethyl methacrylate)-co-polyacrylamide or hydrophobic polystyrene to generate highly photostable and biocompatible sensing films [216]. Nucleophilic substitution of the parafluorine atoms of the pentafuorophenyl groups allows covalent coupling to polymeric materials such as polystyrene copolymers [114] and silica gel [25]. Due to its excellent photostability, PtTFPP has been extensively used for those 
Table 3 Photophysical properties of most common metalloporphyrin oxygen indicators

\begin{tabular}{|c|c|c|c|c|c|c|}
\hline Dye & $\lambda_{\max }{ }^{\text {abs }}(\mathrm{nm})\left(\varepsilon \times 10^{-3} \mathrm{M}^{-1} \mathrm{~cm}^{-1}\right)$ & $\begin{array}{l}\lambda_{\max }^{\mathrm{em}} \\
(\mathrm{nm})\end{array}$ & Medium & $\Phi$ & $\tau$ & References \\
\hline 30 PtOEP & $382 / 536$ & 649 & Toluene & 0.41 & $75 \mu \mathrm{s}$ & [115] \\
\hline 31 PdOEP & 546 & 670 & PS & 0.20 & $990 \mu \mathrm{s}$ & {$[177]$} \\
\hline 32 PtTFPP & $390(323) / 504(23.2) / 538(29.4)$ & $647 / 710$ & $\mathrm{CH}_{2} \mathrm{Cl}_{2}$ & 0.088 & $60 \mu \mathrm{s}$ & {$[123]$} \\
\hline 33 PdTFPP $^{\mathrm{a}}$ & $406(192) / 519(18.2) / 552(15.5)$ & 738 & $\mathrm{CH}_{2} \mathrm{Cl}_{2}$ & 0.21 & $1.65 \mathrm{~ms}$ & [209] \\
\hline 34 РtТCРP & $402(210) / 514(21)$ & 675 & Water & 0.01 & $34 \mu \mathrm{s}$ & [222] \\
\hline 35 РdTCPP & $418 / 523 / 556$ & 700 & DMF & - & - & [4] \\
\hline $36 \mathrm{PtOEPK}^{\mathrm{b}}$ & $398(86.2) / 592(55.1)$ & 758 & $\mathrm{CHCl}_{3}$ & 0.12 & $60 \mu \mathrm{s}$ & [179] \\
\hline $37 \mathrm{PdOEPK}^{\mathrm{b}}$ & $410(82.6) / 603(53.5)$ & 789 & $\mathrm{CHCl}_{3}$ & 0.01 & $455 \mu \mathrm{s}$ & [179] \\
\hline 38 PtTFPPL & $396(180) / 574(65.5)$ & 733 & $\begin{array}{r}\text { 3-Methyl } \\
\text { pentane }\end{array}$ & - & $72 \mu \mathrm{s}$ & [102] \\
\hline 39 PdTFPPL & $412(120) / 584(39.2)$ & 758 & $\begin{array}{l}\text { 3-Methyl } \\
\text { pentane }\end{array}$ & - & $0.8 \mathrm{~ms}$ & [102] \\
\hline 40 РtТРТВР & $430(205) / 614(136)$ & 770 & Toluene & 0.51 & $47 \mu \mathrm{s}$ & {$[27]$} \\
\hline 41 РdТРТВР & $443(416) / 628(173)$ & 800 & Toluene & 0.21 & $286 \mu \mathrm{s}$ & [27] \\
\hline 42 РtТРТВРF & $430(212) / 615(146)$ & 773 & Toluene & 0.60 & $50 \mu \mathrm{s}$ & {$[27]$} \\
\hline 43 РdТРТВРF & $443(268) / 629(115)$ & 803 & Toluene & 0.23 & $297 \mu \mathrm{s}$ & {$[27]$} \\
\hline 44 Pt1NF & $434(272) / 628(147) / 638(140)$ & 815 & Toluene & 0.53 & $44 \mu \mathrm{s}$ & {$[172]$} \\
\hline $45 \mathrm{Pd} 1 \mathrm{NF}$ & $450(202) / 641(74.0) / 654(72.6)$ & 849 & Toluene & 0.18 & $203 \mu \mathrm{s}$ & [172] \\
\hline $46 \mathrm{Pt} 2 \mathrm{NF}$ & $438(106) / 652(108)$ & 835 & Toluene & 0.27 & $28 \mu \mathrm{s}$ & {$[172]$} \\
\hline $47 \mathrm{Pd} 2 \mathrm{NF}$ & $452(190) / 608(102) / 666(142)$ & 868 & Toluene & 0.12 & $138 \mu \mathrm{s}$ & [172] \\
\hline $48 \mathrm{Pt} 3 \mathrm{NF}$ & $441(108) / 635(21.9) / 667(83.5) / 678(78.9)$ & 870 & Toluene & 0.25 & $21 \mu \mathrm{s}$ & {$[172]$} \\
\hline $49 \mathrm{Pd} 3 \mathrm{NF}$ & $\begin{array}{l}456(138) / 630(17.0) / 652(22.0) / 681(63.8) / 691 \\
\quad(60.0)\end{array}$ & $\sim 882$ & Toluene & 0.07 & $106 \mu \mathrm{s}$ & [172] \\
\hline 50 PtTPTNP & $436 / 689$ & 883 & Toluene & 0.22 & $8.5 \mu \mathrm{s}$ & {$[207]$} \\
\hline 51 PdTPTNP & $465 / 721$ & 948 & Pyridine & 0.079 & $63 \mu \mathrm{s}$ & {$[72]$} \\
\hline $52 \operatorname{PtTBP}\left(\mathrm{CO}_{2} \mathrm{Bu}\right)_{8}$ & $416(170) / 609(166)$ & 745 & Pyridine & 0.51 & $50 \mu \mathrm{s}$ & [73] \\
\hline $53 \operatorname{PdTBP}\left(\mathrm{CO}_{2} \mathrm{Bu}\right)_{8}$ & $426(302) / 618(158)$ & 770 & $\mathrm{DMF}$ & 0.23 & $400 \mu \mathrm{s}$ & [73] \\
\hline $\begin{array}{l}54 \mathrm{PdPh}_{4} \mathrm{TBP} \\
\left(\mathrm{CO}_{2} \mathrm{Me}\right)_{8}\end{array}$ & $460(251) / 636(87)$ & 787 & DMF & 0.03 & $62 \mu \mathrm{s}$ & [73] \\
\hline 55 PtNTBP & $406(106) / 606(61) / 630(137)$ & 844 & Toluene & 0.22 & $40 \mu \mathrm{s}$ & {$[31]$} \\
\hline 56 PdNTBP & $421(106) / 619(58) / 642(133)$ & 875 & Toluene & 0.08 & $213 \mu \mathrm{s}$ & [31] \\
\hline $57 \mathrm{PtN}_{2 \text {-cis }} \mathrm{TBP}$ & $388(51) / 621(147)$ & 841 & Toluene & 0.17 & $20 \mu \mathrm{s}$ & {$[31]$} \\
\hline $58 \mathrm{PdN}_{2 \text {-cis }} \mathrm{TBP}$ & $380(33) / 631(98)$ & 873 & Toluene & 0.05 & $101 \mu \mathrm{s}$ & {$[31]$} \\
\hline 61 Oxyphor R2 & 415/524 (19) & 690 & Water & 0.10 & $771 \mu \mathrm{s}^{\mathrm{c}}$ & {$[63]$} \\
\hline 62 Oxyphor G2 & $442 / 632(50)$ & 790 & Water & 0.12 & $280 \mu \mathrm{s}^{\mathrm{c}}$ & {$[63]$} \\
\hline $\begin{array}{l}63 \text { PdTBP- } \\
\left(\mathrm{AG}^{2} \mathrm{PEG}\right)_{8}\end{array}$ & $446 / 635$ & 816 & $\begin{array}{l}\text { Phosphate } \\
\text { buffer }\end{array}$ & 0.03 & $270 \mu \mathrm{s}$ & {$[130]$} \\
\hline 64 IrOER-CO-Cl & $404(165) / 518(15) / 550(31)$ & 672 & Toluene & 0.14 & $97 \mu \mathrm{s}$ & [115] \\
\hline $65 \mathrm{Ir}-\mathrm{OEP}-\mathrm{Py}_{2}$ & $389(148) / 509(11) / 539(26.6)$ & 655 & Toluene & 0.195 & $40 \mu \mathrm{s}$ & {$[115]$} \\
\hline 66 Ir-OEP-n-butIm 2 & $390(150) / 508(9.7) / 541(15)$ & 655 & Toluene & 0.20 & $27 \mu \mathrm{s}$ & [115] \\
\hline 67 IR-OEP-CarbIm 2 & $388(142) / 507(10) / 538(18)^{\mathrm{h}}$ & $652^{\mathrm{d}}$ & Toluene & $0.21^{\mathrm{d}}$ & $37 \mu \mathrm{s}^{\mathrm{e}}$ & [115] \\
\hline
\end{tabular}

${ }^{\text {a }}$ Emission spectra $\Phi$ and lifetimes were measured in 3-methylpenthane at $77 \mathrm{~K}$

${ }^{\mathrm{b}}$ Emission spectra $\Phi$ and lifetimes were measured in a sodium sulfite solution

${ }^{\mathrm{c}}$ Measured in deoxygenated condition at $23.5^{\circ} \mathrm{C}$ and $\mathrm{pH}=6.4$

${ }^{\mathrm{d}}$ In polystyrene at $25^{\circ} \mathrm{C}$

${ }^{\mathrm{e}}$ Measured in $\mathrm{EtOH}$

applications in which high light intensities are used, primary in fiber-optic microsensors and microscopy [69], but also in multi-analyte sensors and as components for pressuresensitive paints [76]. 
The Pd(II) analogue $\mathbf{3 3}$ is characterized by a rather long lifetime ( $\sim 1 \mathrm{~ms}$ at room temperature); sensors based on this complex covalently attached to the surface of aminomodified silica-gel particles and dispersed in silicon rubber, show higher sensitivity with a dynamic range from 0.02 to $100 \mathrm{~Pa}$ and therefore can be used to measure trace level of oxygen. Both PtTFPP and PdTFPP were covalently immobilized on amino-functionalized silica-gel particle to obtain heterogeneous sensing materials which possess high photostability and fast response time [25].

Platinum and palladium tetrakis(4-carboxyphenyl)porphyrin (PtTCPP 34 an PdTCPP 35) do not possess very high quantum yields or long lifetimes; nevertheless, several sensors using these compounds have been reported [4, 10, 146]. The metal complexes can be chemisorbed on alumina because of the formation of a stable bond between alumina and the carboxyl group of the TCPP.

More exotic oxygen sensors relied on platinum(II) and palladium(II) complexes with cationic water-soluble porphyrins which were electrostatically immobilized in the negatively charged fluorinated Nafion ${ }^{\circledR}$ membrane [221]. The sensors were shown to be suitable for measurements of oxygen in gas phase but their performance in aqueous solutions, evidently, may be compromised by ionic species.

The brightness (defined as the product of the molar absorption coefficient $\varepsilon$ and the quantum yield $\Phi$ ) of the $\mathrm{Pt}(\mathrm{II})$ and $\mathrm{Pd}(\mathrm{II})$ complexes with OEP and TFPP is very good upon excitation in the Soret band (UV/violet light) due to high molar absorption coefficients for this transition (Table 3). However, excitation in the Q bands located in the green part of the spectrum (which is often more preferable) is about tenfold less efficient. Therefore, rather thick sensing layers are necessary to insure sufficient absorption and a good $\mathrm{S} / \mathrm{N}$ ratio. This results in slower dynamic response of the sensors. Also, if used in the form of oxygen-sensitive nanoparticles higher concentration of those is required and this can disturb biological systems. To overcome this drawback, Mayr and co-workers proposed an approach to enhance the brightness of oxygen (and other optical sensors) via light harvesting [151]. Here, excitation is performed via an antenna dye which is added along with an oxygen indicator; the latter becomes excited via the Föster Resonance Energy Transfer.

The indicators described so far efficiently absorb light only in the UV-vis region and therefore suffer from some drawbacks: (1) high level of autofluorescence is produced upon excitation in the UV-vis since many natural compounds which are present in biological samples, such as nucleotides FAD and NAD, are fluorescent, (2) they are poorly suitable for measurements in scattering media such as marine sediments or tissues, (3) they cannot be used in implantable sensors since blood efficiently absorbs in visible region.
Excitation in the red part of the spectrum is strongly preferred not only because it allows sensing in highly scattering media and in tissue but also because it can be combined with cheaper optical components; for example, the sensitivity of cheap and compact Si photodiodes increases at wavelengths longer than $600 \mathrm{~nm}$ and reaches a maximum at $850-900 \mathrm{~nm}$ [27]. For these reasons, red-excitable and NIRemitting indicators are becoming increasingly popular for the development of optical oxygen sensors to be used in marine sediments, in blood, in cells, or in tissues.

Compared to the metalloporphyrins described above, platinum(II) and palladium(II) complexes with porphyrin ketones (PtOEPK 36, PdOEPK 37) and porphyrin lactones (PtTFPPL 38, PdTFPPL 39) possess bathochromically shifted absorption peaking at $570-600 \mathrm{~nm}$. Unfortunately, these dyes have only moderate emission in the NIR (Table 3 ).

The $\operatorname{Pt}(\mathrm{II})$ and $\mathrm{Pd}(\mathrm{II})$ porphyrin ketones which were obtained via oxidation of the porphyrin macrocycle and displayed high photochemical stability [177]. PtOEPK and PrOEPK display room temperature phosphorescence with reasonable quantum yield, particularly the $\mathrm{Pt}(\mathrm{II})$ complex $\left(\Phi_{P}>0.1\right)$, and long lifetimes ( $60 \mu \mathrm{s}$ for the Pt(II) and $455 \mu \mathrm{s}$ for the Pd(II) complexes) but only moderate to low brightness; they have been used in different matrices such as polystyrene and polyvinylchloride which influenced the dynamic range of the sensors [104, 111, 217].

Recently, Nock et al. [173] applied the platinum(II) octaethylporphyrinketone/polystyrene probe for measurements of both gaseous and dissolved oxygen in microfluidic devices. Platinum(II) and palladium(II) tetra(pentafluorophenyl)porpholactone are similar in their spectral properties to the complexes of porphyrin-ketones and show phosphorescence lifetimes that are about $60 \%$ that of the unmodified TFPP complexes $(\sim 70 \mu$ s for PtTFPPL and $\sim 1 \mathrm{~ms}$ for PdTFPPL). The lactone ring was produced from the parent free-base porphyrin via oxidation and it is responsible for a shift in the emission spectra toward longer wavelengths; also, the lactone functionality makes this indicators even more stable toward photo-oxidation [102].

Palladium(II) and platinum(II) complexes with benzo[188] and naphthoporhyrins [73, 188, 191] represent another group of the NIR oxygen indicators. These dyes belong to the class of $\pi$-extended porphyrins which are characterized by an extended aromatic fragment fused on the porphyrin core; this feature is responsible for the bathochromic shift of the absorption and emission bands.

The complexes possess excellent brightness upon excitation both in the blue and red region due to very high molar absorption coefficients and quantum yields. For example, molar absorption coefficients for the platinum(II) and palladium(II) complexes with tetraphenyltetrabenzoporphyrin PtTPTBP 40 and PdTPTBP 41 (Fig. 8), respectively, exceed $200,000 \mathrm{M}^{-1} \mathrm{~cm}^{-1}$ for the blue region and $130,000 \mathrm{M}^{-1}$ 
$\mathrm{cm}^{-1}$ for the red region, and the emission quantum yields are about 0.50 and 0.20 , respectively. The $\operatorname{Pd}(\mathrm{II})$ complexes with tetraphenyltetrabenzoporphyrin are water insoluble and not cell penetrating, but once incorporated into polystyrene nanoparticle, functionalized with polyethylene glycol (PEG) and an antibody, they were successfully used for in vivo imaging [170].

PtTPTBPF 42 and PdTPTBPF 43 (Fig. 8) are obtained by substitution of the hydrogen to fluorine in the meso-phenyl rings, which slightly improves the luminescence quantum yield of both $\mathrm{Pt}(\mathrm{II})$ and $\mathrm{Pd}(\mathrm{II})$ complexes (Table 3) and enhances their photostability [27].
Solubility of an indicator in polymeric matrices is an important parameter for its application in optical sensors; planar $\pi$-extended porphyrins were shown to aggregate readily, but substituents in the meso-position of the porphyrin ring significantly improve their solubility. For example, meso-substituted benzoporphyrins as $\mathbf{4 0}, \mathbf{4 1}, \mathbf{4 2}$, and $\mathbf{4 3}$ show a low tendency to aggregate in nonpolar polymers such as polystyrene [28].

In general, when dissolved in polystyrene, the $\mathrm{Pt}(\mathrm{II})$ meso-substituted benzoporphyrins are ideally suitable for measurements from 0 to $100 \%$ air saturation while the analog $\mathrm{Pd}(\mathrm{II})$ dyes, as they show a significantly higher

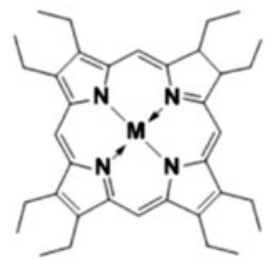

$30 \mathbf{M}=\mathbf{P t}$

Platium(II) octaethylporphyrin PtOEP

$31 \mathbf{M}=\mathbf{P d}$

Palladium(II) octaethylporphyrin PdOFP

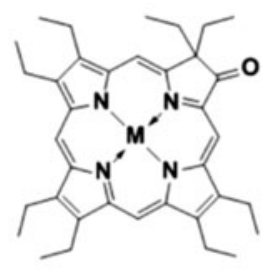

$36 \mathrm{M}=\mathbf{P t}$

Platium(II) octaethylporphyrinketone PIOEPK $37 \mathbf{M}=\mathbf{P d}$

Palladium(II) octaethylporphyrinketone PdOEPK

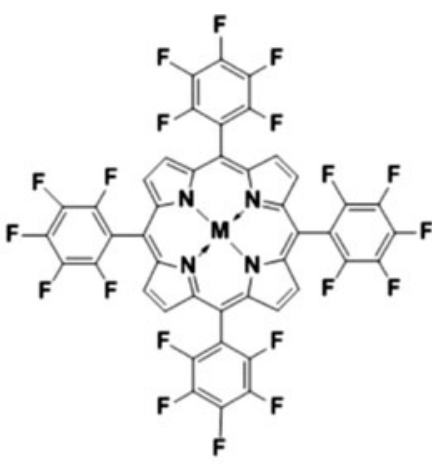

$32 \mathbf{M}=\mathbf{P t}$

Platium(II)-5, 10,15,20-tetrakis-(2,3,4,5,6pentafluorophenyl)-porphyrin

PtTFPP

$33 \mathbf{M}=\mathbf{P d}$

Palladium(II)-5,10,15,20-tetrakis-(2,3,4,5,6pentafuorlophenyl)-porphyrin PdTFPP

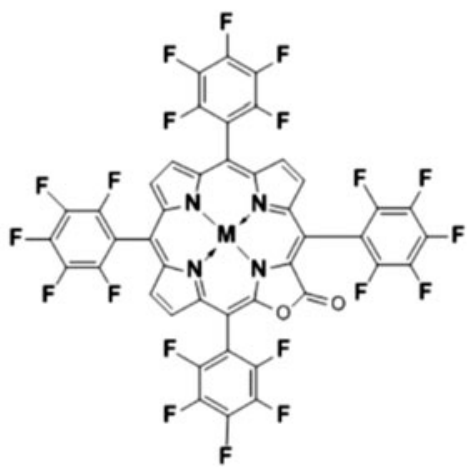

$38 \mathrm{M}=\mathbf{P t}$

Platium(II)-5, 10,15,20-tetrakis-(2,3,4,5,6pentafluorophenyl)-porpholactone PITFPPL

$39 \mathbf{M}=\mathbf{P d}$

Palladium(II)-5, 10,15,20-tetrakis-(2,3,4,5,6pentafuorlophenyl)-porpholactone PdTFPPL

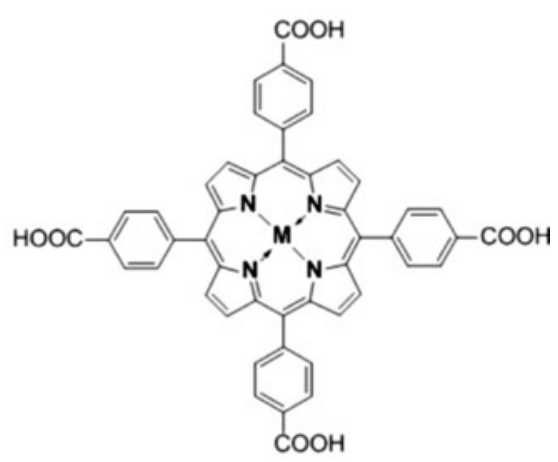

$34 \mathbf{~ M}=\mathbf{P t}$

Platium(II) tetrakis(4-carboxyphenyl)-porphyrin PITCPP

$35 \mathbf{M}=\mathbf{P d}$

Palladium(II) tetrakis(4-carboxyphenyl)porphyrin PdTCPP

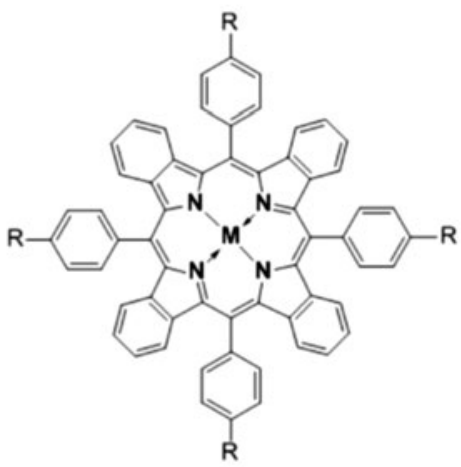

$40 \mathrm{M}=\mathrm{Pt}, \mathrm{R}=\mathrm{H}$

Platium(II) tetraphenyltetrabenzoporphyrin PtTPTBP

$41 \mathrm{M}=\mathrm{Pd}, \mathrm{R}=\mathrm{H}$

Palladium(II) tetraphenyltetrabenzoporphyrin PdTPTBP

$42 \mathrm{M}=\mathbf{P t}, \mathrm{R}=\mathrm{F}$

Platium(II)-6,13,20,27-tetrakis

(4-fuorophenyl)tetrabenzoporphyrin PITPTBPF

$43 \mathrm{M}=\mathrm{Pd}, \mathrm{R}=\mathrm{F}$

Palladium(II)-6,13,20,27-tetrakis

(4-fuorophenyl)tetrabenzoporphyrin PdTPTBPF

Fig. 8 Chemical structures of Pt(II) and Pd(II) porphyrin complexes 
sensitivity to oxygen with decay times in the order of $300 \mu$ s, are more adequate for trace oxygen sensing because their luminescence is almost completely quenched at air saturation. However, the $\operatorname{Pd}($ II) complexes could be used to measure oxygen up to air saturation when incorporated into polymers with lower oxygen permeability such as poly (styrene-co-acrylonitrile).

NIR indicators efficiently absorb light at wavelengths higher than $600 \mathrm{~nm}$; therefore, they have the potential to be used in the so called "smart tattoos". These are sensors that are implanted into subcutaneous tissues and can be exploited for continuous noninvasive monitoring of vital analytes like oxygen or glucose [28]. Further, bathochromic shifts of the absorption and emission can improve the performance in such applications even more. This can be realized by further extension of the $\pi$-system as for tetranaphthoporphyrins TNP (Fig. 9). Compared to the benzoporphyrins, the absorption (for the $\mathrm{Q}$ bands) and emission of these dyes shift bathocromically by about $80 \mathrm{~nm}$ (Table 3). Unfortunately, this is accompanied by the decrease in the phosphorescence quantum yields ( $\Phi_{P}=0.22$ for PtTPTNP 50 and $\Phi_{P}=0.079$ for PdTPTNP 51) [71, 73]. Even more importantly, the photostability of these dyes decreases dramatically [148] in comparison with the corresponding tetrabenzoporphyrins; which can compromise potential application in oxygen sensing, organic light-emitting diodes (OLEDs) [207], and photovoltaics [52].

Lower solubility of the meso-tetraphenyltetranaphthoporphyrins is another drawback, but other more soluble derivatives are known and will be discussed below. It should be mentioned here that a synthetic way to render halogenated naphthoporphyrins significantly more photostable and better soluble have been recently described [70]. However, the multistep synthesis of precursors and the porphyrins is not unchallenging.

Hybrid benzo- and naphthoporphyrin complexes of platinum(II) and palladium(II) with tunable spectral properties were reported by Niedermair et al. [172] The photophysical properties of the platinum(II)-meso-tetra-(4-fluorophenyl)mononaphthotribezoporphyrin (Pt1NF 44), the cis-platinum(II)-meso-tetra-(4-fluorophenyl)dibenzodinaphthoporphyrin (cis-Pt2NF 46) and the platinum(II)-meso-tetra-(4fluorophenyl)monobenzotrinaphthoporphyrin (Pt3NF 48) and the corresponding palladium(II) complexes (Pd1NF 45, cis-Pd2NF 47, Pd3NF 49; Fig. 9) are reported in Table 3. These complexes absorb intensively in the near-infrared region between 628 and $691 \mathrm{~nm}$ (the higher the number of the naphtha moieties annealed to the porphyrin system, the higher the bathochromic shift) and emit at room temperature between 815 and $882 \mathrm{~nm}$. The phosphorescence quantum yields decrease with the number of naphtha moieties and they range from 0.53 to 0.25 for the $\mathrm{Pt}(\mathrm{II})$ complexes and from 0.18 to 0.07 for the $\operatorname{Pd}(\mathrm{II})$ complexes. The luminescence decay times follow the same trend decreasing from 44 to $21 \mu$ s for the $\operatorname{Pt}(\mathrm{II})$ complexes and from 203 to $106 \mu$ s for the analog Pd(II) complexes; therefore, it can be stated that the sensitivity to oxygen is affected and gradually reduces upon substitution. It has been reported that the decrease in photostability of these indicators correlates well with the number of naphtho moieties annealed to the porphyrin system. Thanks to their tunable properties, the described chromophores are good candidates for different multiplexing applications as for example the simultaneous measurement of glucose and oxygen in enzymatic sensors [172].

Platinum(II) and palladium(II) tetrabenzoporphyrinoctabutylester $\left(\operatorname{PtTBP}\left(\mathrm{CO}_{2} \mathrm{Bu}\right)_{8}\right.$ 52, $\operatorname{PdTBP}\left(\mathrm{CO}_{2} \mathrm{Bu}\right)_{8} \mathbf{5 3}$; Fig. 9) and the palladium(II) tetraphenyltetrabenzoporphyrin-octamethylester $\left(\left(\mathrm{Pd}-\mathrm{Ph}_{4} \mathrm{TBP}\right) \mathrm{CO}_{2} \mathrm{Me}\right)_{8} \mathbf{5 4}$ (Fig. 9) represents another variation in the class of $\pi$ extended porphyrins which were synthesized and characterized by Vinogradov and co-workers [73].

The absorption bands of the meso-unsubstituted tetrabenzoporphyrins (52 and $\mathbf{5 3}$ ) are blue shifted by about 10 $30 \mathrm{~nm}$ when compared to the corresponding bands of the TPTBP analog (40-41; Table 3) while the emission decay times and quantum yields are comparable.

Another class of red excitable dyes for optical oxygen sensing is the platinum(II) and palladium(II) complexes with azatetrabenzoporphyrins recently reported by Borisov et al. [31]. These compounds can be viewed as hybrids between tetrabenzoporphyrins and phthalocyanines and combine the advantages of both. Pt(II) and Pd(II) phthalocyanines are characterized by extremely good chemical, thermal, and photostability but their phosphorescence quantum yields are very poor $\left(\Phi_{P}<0.01\right)[190]$ which makes them hardly feasible for optical sensing or imaging of oxygen. The photophysical properties of platinum(II) 6-aza-13-20-27-triphenyltetrabenzoporphyrin (PtNTBP 55), platinum(II) 6-aza13-20-27-triphenyltetrabenzoporphyrin $\left(\mathrm{PtN}_{2-c i s} \mathrm{TBP} 57\right)$ and the corresponding palladium(II) analog (PdNTBP 56, $\mathrm{PdN}_{2-c i s}$ TBP 58) are reported in Table 3. When compared to the respective TPTBP complexes, they show a hypsochromic shift of the Soret band and a bathochromic shift of the Q bands. In general, the decay times and the emission quantum yields of complexes 55-58 are lower when compared to the ones of the respective meso-tetraphenyltetrabenzoporphyrins; but despite this, the brightness of such indicators is quite adequate for practical applications and the lower sensitivity can be exploited in application where the oxygen partial pressure is higher than $21 \mathrm{kPa}$ (e.g., in photosynthetic systems). Importantly, the aza-modified complexes were shown to possess a much higher photostability than the corresponding TPTBP complexes.

Porphyrin conjugates and dendrimers represent another group of oxygen probes and have been reported both for non-extended and $\pi$-extended porphyrins. Usually, the aim of the synthetic modifications is to provide additional 


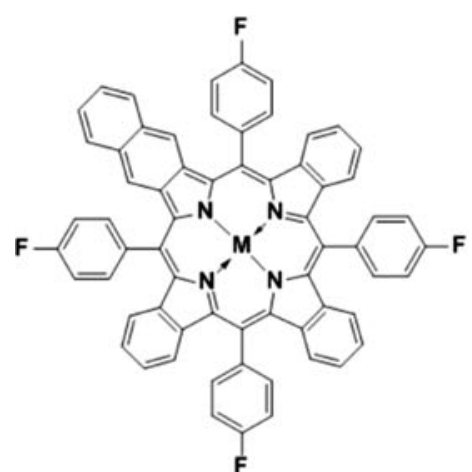

$44 \mathrm{M}=\mathrm{Pt}$

Platinum(II)-meso-tetra-(4-fuorophenyl) mononaphthotribenzoporphyrin PtINF

$45 \mathrm{M}=\mathbf{P d}$

Palladium(II)-meso-(4-fluorophenyl) mononaphthotribenzopophyrin PdINF

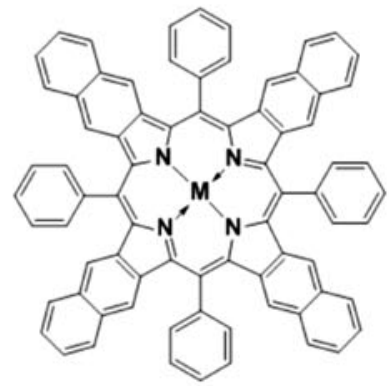

$50 \mathbf{M}=\mathbf{P t}$

Platinum(II) tetraphenyl tetranaphthoporphyrin PITPTNP

$51 \mathbf{M}=\mathbf{P d}$

Palladium(II) tetraphenyl tetranaphthoporphyrin

PdTPTNP

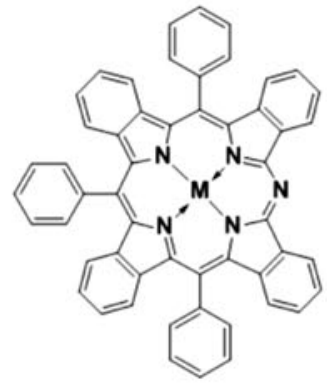

$55 \mathbf{M}=\mathbf{P t}$

Platium(II)-6-aza-13,20,27. triphenyltetrabenzoporphyrin PtNTBP

$56 \mathrm{M}=\mathbf{P d}$

Palladium(II)-6-aza-13,20,27. tetraphenyltetrabezoporphyrin PdNTBP

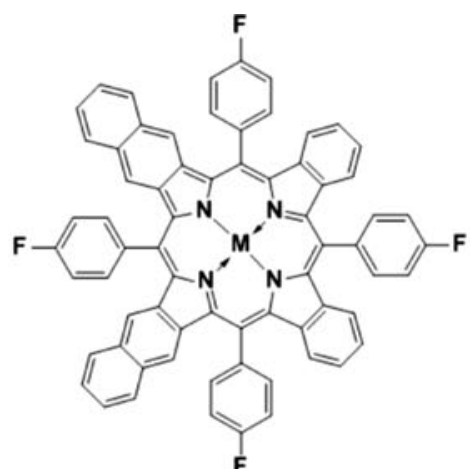

$46 \mathrm{M}=\mathrm{Pt}$

cis-Platinum(II)-meso-tetra-(4-fluorophenyl) dibenzodinaphthoporphyrin cis $\mathrm{P}$ t2NF

$47 \mathbf{M}=\mathbf{P d}$

cis-Palladium(II)-meso-tetra-(4-fluorophenyl) dibenzodinaphthoporphyrin cis $\mathrm{Pd} 2 \mathrm{NF}$

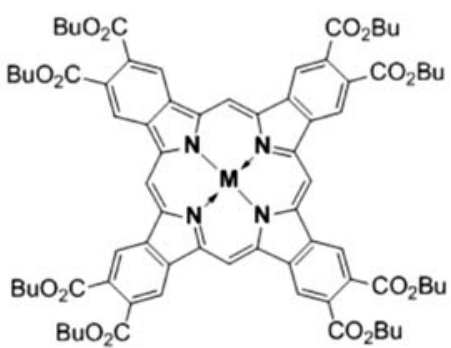

$52 \mathbf{M}=\mathbf{P t}$

Platinum(II) tetrabenzoporphyrin octabutylester $\operatorname{PtTBP}\left(\mathrm{CO}_{2} \mathrm{Bu}\right)_{8}$

$53 \mathbf{M}=\mathbf{P d}$

Palladium(II) tetrabenzoporphyrin octabutylester $\operatorname{PdTBP}\left(\mathrm{CO}_{2} \mathrm{Bu}\right)_{8}$

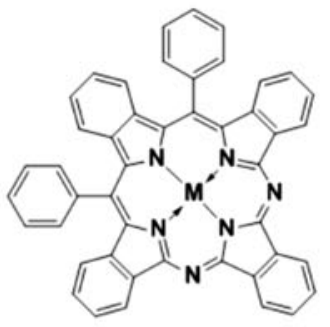

$57 \mathbf{M}=\mathbf{P t}$

Platium(II)-6,13-diaza-20,27. triphenyltetrabenzoporphyrin

$$
\mathrm{Pt} \mathrm{N}_{2 \text {-cis }} \mathrm{TBP}
$$

$58 \mathrm{M}=\mathbf{P d}$

Palladium(II)-6,13-diaza-20,27tetraphenyltetrabezoporphyrin $\mathrm{PdN}_{2 \text {-cis }} \mathrm{TBP}$

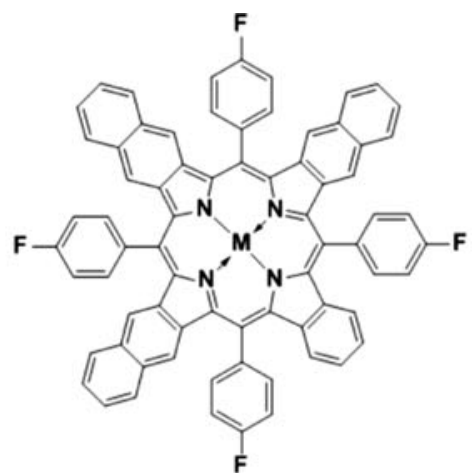

$48 \mathrm{M}=\mathrm{Pt}$

Platinum(II)-meso-tetra-(4-fluorophenyl) monobenzotrinaphthoporphyrin Pt3NF

$49 \mathrm{M}=\mathbf{P d}$

Palladium(II)-meso-tetra-(4-fluorophenyl) monobezotrinaphthoporphyrin Pd3NF

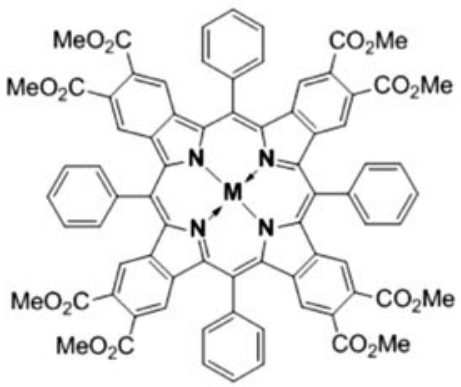

$54 \mathrm{M}=\mathbf{P d}$

Palladium(II) tetraphenyltetrabenzoporphyrin octamethylester $\mathrm{Pd}-\mathrm{Ph}_{4} \mathrm{TBP}\left(\mathrm{CO}_{2} \mathrm{Me}\right)_{8}$

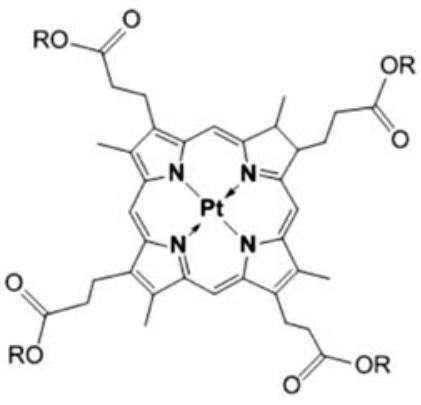

$59 \mathbf{M}=\mathbf{P t}$

Platium(II) coproporphyrin $\mathrm{PtCP}$

$60 \mathrm{M}=\mathbf{P d}$

Palladium(II) coproporphyrin $\mathrm{PdCP}$

$\mathbf{R}=$ peptide

Fig. 9 Chemical structures of $\mathrm{Pt}(\mathrm{II})$ and $\mathrm{Pd}(\mathrm{II})$ porphyrin complexes 
functionality (water solubility, partial shielding from oxygen and other species, cell penetration, recognition of specific cells or cellular components, etc.).

Recently, Papkovsky and co-workers [57] reported on a panel of phosphorescent oligoarginine conjugates of tetracaboxylic Pt(II) and Pd(II)-coproporphyrin I (PtCP 59 and PdCP 60; Fig. 9) mono or tetra-substituted, which were successfully used for sensing intracellular oxygen thanks to their ability to penetrate cells. The authors showed that all the Pt(II)-tetra-substituted conjugates displayed absorption spectra that were similar to those of the free PtCP; on the other hand, it was reported that the conjugation with peptides had a significant decreasing effect on the emission quantum yield (see Supporting Information of [57]) while all the PtCP conjugates displayed very similar phosphorescence lifetimes $(20-23 \mu \mathrm{s}$ in air saturated and $\sim 80 \mu \mathrm{s}$ in deoxygenated media).

The corresponding PdCP conjugates, as expected, showed significantly longer unquenched phosphorescence lifetimes $(\sim 1 \mathrm{~ms})$ and therefore are better suited to measure oxygen at very low concentrations.

Metalloporphyrins are generally hydrophobic and therefore insoluble in water or in physiological fluids; they therefore need to be modified by addition of "molecular coats" in order to enhance their interactions with the environment when used, for example, to measure the oxygenation of tumors in vivo [63]. Oxyphors R2 61 and G2 62 (Fig. 10) have been constructed by modification of Pd(II)-meso-tetra (4-carboxyphenyl)-porphyrin and $\mathrm{Pd}(\mathrm{II})-$-meso-tetra (4-carboxyphenyl)-

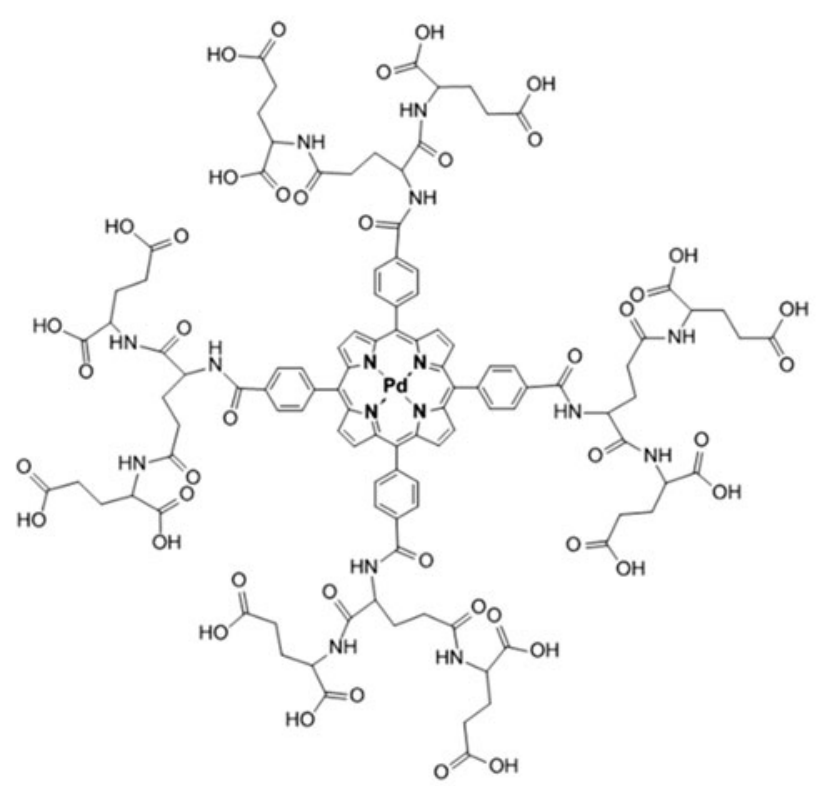

61 Oxyphor R2

Pd-meso-tetra-(4-carboxyphenyl)poprhyrin-glutamate-dendrimer tetrabenzoporphyrin, respectively, and are the second generation of polyglutamic dendrimers. The outer layers of the dendrimers have 16 carboxylate groups which are responsible for both their solubility in biological fluids and their inability to pass through biological membranes. The photophysical properties of the two dendrimers are shown in Table 3 and it can be highlighted that Oxyphor $\mathbf{G 2}$ could be the indicator of choice when measuring tissue oxygenation that require light penetration into the depths of tissue since it has an absorption band near $632 \mathrm{~nm}$

The same phosphor $\mathbf{G 2}$ was incorporated into nanoparticles (PEBBLES) modified with peptides to be used for intracellular oxygen measurements [135]. Metalloporphyrins of palladium(II) and platinum(II) have been also encapsulated into poly(arylglycine) dendrimers modified with poly(ethyleneglycol) residues in order to enhance the dye's solubility, diminish its toxicity and help preventing its interaction with the biological environment when used in vivo [130]. The dendrimer folds in aqueous environments and creates a diffusion barrier for oxygen which can be exploited to regulate the sensitivity and the dynamic range of the probe. The photophysical properties of such a probe PdTBP-( $\left.\mathrm{AG}^{2} \mathrm{OPEG}\right)_{8} 63$ (Fig. 11) are reported in Table 3. Several other water-soluble dendrimers were reported recently by the same group [66]. Vinogradov and co-workers have also reported dendrimeric oxygen probes bearing coumarin antennas along with a porphyrin core $[32,74]$. These probes were found useful for application in two-photon microscopic imaging of oxygen distribution in tissues due

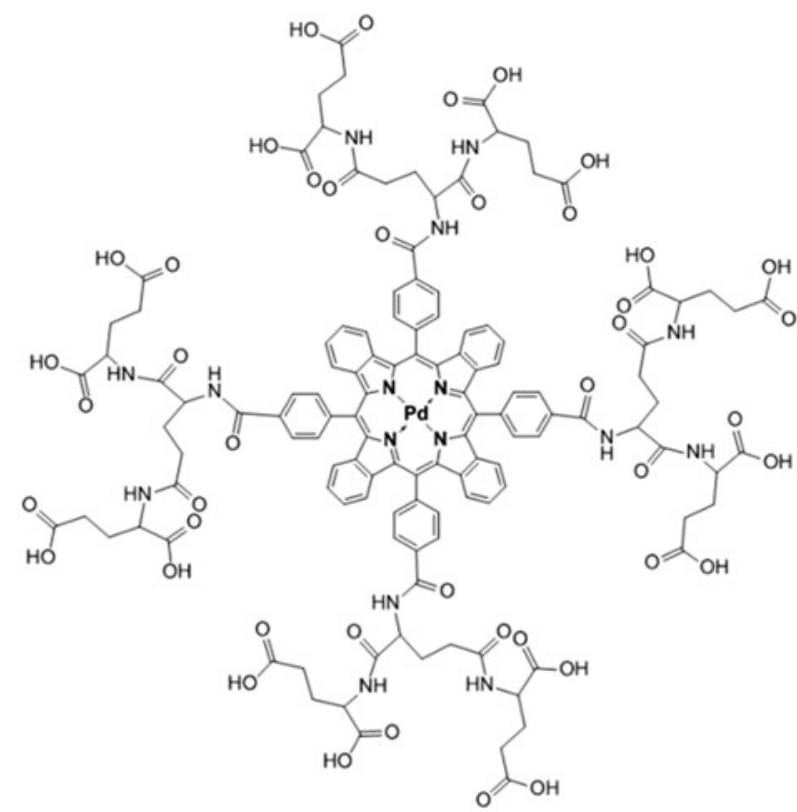

62 Oxyphor G2

Pd-meso-tetra-(4-carboxyphenyl)tetrabenzopoprhyrin-glutamate-dendrimer

Fig. 10 Chemical structure of Oxyphor R2 and Oxyphor G2 
to the fact that the coumarin antennas increased the efficiency of the two-photon excitation compared to the dendrimers solely based on the benzoporphyrin complexes.

It should be mentioned here that lipophilic porphyrins encapsulated into water-dispersible nanoparticles represent an alternative to dendrimeric oxygen probes and often perform similarly despite their significantly larger dimensions (typically tens of nanometer). The polymer of the particle provides necessary protection for the indicator dye from the environment and helps to tune oxygen sensitivity. The functional groups on the surface of the particles not only render them water-dispersible but also can enable, e.g., cell penetration [69].
Recently, Koren et al. [115] reported the synthesis and characterization of new Ir(III) porphyrin complexes. In contrast to the square planar $\mathrm{Pt}(\mathrm{II})$ and $\mathrm{Pd}(\mathrm{II})$ porphyrins, the new hexa-coordinating complexes showed quite interesting photophysical properties which could be tuned by modification of the axial ligands, modifications that demonstrated to have an influence also on the solubility of the complexes. Three different indicators were synthesized from the same parent complex (Ir-OEP-CO-Cl 64 - Fig. 12) by ligand exchange and their photophysical properties are reported in Table 3 together with the ones of the parent complex 64. The positively charged complexes Ir-OEP-Py 2 65, IrOEP- $n$-butIm 2 66, and Ir-OEP-CarbIm ${ }_{2} 67$ with two similar

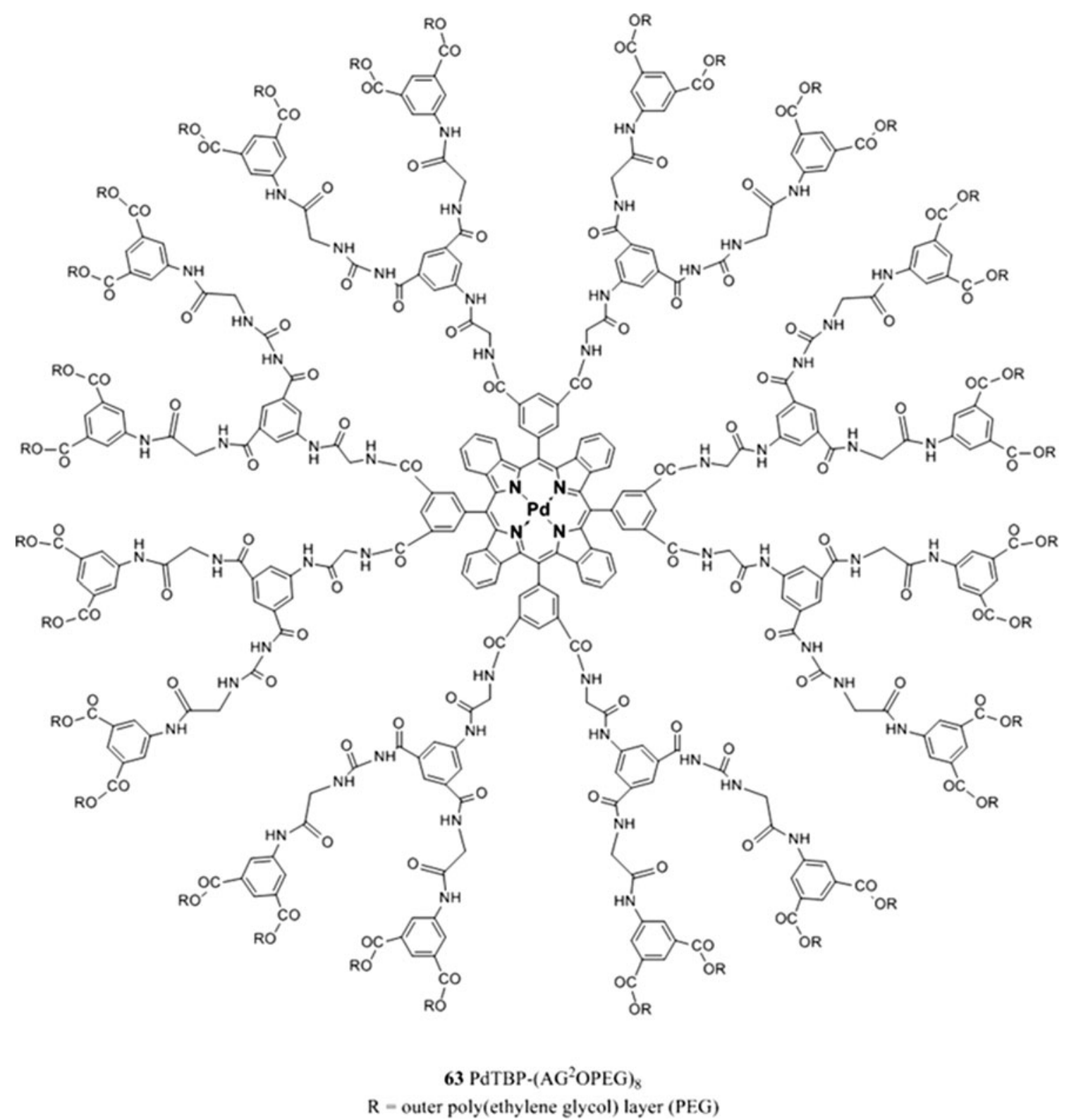

Fig. 11 Schematic structure of PEG modified PdTBP-dendrimer 
axial ligands show similar properties, in contrast to the neutral Ir-OEP-CO-Cl; they all have relatively high phosphorescence quantum yields (up to $21 \%$ ) but shorter decay times. The absorption and emission spectra of 65-67 are bathochromically shifted compared to the Pt(II) complexes and therefore they can be excited with visible light directly in the Soret band (Fig. 12).

The axial ligands can be used not only to modify the solubility of the complexes but also to introduce functional groups to enable, for example, covalent coupling. For example, very recently, Koren et al. [116] directly attached short peptides to the $\operatorname{Ir}(\mathrm{III})$ complex via a hystidine unit at the $N$-terminus of the peptide and used the new probes for oxygen imaging in mammalian cells.

Very recently, an oxygen probe based on a copolymer of a Pt(II) porphyrin and 9,9-dioctylfluorene has been reported [246]. The conjugated polymer combines the properties of a luminescent indicator and a polymeric matrix and, more importantly, possesses dual emission under UV/violet excitation which originates from the fluorene (oxygen-independent fluorescence) and $\mathrm{Pt}(\mathrm{II})$ porphyrin (oxygen-dependent phosphorescence). Thus, ratiometric sensing and imaging becomes possible; the authors also demonstrated that the ratio of the emission intensities can be adjusted by varying the ration of fluorene/Pt(II) porphyrin units.

\section{Cyclometallated complexes}

Another class of indicators which have been exploited for oxygen sensing is represented by the cyclometallated complexes of Ir(III) and Pt(II). The last decade has seen an enormous progress in the field of luminescent cyclometallated complexes which was driven by the development of OLED technology. Some of these dyes were also applied as oxygen indicators.

In general, thesee complexes show high luminescence quantum yields, have large Stokes' shift and are photostable. However, their luminescence decay times are in order of several microseconds; therefore, usually much shorter than the one of metalloporphyrins, also their absorption in the visible region is not efficient ( $\varepsilon$ rarely exceeds $10,000 \mathrm{M}^{-1} \mathrm{~cm}^{-1}$ ).
The tris(2-phenylpyridine) iridium(III) $\left[\operatorname{Ir}(\mathrm{ppy})_{3}\right] \mathbf{6 8}$ displays a very strong green luminescence with high quantum yield (0.90) and relatively long lifetime (1.5 $\mu$ s; Table 4). The molar absorption coefficient in the visible region is comparable to other cyclometallated compound and is rather low $\left(<10,000 \mathrm{M}^{-1} \mathrm{~cm}^{-1}\right)$ [126]. This indicator has been used as oxygen sensor immobilized in different matrices such as: poly(styrene-co-trifluoroethylmetacrylate (TFEM)) in which it showed quite good photostability [7], Ormosil where it was used as a transducer for the detection of uric acid [201], and poly(dimethylsiloxane) which was functionalized with the $\operatorname{Ir}(\mathrm{III})$ complex and blended with polystyrene [117]. Very recently, complex $\mathbf{6 8}$ has been modified to be suitable for imaging living cells; to enable cellular uptake the phenylpyridine ligands were functionalized with three different amino acids (lysine, alanine, and glycine) [211]. The modified complexes were shown to possess relatively high cellular uptake but, compared to $\mathbf{6 8}$, their quantum yields were only moderate $(<0.2)$.

A substitution of the ppy ligands in complex 68 with ppy$\mathrm{NPh}_{2}$ leads to the formation of a new cyclometalated indicator: $\left[\operatorname{Ir}\left(\text { ppy- } \mathrm{NPh}_{2}\right)_{3}\right] 69$ which has the advantage of being less sensitive to self-quenching and is even better soluble in organic solvents and organic polymers [149]. Complex 69 has a high phosphorescence quantum yield ( $70 \%)$, lifetime in the order of several microseconds (Table 4), can be excited at $405 \mathrm{~nm}$ and therefore is compatible with low-cost LED as excitation source and its excitation and emission spectra are well shifted. A third complex possessing the same skeleton as $\mathbf{6 8}$ has been used as red-emitting dye: the tris $\{2-($ benzo[b] thiophene-2-yl)pyridinato- $\mathrm{C}^{3}, \mathrm{~N}$ \} iridium(III) 70; which is characterized by large Stokes' shift and a lifetime of $8.6 \mu \mathrm{s}$ that is suitable for lifetime imaging application. However, similarly to other cyclometallated complexes the absorption is very efficient only in the UV region ( $\varepsilon$ as high as $60,000 \mathrm{M}^{-1} \mathrm{~cm}^{-1}$ at $292 \mathrm{~nm}$ Table 4$)$. $\operatorname{Ir}(\text { btpy })_{3}$ has been used, along with a green-emitting iridium dye, in a dual pressure and temperature sensitive paint [77]. The barometric dye $\mathbf{7 0}$ was incorporated in a cellulose acetate butyrate film and the crosssensitivity to temperature was efficiently corrected by simultaneous optical determination of the temperature.

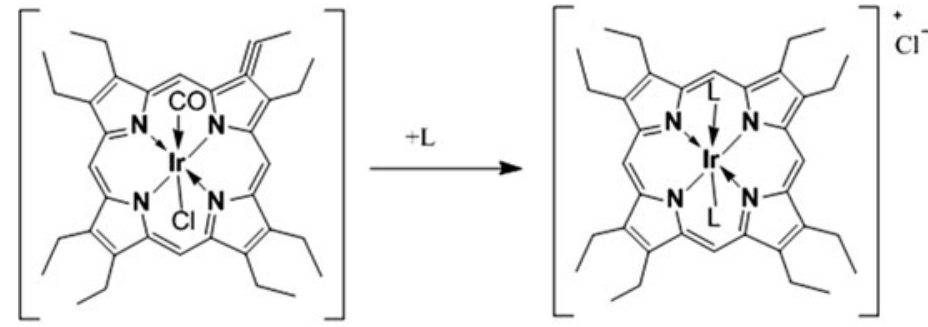

64 Ir-OEP-CO-C

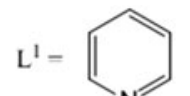

65 Ir-OEP-Py 2

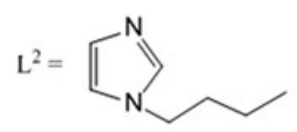

66 Ir-OEP-n-Butlm 2

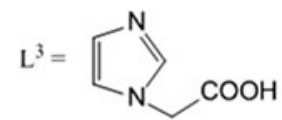

67 Ir-OEP-CarbIm 2

Fig. 12 Chemical structures of $\operatorname{Ir}(\mathrm{III})$ porphyrins complexes 
Table 4 Photophysical properties of cyclometallated complexes of $\operatorname{Ir}(\mathrm{III})$ and $\mathrm{Pt}(\mathrm{II})$

\begin{tabular}{|c|c|c|c|c|c|c|}
\hline Dye & $\lambda_{\max }{ }^{\text {abs }}(\mathrm{nm})\left(\varepsilon \times 10^{3} \mathrm{M}^{-1} \mathrm{~cm}^{-1}\right)$ & $\lambda_{\max }^{\mathrm{em}}(\mathrm{nm})$ & Medium & $\Phi$ & $\tau$ & References \\
\hline $68 \operatorname{Ir}(\mathrm{ppy})_{3}$ & 376 & 512 & THF & 0.90 & $1.5 \mu \mathrm{s}$ & {$[7]$} \\
\hline $69 \operatorname{Ir}(\text { ppy-NPh })_{3}$ & 405 & 527 & 2-MeTHF & 0.70 & $4.3 \mu \mathrm{s}$ & [149] \\
\hline $70 \operatorname{Ir}(\text { btpy })_{3}$ & $292(67.6) / 366(20.4) / 408(21.8)$ & $\begin{array}{l}596 \\
645\end{array}$ & $\mathrm{CHCl}_{3}$ & - & $8.6 \mu \mathrm{s}^{\mathrm{a}}$ & {$[77]$} \\
\hline $71 \mathrm{~N}-948^{\mathrm{b}}$ & 494 & 665 & $\mathrm{CH}_{2} \mathrm{Cl}_{2}$ & $0.58^{\mathrm{b}}$ & $102 \mu \mathrm{s}^{\mathrm{c}}$ & {$[157]$} \\
\hline $72 \operatorname{Ir}\left(\mathrm{C}_{\mathrm{N}}\right)_{2}(\mathrm{acac})$ & $450(57.1) / 421(86.9)$ & 545 & $\mathrm{CHCl}_{3}$ & 0.53 & $8.5 \mu \mathrm{s}$ & {$[24]$} \\
\hline $73 \operatorname{Ir}\left(\mathrm{C}_{\mathrm{O}}\right)_{2}(\mathrm{acac})$ & $467(53.7) / 443(47)$ & 552 & $\mathrm{CHCl}_{3}$ & 0.34 & $10.7 \mu \mathrm{s}$ & {$[24]$} \\
\hline $74 \operatorname{Ir}\left(\mathrm{C}_{\mathrm{S}-\mathrm{Me}}\right)_{2}(\mathrm{acac})$ & $471(75.4) / 441(77.8)$ & 564 & $\mathrm{CHCl}_{3}$ & 0.44 & $11.3 \mu \mathrm{s}$ & {$[24]$} \\
\hline $75 \operatorname{Ir}\left(\mathrm{C}_{\mathrm{S}}\right)_{2}(\mathrm{acac})$ & $472(92.8) / 444(86.8)$ & 563 & $\mathrm{CHCl}_{3}$ & 0.54 & $11.3 \mu \mathrm{s}$ & {$[24]$} \\
\hline $76\left(\mathrm{C}_{\mathrm{N}}\right)_{2} \operatorname{Ir}(\mu-\mathrm{Cl})_{2} \operatorname{Ir}\left(\mathrm{C}_{\mathrm{N}}\right)_{2}$ & $463(87.6) / 433(133.6)$ & 568 & $\mathrm{CHCl}_{3}$ & 0.30 & $9.7 \mu \mathrm{s}$ & {$[24]$} \\
\hline $77\left(\mathrm{C}_{\mathrm{S}}\right)_{2} \operatorname{Ir}(\mu-\mathrm{Cl})_{2} \operatorname{Ir}\left(\mathrm{C}_{\mathrm{S}}\right)_{2}$ & $482(136.5) / 457(136.9)$ & 587 & $\mathrm{CHCl}_{3}$ & 0.21 & $13.1 \mu \mathrm{s}$ & {$[24]$} \\
\hline $78 \operatorname{Ir}(\mathrm{C} 6)_{2}(\mathrm{vacac})$ & $445^{\mathrm{d}}(77.9) / 474^{\mathrm{d}}(86.9)$ & 568 & Toluene & 0.22 & $6.0 \mu \mathrm{s}$ & {$[55]$} \\
\hline $80 \mathrm{Pt}(\text { thpy })_{2}$ & $470(2)$ & $\sim 590$ & Acetonitrile & 0.36 & $4.8 \mu \mathrm{s}$ & {$[59]$} \\
\hline $81 \mathrm{C}^{\wedge} \mathrm{N}_{1} \mathrm{Pt}(\mathrm{acac})$ & $459(13.0)$ & $\begin{array}{l}502 \\
535 \\
683 \\
753\end{array}$ & Toluene & $0.95^{\mathrm{e}} 0.22^{\mathrm{e}}$ & $0.06 \mathrm{~ns} 1.53 \mu \mathrm{s}$ & [143] \\
\hline \multirow[t]{2}{*}{$82 \mathrm{C}^{\wedge} \mathrm{N}_{2} \mathrm{Pt}(\mathrm{acac})$} & $474(21.7)$ & $\begin{array}{l}521 \\
556\end{array}$ & Toluene & $3.03^{\mathrm{e}}$ & $0.14 \mathrm{~ns}$ & {$[143]$} \\
\hline & & $\begin{array}{l}692 \\
762\end{array}$ & & $0.57^{\mathrm{e}}$ & $3.74 \mu \mathrm{s}$ & \\
\hline $83 \mathrm{C}^{\wedge} \mathrm{N}_{3} \mathrm{Pt}(\mathrm{acac})$ & $243(52.0) 390(33.7)$ & $\begin{array}{l}455 \\
638\end{array}$ & $\mathrm{CH}_{2} \mathrm{Cl}_{2}$ & $1.1^{\mathrm{e}}$ & $\begin{array}{l}3.2 \mathrm{~ns} \\
6.6 \mu \mathrm{s}\end{array}$ & [244] \\
\hline $84 \mathrm{C}^{\wedge} \mathrm{N}_{4} \mathrm{Pt}(\mathrm{acac})$ & $357(1.73) 400(0.41)$ & 386538 & $\mathrm{CH}_{2} \mathrm{Cl}_{2}$ & $18.2^{\mathrm{e}}$ & $\begin{array}{l}25 \mathrm{~ns} \\
25.5 \mu \mathrm{s}\end{array}$ & {$[244]$} \\
\hline $85 \mathrm{C}^{\wedge} \mathrm{N}_{5} \mathrm{Pt}(\mathrm{acac})$ & $292(2.76) 396(0.51)$ & 536 & $\mathrm{CH}_{2} \mathrm{Cl}_{2}$ & $32.3^{\mathrm{e}}$ & $5.4 \mu \mathrm{s}$ & [244] \\
\hline $86 \mathrm{C}^{\wedge} \mathrm{N}_{6} \mathrm{Pt}(\mathrm{acac})$ & $234(38.1) 339(25.1)$ & 575 & $\mathrm{CH}_{2} \mathrm{Cl}_{2}$ & $9.1^{\mathrm{e}}$ & $15.8 \mu \mathrm{s}$ & [244] \\
\hline $87 \mathrm{C}^{\wedge} \mathrm{N}_{7} \mathrm{Pt}(\mathrm{acac})$ & $335(2.68) 400(0.63)$ & 560 & $\mathrm{CH}_{2} \mathrm{Cl}_{2}$ & $4.5^{\mathrm{e}}$ & $0.86 \mu \mathrm{s}$ & {$[244]$} \\
\hline 88 dppe-Pt2P & $344^{\mathrm{d}}(12.4) / 496^{\mathrm{d}}(3.2)$ & $\begin{array}{l}677 \\
732\end{array}$ & DMSO & $\begin{array}{l}0.002 \\
0.01\end{array}$ & $\begin{array}{l}0.2 \mathrm{~ns} \\
8.66 \mu \mathrm{s}\end{array}$ & [220] \\
\hline
\end{tabular}

${ }^{a}$ Measured at 50 mbar air pressure and $1{ }^{\circ} \mathrm{C}$

${ }^{\mathrm{b}} \mathrm{N}$-948 $=\operatorname{Ir}(2 \text {-phenylpyridine })_{2}\left(4,44^{\prime}\right.$-bis (2-(4- $N, N$-methylhexylaminophenyl)ethenyl)-2,2'-bipyridine)

${ }^{\mathrm{c}}$ When incorporated in polystyrene (PS)

${ }^{\mathrm{d}}$ Measured in dichloromethane

${ }^{\mathrm{e}}$ Obtained in toluene with $\mathrm{Ru}(\mathrm{byp})_{2}(\mathrm{phen})\left[\mathrm{PF}_{6}\right]_{2}$ as the standard

The [Ir(2-phenylpyridine)2(4,4'-bis(2-(4-N,N-methylhexylaminophenyl)ethyl)-2,2'-bipyridine)Cl] 71 which for convenience was given the name N-948 possesses luminescent emission at a wavelength higher than $650 \mathrm{~nm}(665 \mathrm{~nm}$; Table 4). N-948 was shown to have quite good quantum yields $\left(\Phi_{P}>0.50\right)$, extraordinary long decay time $(102 \mu \mathrm{s}$ when incorporated in polystyrene) and high lipophilicity which increase its retention in rather apolar polymeric films. N-948 was incorporated in both polystyrene and a nanostructured metal oxide matrix which increased its photostability and resistance to heat and $\gamma$-irradiation during sterilization.

As was mentioned above, rather low molar absorption coefficients of the cyclometallated complexes represent a serious disadvantage for their application as oxygen indicators. Cyclometalated iridium(III) complexes with coumarins overcome this drawback $[24,126]$. Such indicators are characterized by efficient visible absorption in the blue part of the spectrum ( $\varepsilon$ as high as $90,000 \mathrm{M}^{-1} \mathrm{~cm}^{-1}$; Table 4$)$ and very strong phosphorescence $\left(\Phi_{P} \sim 0.50\right)$ which results in an exceptionally high brightness and makes them attractive for application in thin films to monitor fast processes and different types of nano- and microparticles. The photophysical properties of cyclometalated $\operatorname{Ir}(\mathrm{III})$ coumarin complexes of general formula $\operatorname{Ir}\left(\mathrm{C}_{\mathrm{X}}\right)_{2}$ (acac) where $X=N(\mathbf{7 2}), \mathrm{O}(\mathbf{7 3}), \mathrm{S}-\mathrm{Me}$ (74) and $S$ (75) are reported in Table 4 and their chemical structures shown in Fig. 13. The coumarin substituent represents a rather flexible system in respect to fine-tuning of spectral properties 
of the complexes, which depend on the $X$ substituent of the coumarin: the bathochromic shift increases when $X=N>\mathrm{O}>\mathrm{S}$ [24]. As already mentioned, these indicators show high luminescence brightness $\left(\varepsilon \times \Phi_{P}\right.$ exceeds 50,000 for $\operatorname{Ir}\left(\mathrm{C}_{\mathrm{S}}\right)_{2}$ (acac) and it is as high as 46,000 for $\left.\operatorname{Ir}\left(\mathrm{C}_{\mathrm{N}}\right)_{2}(\mathrm{acac})\right)$. It should be also mentioned that all the complexes $\mathbf{7 2 - 7 5}$ can be efficiently excited with 425,435 , and $450 \mathrm{~nm}$ LEDs and possess relatively sharp excitation and emission bands therefore are suitable for multi-analyte sensing. The phosphorescent decay times for this class of ultrabright indicators are of $\sim 10 \mu \mathrm{s}$ for all the complexes which insures good sensitivity in polystyrene-based materials [24].

The dimeric coumarin complexes of general formula $\left(\mathrm{C}_{\mathrm{X}}\right)_{2} \operatorname{Ir}(\mu-\mathrm{Cl})_{2} \operatorname{Ir}\left(\mathrm{C}_{\mathrm{X}}\right)_{2}$ were also investigated (76-77, Fig. 13). However, the emission quantum yields are lower than the respective monomeric complexes (Table 4). The absorption and emission maxima of the dimeric complexes shift bathochromically and in general the shift in the emission maxima is more pronounced.

De Rosa et al. presented a derivative of a coumarin complex, $\operatorname{Ir}(\mathrm{C} 6)_{2}$ (vacac) 78 (Fig. 13) which was covalently bound to a polymeric support (silicone rubber) to eliminate dye aggregation. Unfortunately, the indicator in this case exhibited lower brightness in respect to the unbounded derivative. Nevertheless, complex $\mathbf{7 8}$ displayed good quantum yields and luminescence lifetime (Table 4) and was suggested as a good candidate for PSP studies [55].

Very recently, Yoshihara et al. [254] presented a novel intrinsic ratiometric molecular probe, the $\mathrm{C} 343-\mathrm{Pro}_{4}-\mathrm{BTP}$ 79 (Fig. 13) which consists of an oxygen-sensitive phosphor (Ir(III)BTP, BTP= bis (2-(2'-benzothienyl)-pyridinato-N, $\left.\mathrm{C}^{3}\right)$ ) connected to an oxygen-insensitive fluorophore (coumarin C343) by a tetraproline linker. Ideally, this probe was designed to measure local oxygen levels in living cells and tissue but currently cellular uptake is too low to perform quantitative analysis but the proline linker can be modified to enhance the delivery to cells.

As previously mentioned, also Pt(II) cyclometalated complexes have been used as indicators for oxygen sensors and a selection is reported here. Cis-bis[2-(2'-thienyl)pyridine]platinum(II), $\mathrm{Pt}(\text { thpy })_{2} \mathbf{8 0}$ was selected as a luminophore for sensing $\mathrm{O}_{2}$ concentration in seawater [59]. This indicator can be easily excited with blue LED as it absorbs light up to $500 \mathrm{~nm}$, it possesses high luminescence quantum yield $\left(\Phi_{P}=0.36\right)$ and an excited-state lifetime of $4.8 \mu \mathrm{s}$. The non-ionic character makes it basically insoluble in water and therefore it is not susceptible to leaching in presence of water. Similarly to the analogous Ir (III) complexes, cyclometallated Pt(II) indicators possess moderate to low absorption in the visible part of the spectrum. It should be mentioned here that as recently demonstrated by Hanson et al. [90], the visible absorption of the cyclometallated complexes can be enhanced by introducing a highly absorbing ligand in addition to the cyclometallated one. Although this approach has not yet been applied in oxygen sensors, it represents an elegant solution.

As mentioned earlier in this review, it would be highly desirable to design a ratiometric sensor for imaging which uses a single molecule. Only few examples of such indicators were found in the literature, which is understandable since such probes are not easy to design, it is in fact difficult to predict if a molecule will show both fluorescent and phosphorescent emissions and in comparable quantum yields. Some examples of such indicators were recently reported by Zhao et al. [143, 244]. They entailed cyclometalated $\mathrm{Pt}(\mathrm{II})$ complexes of general formula $\mathrm{C}^{\wedge} \mathrm{NPt}(\mathrm{acac})$, some of which show dual fluorescence and phosphorescence emission. The structures of complex 81-87 are shown in Fig. 14 and their photophysical properties, which mainly depend on the $\mathrm{C}^{\wedge} \mathrm{N}$ cyclometallating ligand, are reported in Table 4. Some of the complexes show enhanced absorption in the visible region due to the presence of naphthalimide chromophore and 81- 84 presented well-separated dual emission bands.

$\mathrm{C}^{\wedge} \mathrm{N}_{1} \mathrm{Pt}(\mathrm{acac}) \mathbf{8 1}$ gives fluorescence emission bands at between 500 and $650 \mathrm{~nm}$ with a quantum yield of 0.95 and a lifetime of $0.06 \mathrm{~ns}$, this bands are basically unaffected by the presence of $\mathrm{O}_{2}$. On the other hand, the phosphorescence emission bands at $650-850 \mathrm{~nm}$ with quantum yields of 0.22 and lifetime of $1.53 \mu$ s are quite sensitive toward variation of oxygen concentration. Similar behavior was shown by $\mathrm{C}^{\wedge} \mathrm{N}_{2} \operatorname{Pt}(\mathrm{acac}) \mathbf{8 2}$ which was found to be more sensitive due to its longer phosphorescence lifetime (3.75 $\mu \mathrm{s})$.

$\mathrm{C}^{\wedge} \mathrm{N}_{3} \mathrm{Pt}(\mathrm{acac}) 83$ is the first of a series of (ppy)Pt(acac) complexes which differ from each other by the R substitution in the ppy ligand (Fig. 14). Complex $\mathbf{8 3}$ is the only one showing deep NIR emission $(638 \mathrm{~nm})$ with and emission lifetime of $6.6 \mu \mathrm{s} . \mathrm{C}^{\wedge} \mathrm{N}_{4} \mathrm{Pt}(\mathrm{acac}) \mathbf{8 4}$, which has the same subunit as 83 but attached to the ppy ligand via a methyleneketo group, has a blue-shifted emission at $538 \mathrm{~nm}$ and a longer luminescent lifetime $(25.5 \mu \mathrm{s})$. Minor emission bands for both 83 and 84 could be exploited for ratiometric dual emission measurements.

$\mathrm{C}^{\wedge} \mathrm{N}_{5} \mathrm{Pt}(\mathrm{acac}) 85, \mathrm{C}^{\wedge} \mathrm{N}_{6} \mathrm{Pt}(\mathrm{acac}) \mathbf{8 6}, \mathrm{C}^{\wedge} \mathrm{N}_{7} \mathrm{Pt}(\mathrm{acac}) 87$ emit roughly at the same wavelength range $(530-570 \mathrm{~nm})$ but show different sensitivities towards oxygen quenching as they show quite different decay times, with $\mathrm{C}^{\wedge} \mathrm{N}_{6} \mathrm{Pt}(\mathrm{acac})$ $\mathbf{8 6}$ having the longer one (15.8 $\mu \mathrm{s})$.

Another complex belonging to the same class of dual emitters for oxygen ratiometric measurements is the 1,2bis(diphenylphosphino)ethane- $\mathrm{Pt}\left\{\mathrm{S}_{2} \mathrm{C}_{2}\left(\mathrm{CH}_{2} \mathrm{CH}_{2}-\mathrm{N}\right.\right.$-2-pyridinium) $\}\left[\mathrm{BPh}_{4}\right]$, ddpePtP2 88 [220]. Excitation of 89 leads to a dual emission: a fluorescent one at $677 \mathrm{~nm}$ with a quantum yield of 0.002 and lifetime of $0.2 \mathrm{~ns}$ and a phosphorescent one at $732 \mathrm{~nm}$ with a quantum yield of 0.01 and lifetime of $8.66 \mu \mathrm{s}$. The triplet intensity decreases 


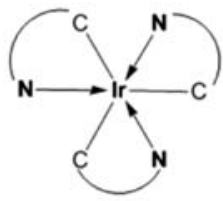

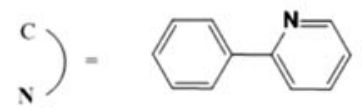

68 Tris(2-phenylpyridine anion) iridium(III) [Ir(ppy) $\left.)_{3}\right]$

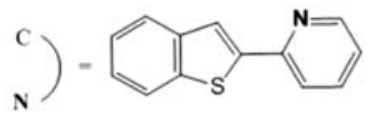

70 Tris $\left\{2-\left(\right.\right.$ benzo[b]thiophene-2-yl)pyridinato- $\left.\mathrm{C}^{3}, \mathrm{~N}\right\}$ iridium(III) [Ir(btpy) $)_{3}$ ]

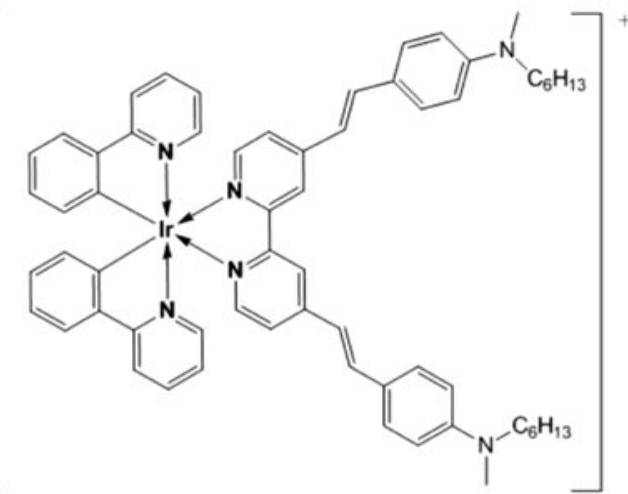

$71 \operatorname{lr}(2 \text {-phenylpyridine })_{2}\left(4-4^{\prime}\right.$-bis(2-(4-N,N-methylhexylaminophenyl)ethenyl)-2,2'bipyridine) N-948

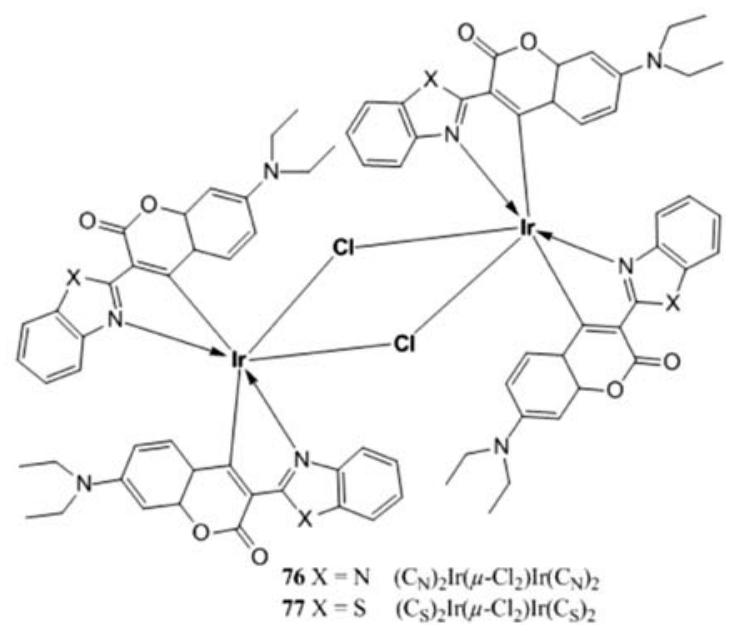

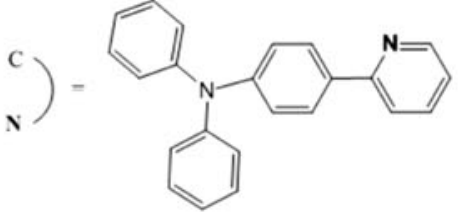

69 Tris(diphenyl-(4'-pyridin-2-yl-phenyl)-amine) iridium(III) $\left[\operatorname{lr}\left(\mathrm{ppy}-\mathrm{NPh}_{2}\right)_{3}\right]$

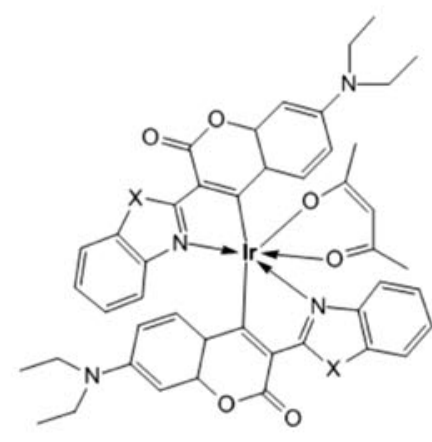

$72 \mathrm{X}=\mathrm{N} \quad \operatorname{lr}\left(\mathrm{C}_{\mathrm{N}}\right)_{2}$ (acac)

$73 \mathrm{X}=\mathrm{O} \quad \operatorname{Ir}\left(\mathrm{C}_{\mathrm{O}}\right)_{2}$ (acac)

$74 \mathrm{X}=\mathrm{S}-\mathrm{Me} \operatorname{Ir}\left(\mathrm{C}_{\mathrm{S}-\mathrm{Me}}\right)_{2}$ (acac)

$75 \mathrm{X}=\mathrm{S} \quad \operatorname{Ir}\left(\mathrm{C}_{\mathrm{S}}\right)_{2}$ (acac)

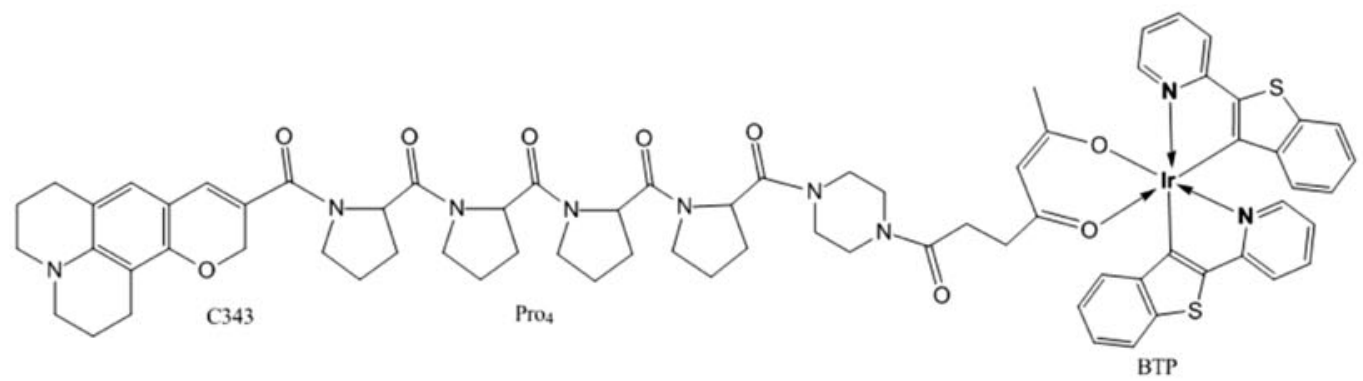

$79 \mathrm{C}^{2} 43-\mathrm{Pro}_{4}$-BTP iridium(III)

Fig. 13 Chemical structures of selected Ir(III) cyclometallated complexes 


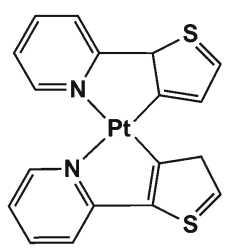

80 cis-bis[2-(2'-thienyl)pyridine] platinum(II) $\operatorname{Pt}(\text { thpy })_{2}$

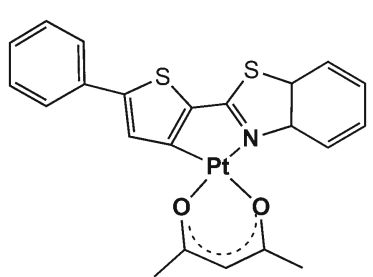

$81 \mathrm{C}^{\wedge} \mathrm{N}_{1} \operatorname{Pt}(\mathrm{acac})$

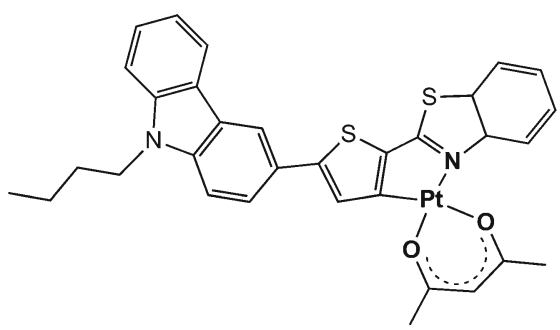

$82 \mathrm{C}^{\wedge} \mathrm{N}_{2} \mathrm{Pt}(\mathrm{acac})$

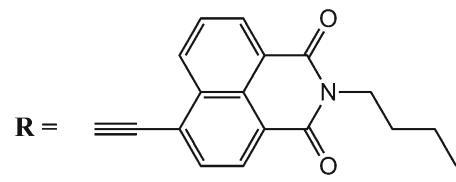

$83 \mathrm{C}^{\wedge} \mathrm{N}_{3} \mathrm{Pt}$ (acac)

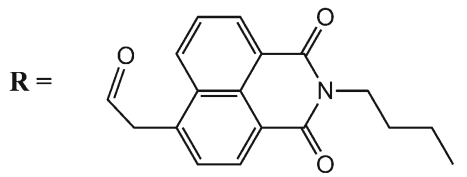

$84 \mathrm{C}^{\wedge} \mathrm{N}_{4} \mathrm{Pt}($ acac $)$

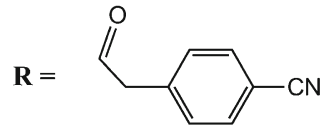

$85 \mathrm{C}^{\wedge} \mathrm{N}_{5} \mathrm{Pt}(\mathrm{acac})$<smiles></smiles>

$86 \mathrm{C}^{\wedge} \mathrm{N}_{6} \operatorname{Pt}($ acac $)$

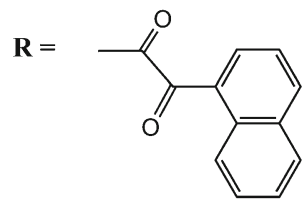

$87 \mathrm{C}^{\wedge} \mathrm{N}_{7} \mathrm{Pt}(\mathrm{acac})$<smiles>c1ccc(P(c2ccccc2)P2CC[PH](c3ccccc3)(c3ccccc3)[PH]2(c2ccccc2)c2ccccc2)cc1</smiles>

88 1,2-bis(diphenylphosphino)ethane$\mathrm{Pt}\left\{\mathrm{S}_{2} \mathrm{C}_{2}\left(\mathrm{CH}_{2} \mathrm{CH}_{2}-N\right.\right.$-2-pyridinium $\}\left[\mathrm{BPh}_{4}\right]$ ddp-Pt2P

Fig. 14 Chemical structures of selected Pt(II) cyclometallated complexes

approximately 2.5 -fold on changing from nitrogen to oxygen while the singlet intensity is basically unaffected; this feature can be therefore used for ratiometric measurement [118]. A complication arises from a significant overlap between the peaks of excitation and emission spectra; to overcome this problem the authors utilized a method that switches between two frequencies of excitation modulation and excludes any overlapping effects. Unfortunately both emissions are rather weak, which is a very serious drawback.
5. Complexes with rarely used central atoms

Under this section, the reader can find those indicators for optical oxygen sensing which possess a central atom that has been used less commonly (Figs. 15 and 16). The primary motivation behind the research of different materials is to provide an alternative to rather expensive platinum group metals as central atoms which can be of relevance for certain applications (e.g., food packaging where the price of the sensing material is one of the most important parameters to be considered). 
Similar to the $\mathrm{Ru}(\mathrm{II})$ polypyridyl complexes, the luminescence of $\mathrm{Pb}$ (II) complexes is dominated by the metal-toligand charge transfer process that involves the promotion of an electron from a metal $d$ orbit to a ligand $\pi^{*}$ orbit.

When the lead(II) complex of 8-hydroxy-5-quinolinesulfonic acid (89) is retained on the surface of anion-exchange resin beads, it exhibits room temperature phosphorescence in suspensions of both aqueous and organic solutions [1]. This complex is characterized by long emission lifetime (Table 5) and very good photostability.
An analogous aluminum complex was shown to possess phosphorescence at room temperature once a heavy atom (iodine) was introduced in the ligand to promote intersystem crossing. The $\mathrm{Al}(\mathrm{III})$-ferron complex 90 was either retained on the surface of anion exchange resin beads [144] or immobilized in sol-gel matrix to monitor oxygen in the gas phase, in water, and in organic solvents [50]; in both cases, the sensor was found to be very photo- and mechanically stable: no bleaching or leaching of the metal-chelate in either aqueous or organic solvent solutions was observed.

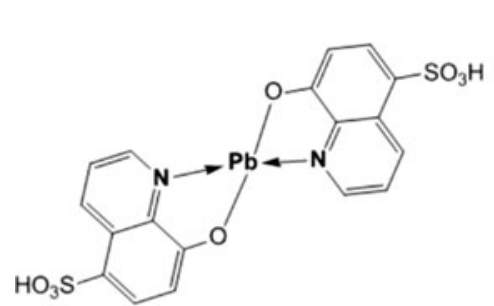

89 Sulfo-8-hydroxy-quinoline-lead(II) $\mathrm{Pb}$ (shq) 2

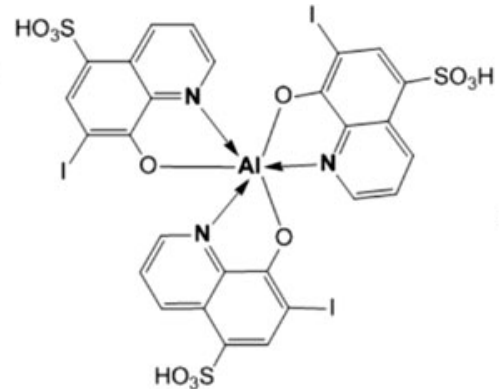

90 Sulfo-8-hydroxy-7-iodo-5-quinoline aluminum(III) Al(III)-ferron<smiles>[R]c1ccc(C(=O)C=C(O[P+](F)(F)F)c2ccc(OCCOC(=O)C(C)OC(C)C)cc2)cc1</smiles>

$91 \mathrm{R}=\mathrm{H}$ boron difluoride dibenzoylmethane $\mathrm{BF}_{2} \mathrm{dbmPLA}$

$92 \mathrm{R}=1 \quad 4$-iodopheyl subsitute of 110 $\mathrm{BF}_{2} \mathrm{dbm}(\mathrm{I}) \mathrm{PLA}$

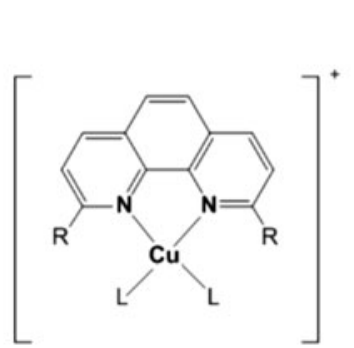

$93 \mathrm{R}=$ methyl $\mathrm{L}=$ bis $[2$ -

(diphenylphosphino(phenyl)]ether

$[\mathrm{Cu}(\mathrm{POP})(\mathrm{dmp})]^{+}$

$94 \mathrm{R}=$ methyl $\mathrm{L}=4,5$-bis(diphenylphosphino)-

9,9-dimethylxanthene

[Cu(xantphos)(dmp)]

$95 \mathrm{R}$ - isopropyl L - 4,5-bis(diphenylphosphino)-

9,9-dimethylxanthene

$\left[\mathrm{Cu}(\text { xantphos)(dipp) }]^{+}\right.$

$96 \mathrm{R}=$ methyl $\mathrm{L}=2$,6dimethylphenylisocyanide $\left[\mathrm{Cu}(\mathrm{CN}-\mathrm{xylyl})_{2}(\mathrm{dmp})\right]^{-}$

$97 \mathrm{R}-$ tert-butyl L - $\mu$-2,5-dimethyl-2,5-

diisobyanohexane

$[\mathrm{Cu}(\mathrm{TM} 4)(\mathrm{dpb})]^{+}$

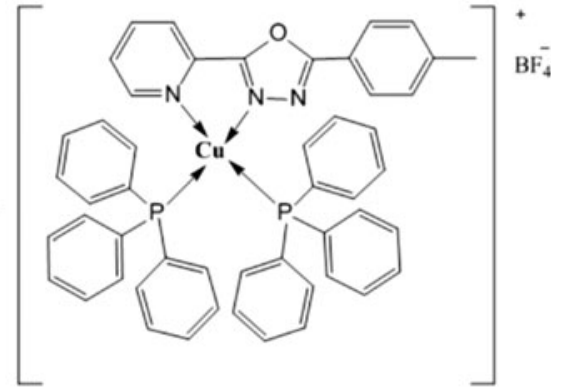

$98\left[\mathrm{Cu}(\mathrm{PTO})\left(\mathrm{PPh}_{3}\right)_{2}\right] \mathrm{BF}_{4}$

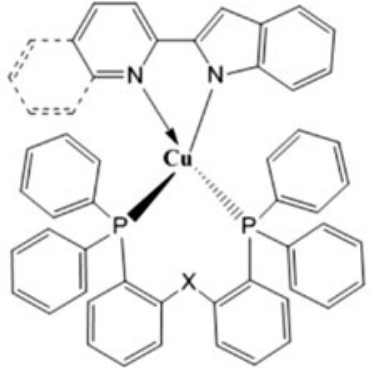

$\mathrm{X}=\mathrm{H}, \mathrm{H} 99\left[\mathrm{Cu}(\right.$ pyin $\left.)\left(\mathrm{PPh}_{3}\right)_{2}\right]$ $100\left[\mathrm{Cu}(\right.$ quin $\left.)\left(\mathrm{pph}_{3}\right)_{2}\right]$

$\mathrm{X}=\mathrm{O} \quad \mathbf{1 0 1}[\mathrm{Cu}($ pyin)(DPEphos) $102[\mathrm{Cu}($ quin)(DPEphos)]

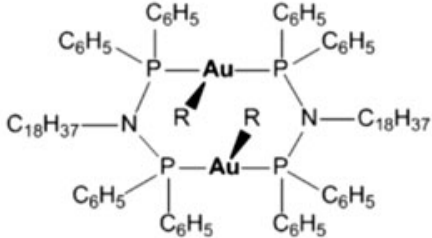

$103 \mathrm{R}=$ I bis $\{\mu$-(bis(diphenylphosphino) octadecylamine $\left.\left.\mathrm{P}, \mathrm{P}^{\prime}\right)\right\}$ diiododigold(1) JM-6277

$104 \mathrm{R}-\mathrm{Cl}$ bis $\{\mu$-(bis(diphenylphosphino) octadecylamine $\mathrm{P}, \mathrm{P}^{\prime}$ ) \} dichlorodigold(I) JM-6275

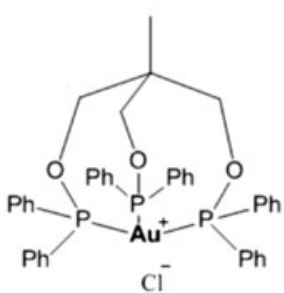

$1051,1,1$, tris(2diphenylphosphenito methyl)-ethane gold(I) JM-6280

Fig. 15 Chemical structures of selected $\mathrm{Al}(\mathrm{III}), \mathrm{Pb}(\mathrm{II}), \mathrm{Cu}(\mathrm{I}), \mathrm{Au}(\mathrm{III})$, and boron complexes 


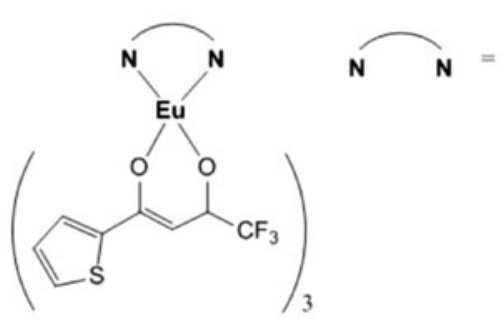

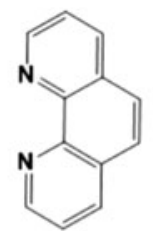

106 (1,10-phenanthroline)-tris (thenoyltrifluoroacetonato) europium(III) [Eu(tta) ${ }_{3}$ phen]<smiles></smiles>

108 ( $10 \mathrm{H}$-dipyrido $[f, h]$ indolo [3,2-b]quinoxaline-tris (thenoyltrifluoroacetonato) curopium(III) [Eu(tta) $)_{3}$ DPIQ]

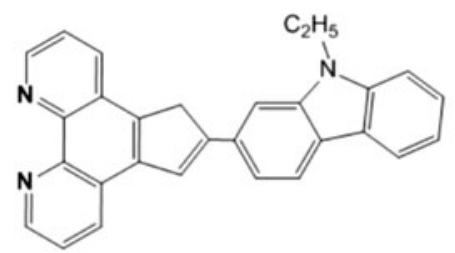

107 (2-( $N$-ethyl-carbazoyl-4)imidazo [4,5-f]1,10-phenanthroline-tris (thenoyltrifluoroacetonato) europium(III) [Eu(tta) ${ }_{3}$ phencarz]<smiles>CCn1c(-c2ccc3c4ccccc4n(CC)c3c2)nc2c3cccnc3c3ncccc3c21</smiles>

109 1-ethyl-(2-(N-ethyl-carbazoyl-4)imidazo [4,5-f]1,10-phenanthroline-tris (thenoyltrifluoroacetonato) europium(III) $\left[\mathrm{Eu}(\mathrm{tta})_{3} \mathrm{ECIP}\right]$

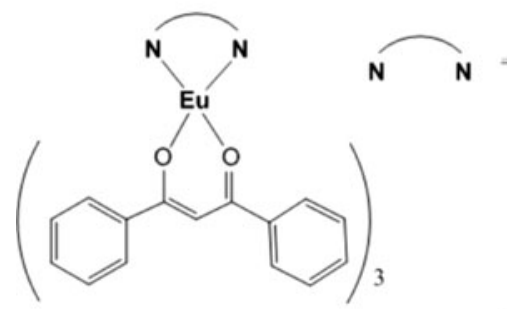

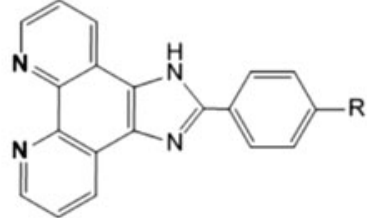

$110 \mathrm{R}=\mathrm{H} \quad$ 2-phenyl-1H-imidazo $[4,5-\mathrm{f}][1,10]$ phenanthroline-tris(1,3-diphenyl-propane-1,3-dione [Eu(DMB) $\left.)_{3} \mathrm{PIP}\right]$

$111 \mathrm{R}=\mathrm{N}(\mathrm{Ph})_{2} \quad 4-(1 \mathrm{H}$-imidazo[4,5-f $][1,10]$ phenanthrolin-2-yl)- $N, N$-diphenylaniline-tris(1,3diphenyl-propane-1,3-dione) $\left[\mathrm{Eu}(\mathrm{DMB})_{3} \mathrm{IPD}\right]$

Fig. 16 Chemical structures of selected $\mathrm{Eu}(\mathrm{III})$ and $\mathrm{Tb}(\mathrm{III})$ complexes

Strong room temperature phosphorescence under deoxygenation was also shown by boron difluoride dibenzoylmethane $\left(\mathrm{BF}_{2} \mathrm{dbm}\right)$ when coupled with poly(lactic acid) (PLA). This is rather surprising since virtually all boron complexes are known to be fluorescent but not phosphorescent (e.g., BODIPY dyes). In dichloromethane solution, $\mathrm{BF}_{2} \mathrm{dbmPLA} 91$ showed a maximum absorption at $396 \mathrm{~nm}$ with a quite high molar absorption coefficient of about 50,000 M-1 $\mathrm{cm}^{-1}$ (Table 5), and an emission maximum at $436 \mathrm{~nm}$ with fluorescence quantum yield of 0.89 [256]. In solid state, on the other hand, $\mathrm{BF}_{2} \mathrm{dbmPLA}$ exhibits both delayed fluorescence and long-lived green room temperature phosphorescence, optical properties that can be exploited for single-component oxygen sensors.
In a more recent report, the same group modified the dually-emissive compound $\mathbf{9 1}$ to obtain the iodidesubstituted difluoroboron dibezoylmethane-poly(lactic acid) compound 92 [258]. The addition of a heavy atom had the effect of enhancing the spin-orbit coupling and therefore increasing the rate of intersystem crossing, rendering $\mathbf{9 2}$ more practical for sensing applications. In fact, as shown in Table 5, the phosphorescence room temperature lifetime decreased from 170 to $4.06 \mathrm{~ms}$. The sensitivity to oxygen of this boron biomaterials was demonstrated by fabricating both thin films and nanoparticles.

Recently, it has been shown that copper(I) complexes in crystalline form can be used as solid-state oxygen gas sensors 
Table 5 Photophysical properties of complexes with rarely used central atoms

\begin{tabular}{|c|c|c|c|c|c|c|}
\hline Dye & $\begin{array}{l}\lambda_{\max }^{\mathrm{abs}}(\mathrm{nm})\left(\varepsilon \times 10^{3} \mathrm{M}^{-1}\right. \\
\left.\mathrm{cm}^{-1}\right)\end{array}$ & $\begin{array}{l}\lambda_{\max }{ }^{\mathrm{em}} \\
(\mathrm{nm})\end{array}$ & Medium & $\Phi$ & $\tau$ & References \\
\hline $89 \mathrm{~Pb}(\mathrm{shq})_{2}$ & 450 & 638 & Toluene & - & $0.16 \mathrm{~ms}$ & {$[1]$} \\
\hline $90 \mathrm{Al}(\mathrm{III})$-ferron & 390 & 600 & Water & - & $460 \mu \mathrm{s}^{\mathrm{a}}$ & {$[144]$} \\
\hline $91 \mathrm{BF}_{2} \mathrm{dbmPLA}$ & $396^{\mathrm{b}}(50.1)$ & 440509 & Thin film & $0.89^{\mathrm{c}}$ & $\begin{array}{l}1.2 \mathrm{~ns} \\
170 \mathrm{~ms}\end{array}$ & [256] \\
\hline $92 \mathrm{BF}_{2} \mathrm{dbm}(\mathrm{I}) \mathrm{PLA}$ & $406^{\mathrm{b}}(33)$ & 485535 & Powder & $0.41^{\mathrm{c}}$ & $\begin{array}{l}0.37 \mathrm{~ns} \\
4.06 \mathrm{~ms}\end{array}$ & {$[258]$} \\
\hline $93[\mathrm{Cu}(\mathrm{POP})(\mathrm{dmp})] \mathrm{tfbp}$ & - & 517 & Solid state & $0.88^{\mathrm{d}}$ & $26.0 \mu \mathrm{s}$ & {$[205]$} \\
\hline $94[\mathrm{Cu}($ xantphos $)(\mathrm{dmp})] \mathrm{tfbp}$ & - & 540 & Solid state & $0.66^{\mathrm{d}}$ & $30.2 \mu \mathrm{s}$ & {$[205]$} \\
\hline $95[\mathrm{Cu}($ xantphos $)(\operatorname{dipp})] \mathrm{tfbp}$ & - & 513 & Solid state & $0.95^{\mathrm{d}}$ & $38.5 \mu \mathrm{s}$ & {$[205]$} \\
\hline $\begin{array}{l}96\left[\mathrm{Cu}(\mathrm{CN}-\mathrm{xylyl})_{2}(\mathrm{dmp})\right] \\
\text { tfbp }\end{array}$ & $\sim 270^{\mathrm{e}}$ & 520 & Solid state & $0.228^{\mathrm{d}}$ & $309 \mu \mathrm{s}$ & {$[206]$} \\
\hline $97[\mathrm{Cu}(\mathrm{TM} 4)(\mathrm{dmp})]_{2}(\mathrm{tfbp})_{2}$ & $\sim 270^{\mathrm{e}}$ & 530 & Solid state & $0.226^{\mathrm{d}}$ & $1.2 \mathrm{~ms}$ & {$[206]$} \\
\hline $98\left[\mathrm{Cu}(\mathrm{PTO})\left(\mathrm{PPh}_{3}\right)_{2}\right] \mathrm{BF}_{4}$ & $220 / 340$ & 515 & $\mathrm{CH}_{2} \mathrm{Cl}_{2}$ & - & $64.4 \mu \mathrm{s}^{\mathrm{b}}$ & {$[88]$} \\
\hline $99\left[\mathrm{Cu}(\right.$ pyin $\left.)\left(\mathrm{PPh}_{3}\right)_{2}\right]$ & $232^{\mathrm{f}}(40.5) 324^{\mathrm{f}}(15.5)$ & 562474 & PMMA film & 0.08 & $\begin{array}{l}1.17 \mu \mathrm{s} \\
4.66 \mathrm{~ns}\end{array}$ & {$[145]$} \\
\hline $\mathbf{1 0 0}\left[\mathrm{Cu}(\right.$ quin $\left.)\left(\mathrm{PPh}_{3}\right)_{2}\right]$ & $231^{\mathrm{f}}(53.1) 354^{\mathrm{f}}(15.6)$ & 608550 & PMMA film & 0.042 & $\begin{array}{l}1.32 \mu \mathrm{s} \\
5.04 \mathrm{~ns}\end{array}$ & {$[145]$} \\
\hline $101[\mathrm{Cu}($ pyin)(DPEphos)] & $231^{\mathrm{f}}(32.4) 324^{\mathrm{f}}(14.9)$ & 566475 & PMMA film & 0.05 & $\begin{array}{l}1.20 \mu \mathrm{s} \\
4.78 \mathrm{~ns}\end{array}$ & {$[145]$} \\
\hline $102[\mathrm{Cu}$ (quin)(DPEphos)] & $231^{\mathrm{f}}(38.1) 354^{\mathrm{f}}(13.9)$ & 610550 & PMMA film & 0.044 & $\begin{array}{l}1.59 \mu \mathrm{s} \\
4.89 \mathrm{~ns}\end{array}$ & {$[145]$} \\
\hline 103 JM-6277 & $418^{\mathrm{g}}$ & 530 & PS & - & $9.8 \mu \mathrm{s}^{\mathrm{d}}$ & {$[163]$} \\
\hline 104 JM-6275 & $405^{\mathrm{g}}$ & 525 & PS & - & & {$[165]$} \\
\hline 105 JM-6280 & $283^{\mathrm{g}}$ & 501 & PS & - & $3.1-12.2 \mu \mathrm{s}^{\mathrm{b}}$ & {$[163]$} \\
\hline $106\left[\mathrm{Eu}(\mathrm{tta})_{3} \mathrm{phen}\right]$ & $268 / 341$ & 612 & $\begin{array}{l}\text { PS-co-TFEM } \\
\text { film }\end{array}$ & l & $340-420 \mu \mathrm{s}^{\mathrm{h}}$ & [12] \\
\hline $107\left[\mathrm{Eu}(\mathrm{tta})_{3} \mathrm{phencarz}\right]$ & $287 / 326$ & 610 & $\mathrm{CH}_{2} \mathrm{Cl}_{2}$ & $\begin{array}{l}0.24- \\
0.31^{\mathrm{i}}\end{array}$ & $\begin{array}{l}0.15- \\
0.53 \mathrm{~ms}^{\mathrm{i}}\end{array}$ & [226] \\
\hline $108\left[\mathrm{Eu}(\mathrm{tta})_{3} \mathrm{DPIQ}\right]$ & $225 / 279$ & 610 & $\mathrm{CH}_{2} \mathrm{Cl}_{2}$ & - & $300 \mu \mathrm{s}$ & {$[260]$} \\
\hline $109\left[\mathrm{Eu}(\mathrm{tta})_{3} \mathrm{ECIP}\right]$ & $260 / 350$ & 610 & PS film & - & $380-440 \mu \mathrm{s}^{1}$ & [208] \\
\hline $110\left[\mathrm{Eu}(\mathrm{DMB})_{3} \mathrm{PIP}\right]$ & $256 / 293 / 353$ & 610 & $\mathrm{CH}_{2} \mathrm{Cl}_{2}$ & 0.18 & $215 \mu \mathrm{s}$ & {$[138]$} \\
\hline $111\left[\mathrm{Eu}(\mathrm{DMB})_{3} \mathrm{IPD}\right]$ & 352 & 610 & $\mathrm{CH}_{2} \mathrm{Cl}_{2}$ & - & $400 \mu \mathrm{s}$ & {$[68]$} \\
\hline $112\left[\mathrm{~Tb}(\mathrm{acac})_{3}(\right.$ phen $\left.)\right]$ & $228 / 268$ & 546 & Alumina film & - & - & [8] \\
\hline
\end{tabular}

${ }^{\mathrm{a}}$ Measured in argon media and taken from [50]

${ }^{\mathrm{b}}$ Absorption measured in $\mathrm{CH}_{2} \mathrm{Cl}_{2}$

${ }^{\mathrm{c}}$ Fluorescence lifetime

${ }^{\mathrm{d}}$ Under pure nitrogen

${ }^{\mathrm{e}}$ In methanol

${ }^{\mathrm{f}}$ In dichloromethane

${ }^{\mathrm{g}} \lambda_{\max }{ }^{\mathrm{exc}}$

${ }^{\mathrm{h}}$ Range of lifetimes of the PS nanofibrous membranes doped with different amounts of complex 106 [253]

${ }^{\mathrm{i}}$ Percentage of quantum yield and lifetimes of complex 107 in 1, 2, 3, and $4 \mathrm{wt} \%$ in PS in DMF solution

${ }^{1}$ Range of lifetimes of the nanofibrous membranes doped with different amounts of complex 109

and their sensing ability correlates well with the amount of void space contained within their lattice structures [205].

An advantage of these indicators is that they replace precious metals such as ruthenium, iridium, or platinum with copper which is significantly cheaper and oxygensensitive materials can be synthesized in few steps from commercially available starting material.

Copper complexes 93-95 (Fig. 15) are based on the same basic structure but differ by the substituent on the 
phenanthroline ligand (denoted with $\mathrm{R}$ ) and by the other two ligands to the copper central atom (denoted with $\mathrm{L}$ ).

$[\mathrm{Cu}(\mathrm{POP})(\mathrm{dmp})] \mathrm{tfbp} 93$ exhibits reasonable oxygen sensitivity but suffers from rapid photochemical degradation [205]; when the POP ligand (POP=bis[2-(diphenylphosphino)phenyl]ether) was substituted with the more rigid xantphos ligand (xantphos $=4,5-$ bis (diphenylphosphino)-9,9dimethylxanthene), the stability of the resulting indicators increased. Complexes 93-95 possess good quantum yields $(0.60-0.90)$ in the rigid matrices and lifetime in a range between 26-32 $\mu$ s (Table 5).

Mann et al. [206] have recently shown that $[\mathrm{Cu}(\mathrm{CN}-$ xylyl $\left.)_{2}(\mathrm{dmp})\right]$ tfbp 96 and $[\mathrm{Cu}(\mathrm{TM} 4)(\mathrm{dmp})]_{2}(\mathrm{tfbp})_{2} 97$ can also be used as efficient crystalline oxygen sensors. These complexes showed much longer excited-stated lifetimes (in the order of ms) when compared to the previously reported [205] and therefore higher sensitivity to oxygen. It has been also reported that complex $\mathbf{9 7}$ shows higher stability under continuous illumination when compared to $\mathbf{9 6}$.

Haitao et al. [88] recently constructed an optical sensor based on the sensitivity to oxygen of a novel $\mathrm{Cu}(\mathrm{I})$ complex: $\left[\mathrm{Cu}(\mathrm{PTO})\left(\mathrm{PPh}_{3}\right)_{2}\right] \mathrm{BF}_{4}$ 98, which was embedded in mesoporous silica matrix. The photo-hysical properties of the complex are reported, in dichloromethane solution, in Table 5; the lifetime under pure nitrogen was found to be $64.4 \mu$ s which sharply decreases to $2.5 \mu$ s under $100 \%$ $\mathrm{O}_{2}$ suggesting quite good sensitivity. When grafted onto silica matrix, the probe showed a red shift in the emission spectra from 515 to $554 \mathrm{~nm}$ due to a breakdown of the rigid structure of $\mathbf{9 8}$ when dispersed in the matrix; it was also demonstrated that the doping concentration has an influence on the sensitivity of the probe.

Very recently, a series of $\mathrm{Cu}(\mathrm{I})$ complexes based on indole derivatives (99-102; Table 5), were shown to possess dual emission - a feature that can be exploited for ratiometric fluorescence oxygen sensing [145].

All of these complexes, when in their solid state at room temperature did not show any emission because of triplettriplet annihilation, but once dispersed in a rigid matrix like PMMA they showed quite good emission. The maximum emission peak of complexes $\mathbf{9 9}, \mathbf{1 0 0}, \mathbf{1 0 1}$, and $\mathbf{1 0 2}$ are 562, 566,608 and $610 \mathrm{~nm}$, respectively, and can be assigned to the emission from the MLCT-excited states, which have a lifetime in the range of $1.10-1.50 \mu \mathrm{s}$. The second weaker emissions at lower wavelengths were found to have a much longer lifetime in the order of ms. Further developments of this new neutral $\mathrm{Cu}(\mathrm{I})$ complexes are currently under progress.

Generally, the main drawback of the $\mathrm{Cu}(\mathrm{I})$ complexes as oxygen indicators is their inefficient absorption in the visible part of the spectrum. In fact, most of the complexes can be efficiently excited only with the UV light.

Binuclear and polynuclear complexes of $\mathrm{Au}(\mathrm{I})$ were shown to exhibit strong visible luminescence when excited in the UV; this luminescence is associated with the $\mathrm{Au}-\mathrm{Au}$ interaction which is thought to give rise to a metal-centered emission with excited state lifetime, in the absence of oxygen, between 4 and $200 \mu$ s [163]. Three different gold compounds are reported here: two containing two gold metal centers, the bis $\{\mu$-(bis (diphenylphosphino)octadecylamine-P, $\mathrm{P}^{\prime}$ ) $\}$ diiododigold(I) referred as JM6277 103 and bis $\{\mu$-(bis(diphenylphosphino)octadecylamine-P,P')\} dichlorodigold(I) referred as JM6275 104, and one possessing a tripod structure containing only one gold metal center, the 1,1,1,-tris(2-diphenylphosphenitomethyl)-ethane gold(I) referred as JM6280 105 (Fig. 16). Once incorporated in polystyrene, complex $\mathbf{1 0 3}$ showed an excitation maximum at $418 \mathrm{~nm}$, an emission maximum at $530 \mathrm{~nm}$, and an excited-state lifetime under nitrogen of $9.8 \mu \mathrm{s}$; the films showed good sensitivity to oxygen but their photostability was rather low since sunlight exposure caused complete photobleaching within 5 days [163]. When the iodine ligand of complex 103 was changed with chlorine, photobleaching was slightly reduced but still present especially after prolonged exposure to strong sunlight. Complex 104 was incorporated in both polystyrene $\left(\lambda_{\max }{ }^{\mathrm{ex}}=405 \mathrm{~nm}\right.$ and $\left.\lambda_{\max }{ }^{\mathrm{em}}=525 \mathrm{~nm}\right)$ and Ormosil matrices $\left(\lambda_{\max }{ }^{\mathrm{ex}}=360 \mathrm{~nm}\right.$ and $\left.\lambda_{\max }{ }^{\mathrm{em}}=525 \mathrm{~nm}\right)$ with latter showing a higher sensitivity to oxygen. The encapsulation in Ormosil resulted in a hypsochromic shift in the excitation maximum of $45 \mathrm{~nm}$ which suggests that the luminescence of the gold complex is affected by molecular interactions with the host matrix [165].

The mono gold(I) complex $\mathbf{1 0 5}$ showed strong luminescence not only in solid state but also in nonaqueous solvents like dichloromethane and tetrahydrofuran. Once incorporated in polystyrene, $\mathbf{1 0 5}$ showed an excitation maximum at $283 \mathrm{~nm}$, an emission maximum at $501 \mathrm{~nm}$ and nonmonoexponential decay curves with a short and a long lifetime components of 3.1 and $12.2 \mu \mathrm{s}$, respectively.

Europium(III) complexes, thanks to their strong luminescence which is attributed to the $4 f-4 f$ transitions, have been widely applied in optical amplification, light conversion molecular devices, OLEDs, and their luminescence properties have been exploited for oxygen sensing [260]. Very narrow luminescence bands are of particular interest for oxygen sensing because of the potential for multiplexing applications where emission of other probes or labels can be used in different spectral windows.

A series of europium(III) complexes bearing similar structure have been recently reported and studied to be used as oxygen probes; complex 106-109 differ from each other by the diaza ligand as show in Fig. 15.

Amao et al. [12] immobilized [Eu(thenoyltrifluoroacetonato (tta) $)_{3}$ phen] 106 in polystyrene-co-2,2,2-TFEM and characterized the resulting oxygen-sensitive film (Table 5). The $\left[\mathrm{Eu}(\mathrm{tta})_{3}\right.$ phen] films were shown to be sensitive to oxygen and possessed good photostability (no spectral 
changes after continuous irradiation using a $150 \mathrm{~W}$ tungsten lamp for $12 \mathrm{~h}$ ). It has been reported that complex 106 suffers from photobleaching when used as powder but its photostability greatly increases once immobilized in rigid matrix [253]. Another group, in fact, used the same Eu(III) dye to dope a polystyrene nanofibrous membrane which resulted in a sensor for oxygen. Interestingly, the sensitivity increases with the weight percent of dopant up to $3 \%$ [253].

Despite rather long luminescence lifetimes (several hundred microseconds), the sensitivity of the $\mathrm{Eu}(\mathrm{III})$ complexes is rather low. The luminescence of $\mathrm{Eu}$ (III) complexes is influenced by the energy gap between the $\mathrm{Eu}^{3+}$ ions and the antenna ligand and it is supposed to be more sensitive to the presence of oxygen when this energy gap is less than $1,500 \mathrm{~cm}^{-1}$ [129]. Therefore, a good way to increase the sensitivity of such complexes to oxygen is to change the nature of the ligand in order to modulate this energy gap.

Recently the group of $\mathrm{Li}$ and $\mathrm{Su}$ [226] reported the preparation of an optical oxygen sensor based on $\left[\mathrm{Eu}(\mathrm{tta})_{3-}\right.$ phencarz] 107, which has a metal-ligand energy gap of $721 \mathrm{~cm}^{-1}$. The complex was electrospun in polymer nanofibrous membrane. In this case as well, the sensitivity of the sensor showed a dependence on the amount of dye (weight percent) used to dope the nanofibrous membrane (lifetimes were in order of ms) and the best performances were obtained with $3 \%$ of $\mathbf{1 0 7}$ in the matrix.

Two further complexes featuring three tta ligands and an additional antenna ligand have been reported: $\left[\mathrm{Eu}(\mathrm{tta})_{3} \mathrm{D}-\right.$ PIQ] 108 and [Eu(tta) $)_{3}$ ECIP] 109 which were respectively incorporated in a mesoporous matrix and in polystyrene nanofibrous membrane $[208,260]$. The sensitivity to oxygen of these two complexes was lower than the one of complex 107; the photophysical properties can be found in Table 5.

Complexes 110 and 111 (Fig. 16) possess the same basic structure (the tta ligands are changed with DMB (1,3diphenyl-propane-1,3-dione)) but differ from each other by the diaza ligand. $\left[\mathrm{Eu}(\mathrm{DMB})_{3} \mathrm{PIP}\right] \mathbf{1 1 0}$ was electrospun into poly(vinypyrrolidone) [138] while [Eu(DMB) $\left.{ }_{3} \mathrm{IPD}\right] 111$ was used to dope silica matrix [68]. Both were shown to have good sensitivity toward oxygen and to be potentially useful, once incorporated into the matrix, as optical oxygen sensors.

The strong luminescence of another lanthanide complex has been exploited by Amao et al. [8] to fabricate optical oxygen sensing material: the tris-(acethylacetonato)(1,10phenanthroline) terbium(III) complex 112.

The luminescence lifetime of $\mathrm{Tb}(\mathrm{III})$ complexes are usually quite long (up to several ms) and the quantum yields often about $50 \%$, but the actual values for $\mathbf{1 1 2}$ were not reported by the authors. The major drawback of this indicator is that it cannot be excited in the visible light but only in the UV region because the main resonance level of terbium ${ }^{5} \mathrm{D}_{4}$ is located at rather high energies $\left(\sim 20,400 \mathrm{~cm}^{-1}\right)$.
It should be mentioned here that for the similar reasons, the excitation of most $\mathrm{Eu}(\mathrm{III})$ complexes is also located in the UV region which is a serious drawback. Additionally, it should be noted that the luminescence of the Eu(III) complexes is usually strongly affected by temperature, which enabled their application as optical thermometers and their use for simultaneous luminescent sensing of temperature and oxygen [29].

Very recently, an oxygen indicator based on a gadolinium (III) complex was reported [26]. The acridone antenna was covalently bound to a polystyrene backbone to enable excitation with violet light. Gadolinium(III) tris-thenoyltrifluoroacetonate complex was used as an energy acceptor and showed rather strong phosphorescence $(\Phi=14 \%)$ at room temperature in the absence of oxygen which is attributed to efficient intersystem crossing due to the heavy atom effect and paramagnetism of $\mathrm{Gd}(\mathrm{III})$. Quenching by oxygen was rather efficient due to a long decay time of about $900 \mu$ s, but Stern-Volmer plots showed pronounced nonlinearity indicating high heterogeneity of the material. Nevertheless, the work demonstrated for the first time the potential of Gd(III) complexes as new phosphorescent indicators for oxygen sensors.

\section{Miscellaneous indicators}

In this section, the reader will find all those indicators that do not belong to any specific class but still have been successfully used for optical oxygen sensing.

The thermally activated E-type delayed fluorescence (DF) of fullerene $\mathrm{C}_{70} 113$ (Table 6) has been exploited by Nagl et al. [169] to make an optical oxygen sensor that is especially suited for sensing oxygen down to the ppb range. High sensitivities are explained by exceptionally long decay time of the delayed fluorescence $(20 \mathrm{~ms})$. The DF quantum yield of $\mathbf{1 1 3}$ increases from 0.01 at $20{ }^{\circ} \mathrm{C}$ to 0.08 at temperatures around $150{ }^{\circ} \mathrm{C}$. Fullerene $\mathrm{C}_{70}$ was incorporated into highly oxygenpermeable matrices such as organically modified silica and ethyl cellulose to enable good sensitivity. Another feature is high chemical and photochemical stability of the material; on the other hand, moderate luminescence brightness (particularly at room temperatures) is a clear disadvantage.

The photophysical properties of molybdenum cluster 114 (Table 6) were shown to be well suited for oxygen sensing, as the red luminescence of the Mo cluster in PTMSP (poly[1-trymethylsilyl-1-propyne]) can be efficiently quenched by oxygen. The luminescence intensity can be easily detected by integration over the broad emission band as the cluster exhibits quite a long lifetime $(>100 \mu \mathrm{s})$ and a large Stokes' shift $(300 \mathrm{~nm})$ [82]. The advantage of Mo cluster is that they and show exceptional thermal stability with no sign of decomposition even at temperatures higher than $600{ }^{\circ} \mathrm{C}$.

Mo clusters were modified to be used for aqueous applications: $\mathrm{K}_{2} \mathrm{Mo}_{6} \mathrm{Cl}_{14}$ clusters were caged in a hydrophobic 
Table 6 Photophysical properties of miscellaneous indicators

\begin{tabular}{|c|c|c|c|c|c|c|}
\hline Dye & $\lambda_{\max }{ }^{\text {abs }}(\mathrm{nm})\left(\varepsilon \times 10^{3} \mathrm{M}^{-} \mathrm{cm}^{-1}\right)$ & $\lambda_{\max }^{\mathrm{em}}(\mathrm{nm})$ & Medium & $\Phi$ & $\tau$ & Reference \\
\hline 113 Fullerene $\mathrm{C}_{70}$ & $470(20)$ & $650-725$ & Organosilica & 0.01 & $20 \mathrm{~ms}$ & [169] \\
\hline $114\left[\mathrm{Mo}_{6} \mathrm{Cl}_{8}\right] \mathrm{Cl}_{4} \mathrm{~L}_{2}$ & $300-400$ & $600-900$ & PTMSP $^{\mathrm{a}}$ & - & $100 \mu \mathrm{s}$ & {$[82]$} \\
\hline
\end{tabular}

${ }^{\text {a }}$ Poly[1-trymethylsilyl-1-propyne]

oxygen polymer matrix, the [(acryloxypropyl)-methylsiloxane-dimethylsiloxane copolymer] [81]. A fiber optic sensor based on the phosphorescence quenching of $\mathrm{K}_{2} \mathrm{Mo}_{6} \mathrm{Cl}_{14}$ clusters has been developed and if showed no photobleaching after more than 13,000 measurements and it gave a linear response in the temperature range between 10 and $37{ }^{\circ} \mathrm{C}$.

The dependence of the fluorescent spectra of $\operatorname{poly}(9,9-$ dioctylfluorene) (PF8) on the oxygen content has been recently exploited to create an optical oxygen gas sensor [15]. It has been shown that in addition to the irreversible oxidation of PF8, which results in the formation of Keto defects, reversible fluorescence quenching is also observed when the PF8 thin films are excited with a $\mathrm{He}-\mathrm{Cd}$ laser at $325 \mathrm{~nm}$. The sensitivity of the conjugated polymer was only moderated and unfortunately, the sensors based on PF8 degrade irreversibly after $12 \mathrm{~h}$ of continuous laser exposure.

\section{Criteria for selection of indicators}

As it has been highlighted, numerous classes of oxygen indicators exist and feature significantly different photophysical and sensing properties. After giving an overview of the available indicators for optical oxygen sensing, in order to help the reader to choose the most suitable one for his/her needs, useful criteria for selection will be given in this session.

\section{Absorption and emission spectra}

In general, excitation in the UV part of the spectrum should be avoided due to high levels of background fluorescence originating from many biological substances, sensor supports, optical components etc. Additionally, UV light can be often disturbing for many biological systems. These are among the reasons why indicators excitable in the visible part of the spectrum are strongly preferable. Oxygen monitoring in tissues is more demanding and requires indicators that can be excited in the red or NIR part of the spectrum; this ensures deeper penetration depth of the excitation light and minimizes the loss of the emission light. As was demonstrated above, Pt(II) and Pd(II) complexes with $\pi$-extended benzo-naphthoporphyrins as well as azabenzoporphyrins represent an excellent choice for such applications.
Generally, large Stokes' shifts are strongly preferable since the emission can be easily separated from the excitation light by means of optical filters. Fortunately, this requirement is almost always fulfilled for luminescent indicators. Compatibility with the available excitation sources and detectors is another important issue. Depending on the application the excitation sources of choice can be LEDs, laser diodes, lasers or, e.g., a mercury lamp. For example, bright LEDs are now available for virtually all parts of the spectrum; however, there is a gap between 540 and $580 \mathrm{~nm}$. Compatibility with the detector can be another critical issue. For example, oxygen imaging with NIRemitting dyes can be critical because of the lower sensitivity of the CCD chips in this region. The same is even more crucial for the photomultipliers as most devices (e.g. confocal microscopes) are still equipped with cheaper models which become almost insensitive at $\lambda>700 \mathrm{~nm}$. Finally, compatibility with other optical components can be important for some particular sensors. For instance, the attenuation of cheap plastic optical fibers peaks at about $740 \mathrm{~nm}$ and then further increases above $820 \mathrm{~nm}$, which can represent a certain problem when using NIR dyes. Fortunately, benzoporphyrin complexes emit between 770 and $800 \mathrm{~nm}$, where the attenuation is lower.

Luminescence brightness of the probe

The luminescent brightness is defined as the product of the molar absorption coefficient $(\varepsilon)$ and the luminescence quantum yields $(\Phi)$. Therefore, an indicator possessing a quantum yield close to unity but a molar absorption coefficient of only several thousand moles per centimeter can still not be bright enough for some applications. This situation is typical for most cyclometallated complexes of $\operatorname{Ir}(\mathrm{III})$ and $\mathrm{Pt}(\mathrm{II})$.

Generally, an advantage of indicators with high luminescence brightness is that they can be used in lower concentration within the polymeric matrix (thus avoiding aggregation) and therefore enable the preparation of fast responding thinfilm planar optodes or optical fibers. Nanoparticle sensors based on bright indicators can be used in lower concentration thus providing less interference to the biological systems. High luminescence brightness is of particular importance for measurements in tissues since the loss of excitation and the emission light due to absorption and scattering is very significant. 
Clearly, the oxygen indicators with the highest brightness reported are the orange light-emitting Ir(III) coumarin complexes and NIR emitting Pt(II) benzoporphyrins. In fact, these dyes possess both very high molar absorption coefficients $\left(>80,000 \mathrm{M}^{-1} \mathrm{~cm}^{-1}\right)$ and luminescence quantum yields $(>0.5)$. The brightness of the not extended Pt(II) porphyrins (e.g., octaethylporphyrin) is also very high but only upon excitation in the Soret band located in the UV region.

\section{Luminescence decay times}

The luminescence decay time of an indicator is also a very important parameter since the sensitivity of an optical oxygen sensor is proportional to both the decay time of the indicator and the gas permeability of the polymer. Thus, indicators with moderately long decay times (several microseconds) will show sufficient sensitivity only in highly gaspermeable matrices (silicone rubber, fluorinated polymers, or Ormosils) but in many common polymers used for the preparation of planar optodes, fiber-optic sensors, and nanoparticles (e.g., polystyrene) they will not show adequate sensitivity. On the other hand, long decay times ( $>1 \mathrm{~ms})$ are often too long to design sensors which can operate between 0 and $21 \mathrm{kPa}^{\mathrm{pO}} \mathrm{O}_{2}$. In fact, the luminescence of such indicators will be almost completely quenched at low $\mathrm{pO}_{2}$; in these cases, a solution could be to use polymers with low gas permeability even though it should be considered that the dynamic response of such materials will be negatively affected. Conversely, indicators with long decay times are indispensible when designing trace oxygen sensors. In fact, the sensors for moderately low oxygen concentrations can be designed on the basis of $\mathrm{Pd}(\mathrm{II})$ porphyrins (decay times about $1 \mathrm{~ms}$ ) but ultratrace oxygen sensors require indicators with even longer decay times. Fullerene C70 $(\tau=20 \mathrm{~ms})$ was found to be useful for such applications. On the other hand, Pt(II) porphyrins with their phosphorescence decay times of 40-80 $\mu$ s represent most popular indicators for designing oxygen sensors operating in physiologically relevant concentrations.

\section{Chemical stability and photostability}

In general, the chemical stability of the majority of the indicators used for oxygen sensing is acceptably good. However, their stability in harsh conditions (high temperature and humidity during sterilization, presence of oxidizing species such as hypochlorite, etc.) can be poor.

On the other hand, the photostability of different dyes can vary a lot even among compounds that are chemically closely related. This property is not critical for indicators used in disposable systems but it is fundamental for those applications where high light intensities are used and/or prolonged measurements are performed. Photosensitized singlet oxygen is often responsible for the photodegradation of indicator dyes through oxidation; therefore the introduction of electron-withdrawing substituents (such as halogens) in the indicator molecule usually helps to improve their photostability. For this reason, the complexes of $\mathrm{Pt}(\mathrm{II})$ and $\operatorname{Pd}(\mathrm{II})$ with highly fluorinated tetra(pentafluorophenyl)porphyrin are known to be one of the most photostable indicators reported. Unfortunately, very little data comparing the photostabilities of different classes of oxygen indicators is available.

\section{Cross-sensitivity to other parameters}

The luminescence of an indicator can be affected by the presence of ionic species and water. This can be critical for water-soluble indicators but it is of less relevance for the lipophilic ones since they are incorporated in polymers which can act as permeation-selective membrane for ionic species.

The phosphorescence of all luminescent dyes is prone to thermal quenching; however, the extent of this process varies dramatically for different indicator groups. Particularly, MLCT indicators (e.g., Ru(II) polypyridyl complexes) and luminescent $\mathrm{Eu}(\mathrm{III})$ complexes show a much higher degree of thermal quenching than, for example, Pt(II) metalloporphyrins $(0.05-0.2 \%$ of the decay time change per $1 \mathrm{~K})$. The temperature cross-sensitivity of oxygen-sensing materials does not only depend on the nature of the compound but mostly is dominated by the temperature dependence of the diffusion and solubility of oxygen in polymers.

\section{Solubility in the polymeric matrices/analyzed media}

Low solubility of an indicator in the polymeric matrix can result in either aggregation or migration to other components (e.g., the material of the sensor support). Aggregation is of particular concern in case of planar $\pi$-extended molecules such as, e.g., unsubstituted porphyne, tetrabenzoporphyrin or phthalocyanine. The solubility in apolar polymers can usually be enhanced by introducing bulky substituents in the indicator molecule (e.g., alkyl chains). In case of porphyrins, it is efficiently suppressed by introducing phenyl rings in the meso-position of the porphyrin macrocycle. On the contrary, polar groups (e.g., charged groups, polyethylene glycol chains, peptides or proteins, etc.) can be introduced to enable/enhance the solubility of an indicator in water. An alternative method to suppress dye migration and leaching is to covalently grafting the indicator into the matrix. However, often tedious modification of the indicator is necessary to achieve this goal. It should be mentioned here that the solubility in the analyzed media can also be obtained by immobilizing lipophilic indicators in the core of amphiphilic 
polymeric nanoparticles bearing polar groups on their surface. In this case modification of an indicator is not necessary.

\section{Toxicity}

Toxicity of an indicator is of main concern for biological and medical applications. Usually, encapsulation of the indicator into a polymeric matrix greatly reduces its toxicity. However, the phototoxicity caused by the production of singlet oxygen cannot be eliminated completely. This is especially true for water-soluble indicators and nanoparticles since the diffusion ways are short enough for the singlet oxygen to damage the cells despite its relatively short lifetime (about $3 \mu$ s) in aqueous media. Here, indicators with exceptional brightness are very useful since the loading of the probe (and consequently damage for the live cells) can be substantially reduced without compromising the $\mathrm{S} / \mathrm{N}$ ratio.

\section{Commercial or synthetic availability}

Commercial availability is very important for numerous researchers who do not have enough facilities/experience to prepare the oxygen indicators by themselves. Unfortunately, only few oxygen indicators are commercially available at acceptable prices, such as, for example, the Ru(III) polypyridyl complexes and Pt(II) and Pd(II) complexes with some porphyrins including OEP and TFPP. If the synthesis of the indicators cannot be avoided the simplicity of the method is often of crucial significance. Price and/or simplicity of the synthetic pathway are of much less importance if the indicators are used in microscopic imaging or in fiber-optic microsensors because the amount of dye needed is usually very small. On the other hand, some emerging applications (e.g., food packaging) would require high quantities of the indicators at very competitive price. In this case, the less conventional indicators such as copper(I) or lanthanide(III) complexes can be very promising providing that they possess efficient absorption in the visible or NIR part of the spectrum and acceptable luminescence quantum yields.

\section{Concluding remarks}

To summarize, there is no perfect indicator which would be suitable for all oxygen-sensing applications. An adequate indicator should rather be carefully chosen according to the above mentioned criteria. Among different dye classes, Pt(II) and $\operatorname{Pd}(\mathrm{II})$ complexes with benzoporphyrins can be considered the most promising due to the high flexibility in tuning their spectral properties but also because of excellent luminescent brightness and photo-stability of some representatives.

These dyes are also suitable for further synthetic modification to provide additional functionalities. However, certain representatives of other classes possess interesting photophysical and sensing properties, such as for example ultrabright emission (iridium(III) coumarin complexes), dual emission (some platinum(II) complexes) which makes them particularly promising for ratiometric imaging. Despite the significant progress in the field of oxygen indicators that has been achieved in the last decade, there is still work to be done particularly in designing tailor-made dyes for many vital applications where state-of-the-art systems may not be fully adequate.

Acknowledgments Financial support from the European Commission (Grant Agreement number 264772 - ITN CHEBANA) and European Research Council (Project “Oxygen”, N 207233) is gratefully acknowledged.

Open Access This article is distributed under the terms of the Creative Commons Attribution License which permits any use, distribution, and reproduction in any medium, provided the original author(s) and the source are credited.

\section{References}

1. Alava-Moreno F, Valencia-Gonzalez MJ, Sanz-Medel A, DiazGarcia ME (1997) Oxygen sensing based on the room temperature phosphorescence intensity quenching of some lead-8hydroxyquinoline complexes. Analyst 122:807-810

2. Alford PC, Cook MJ, Lewis APMGSG, Skarda V, Thomson AJ, Glasper JL, Robbins DJ (1985) Luminescent metal complexes. Part 5. Luminescence properites of ring-substituted 1,10-phenanthroline tris-complexes of ruthenium (II). J Chem Soc Perkin Trans 2:705-709

3. Amao Y (2003) Probes and polymers for optical sensing of oxygen. Mikrochim Acta 143(1):1-12

4. Amao Y, Asai K, Okura I (1999) Photoluminescent oxygen sensing using palladium tetrakis(4-carboxyphenyl)porphyrin selfassembled membrane on alumina. Anal Commun 36(5):179-180

5. Amao Y, Asai K, Okura I (2000) Oxygen sensing based on lifetime of photoexcited triplet state of platinum porphyrinpolystyrene film using time-resolved spectroscopy. J Porphyrins Phthalocyanines 4:292-299

6. Amao Y, Asai KOI, Shinohara H, Nishide H (2000) Platinum porphyrin embedded in poly(1-trimethylsilyl-1-propyne) film as an optical sensor for trace analysis oxygen. Analyst 125:1911-1914

7. Amao Y, Ishikawa Y, Okura I (2001) Green luminescent iridium (III) complex immobilized in fluoropolymer film as optical oxygen-sensing matrial. Anal Chem Acta 445:177-182

8. Amao Y, Ishikawa Y, Okura I, Miyashita T (2001) Optical oxygen sensing material: terbium(III) complex adsorbed thin film. Bull Chem Soc Jpn 74:2455-2449

9. Amao Y, Miyashita T, Okura I (2000) Optical oxygen sensing based on the luminescence change of metalloporphyrins immobilized in styrene-pentafuorostyrene copolymer film. Analyst $125: 871-875$

10. Amao Y, Okura I (2000) An oxygen sensing system based on the phosphorescence quenching of metalloporohyrin thin film on allumina plates. Analyst 125:1601-1604

11. Amao Y, Okura I (2003) Optical oxygen sensing materials: chemisorption film of ruthenium(II) polypyridyl complexes attached to anionic polymer. Sens Actuators B 88:162-167

12. Amao Y, Okura I, Miyashita T (2000) Optical oxygen sensing based on the luminescence quenching of Europium(III) complex 
immobilized in fluoropolymer film. Bull Chem Soc Jpn 73:26632668

13. Amao Y, Okura I, Miyashita T (2001) Pyrene chemisorption film on an alumina plate as an optical oxygen-sensing material. Bull Chem Soc Jpn 74:1159-1160

14. Amao Y, Tabuchi Y, Yamashita Y, Kimura K (2002) Novel optical oxygen sensing material: metalloporphyrin dispersed in fluorinated poly(aryl ether ketone) films. Eur Polym J 38:675-681

15. Anni M, Rella R (2010) Oxygen optical gas sensing by reversible fluorescence quenching in photo-oxidized poly(9,9-dioctylfluorene) thin films. J Phys Chem B 114:1559-1561

16. Arain S, Gernot JT, Krause C, Gerlach J, Wolfbeis OS, Klimant I (2006) Characterization of microtiterplates with integrated optical sensors for oxygen and $\mathrm{pH}$, and their applications to enzyme activity screening, respirometry, and toxicological assays. Sensors Actuators B Chem 113(2):639-648

17. Babilas P, Lamby P, Prantl L, Schreml S, Jung EM, Liebsch G, Wolfbeis OS, Landthaler M, Szeimies R-M, Abels C (2008) Transcutaneous pO2 imaging during tourniquet-induced forearm ischemia using planar optical oxygen sensors. Skin Res Technol 14(3):304-311

18. Badocco D, Mondin A, Pastore P, Voltolina S, Gross S (2008) dependence of calibration sensitivity of a polysulfone/Ru(II)-tris (4,7-diphenyl-1.10-phenanthroline)-based oxygen optical sensor on its structural parameters. Anal Chem Acta 627:239-246

19. Baldini F, Bacci M, Cosi F, Bianco ADB (1992) Absorptionbased optical-fibre oxygen sensor. Sens Actuators B 7:752757

20. Basu BJ, Anandan C, Rajam KS (2003) Study of the mechanism of degradation of pyrene-based pressure sensitive paints. Sens Actuators B 94(3):257-266

21. Basu BJ, Thirumurugan A, Dinesh AR, Anandan C, Rajam K (2005) Optical oxygen sensor coating based on the fluorescence quenching of a new pyrene derivative. Sens Actuators B 104 (1): $15-22$

22. Bergman I (1968) Rapid-response atmospheric oxygen monitor based on fluorescence quenching. Nature 218:396

23. Bizzarri A, Koehler H, Cajlakovic M, Pasic A, Schaupp L, Klimant I, Ribitsch V (2006) Continuous oxygen monitoring in subcutaneous adipose tissue using microdialysis. Anal Chim Acta 573-574:48-56

24. Borisov SM, Klimant I (2007) Ultrabright oxygen optodes based on cyclometalated iridium(III) coumarin complexes. Anal Chem 79:7501-7509

25. Borisov SMLP, Klimant I (2011) Novel optical trace oxygen sensors based on platinum(II) and palladium(II) complexes with 5,10,15,20-meso-tetrakis-(2,3,4,5,6-pentafluorphenyl)-porphyrin covalently immobilized on silica-gel particles. Anal Chim Acta 690(1):108-115

26. Borisov S, Klimant I (2012) New luminescent oxygen-sensing and temperature-sensing materials based on gadolinium(III) and europium(III) complexes embedded in an acridone/polystyrene conjugate. Anal Bioanal Chem. doi:10.1007/s00216012-6244-8

27. Borisov SM, Nuss G, Haas W, Saf R, Schmuck M, Klimant I (2009) New NIR-emitting complexes of platinum(II) and palladium(II) with fuorinated benzoporphyrins. J Photochem Photobio A 201:128-135

28. Borisov SM, Nuss G, Klimant I (2008) Red light-excitable oxygen sensing materials based on platinum(II) and palladium(II) benzoporphyrins. Anal Chem 80(24):9435-9442

29. Borisov SM, Wolfbeis OS (2006) Temperature-sensitive europium(III) probes and their use for simultaneous luminescent sensing of temperature and oxygen. Anal Chem 78(14):5094-5101

30. Borisov SM, Wolfbeis OS (2008) Optical biosensors. Chem Rev 108(2):423-461
31. Borisov SM, Zenkl G, Klimant I (2010) Phosphorescent platinum (II) and palladium(II) complexes with azatetrabenzoporphyrinsnew red laser diode-compatible indicators for optical oxygen sensing. ACS App Mater Interfaces 2(2):366-374

32. Brinas RP, Troxler T, Hochstrasser RM, Vinogradov SA (2005) Phosphorescent oxygen sensor with dendritic protection and twophoton absorbing antenna. J Am Chem Soc 127(33):1185111862

33. Burke CS, Moore JP, Wencel D, McEvoy AK, MacCraith BD (2008) Breath-by-breath measurement of oxygen using a compact optical sensor. J Biomed Opt 13(no. 1):014027

34. Cao Y, Koo Y-EL, Kopelman R (2004) Poly(decyl methacrylate)based fluorescent PEBBLE swarm nanosensors for measuring dissolved oxygen in biosamples. Analyst 129(8):745-750

35. Carraway ER, Demas JN, DeGraff BA (1991) Luminescence quenching mechanism for microheterogeneous systems. Anal Chem 63(4):332-336

36. Cattaneo MV, Male KB, Luong JHT (1992) A chemiluminescence fiber-optic biosensor system for the determination of glutamine in mammalian cell cultures. Biosens Bioelec 7(8):569-574

37. Ceroni P, Lebedev AY, Marchi E, Yuan M, Esipova TV, Bergamini G, Wilson DF, Busch TM, Vinogradov SA (2011) Evaluation of phototoxicity of dendritic porphyrin-based phosphorescent oxygen probes: an in vitro study. Photochem Photobiol Sci 10(6):10561065

38. Chan C-M, Chan M-Y, Zhang M, Lo W, Wong K-Y (1999) The performance of oxygen sensing films with ruthenium-adsorbed fumed silica dispersed in silicone rubber. Analyst 124:691-694

39. Chang G, Morigaki K, Tatsu Y, Hikawa T, Goto T, Imaishi H (2011) Vertically integrated human P450 and oxygen sensing film for the annays of P450 metabolic activity. Anal Chem 83:29562963

40. Choi MF, Hawkins P (1995) A novel oxygen and/or carbon dioxide-sensitive optical transducer. Talanta 42(3):483-492

41. Choi MF, Hawkins P (1996) A fibre-optic oxygen sensor based on contact charge-transfer absorption. Sens Actuators B 30 (3):167-171

42. Choi MMF, Pang WSH, Xiao D, Wu X (2001) An optical glucose biosensor with eggshell membrane as an enzyme immobilization platform. Analyst 126:1558-1563

43. Choi NW, Verbridge SS, Williams RM, Chen J, Kim J-Y, Schmehl R, Farnum CE, Zipfel WR, Fischbach C, Stroock AD (2012) Phosphorescent nanoparticles for quantitative measurements of oxygen profiles in vitro and in vivo. Biomaterials 33 (9):2710-2722

44. Chu C-S, Lo Y-L (2010) 2D full-field measurement of oxygen concentration based on the phase fluorometry technique that uses the four-frame integrating-bucket method. Sens Actuators B 147 (1):310-315

45. Chu C-S, Lo Y-L (2011) Highly sensitive and linear calibration optical fiber oxygen sensor based on Pt(II) complex embedded in sol-gel matrix. Sens Actuators B 155(1):53-57

46. Clark HA, Barker SL, Brasuel M, Miller MT, Monson E, Parus S, Shi Z-Y, Song A, Thorsrud B, Kopelman R, Ade A, Meixner W, Athey B, Hoyer M, Hill D, Lightle R, Philbert MA (1998) Subcellular optochemical nanobiosensors: probes encapsulated by biologically localised embedding (PEBBLEs). Sens Actuators B 51:12-16

47. Collman JP, Brauman JI, Doxsee KM, Halbert TR, Hayes SE, Suslick KS (1978) Oxygen binding to cobalt porphyrins. J Am Chem Soc 100(9):2761-2766

48. Cook MJ, Lewis AP, McAuliffe GSG, Skarda V, Thomson AJ, Glasper JL, Robbins DJ (1984) Luminescent metal complexes. Part 1. Tris-chelate of substituted 2,2'-bipyriydyls with ruthenium (II) as dyes for luminescent solar collectors. J Chem Soc Perkin Trans II 1293-1301 
49. Cook PLM, Wenzhöfer F, Glud RN, Janssen F, Huettel M (2007) Benthic solute exchange and carbon mineralization on two shallow subtidal sandy sediments: effect of advective pore-water exchange. Limnol Oceanogr 5(52):1943-1963

50. Costa-Fernandez JM, Diaz-Garcia ME, Sanz-Medel A (1998) Solgel immobilized room-temperature phosphorescent metal-chelate as luminescent oxygen sensing material. Anal Chem Acta 360:17-26

51. Coyle LM, Gouterman M (1999) Correcting lifetime measurements for temperature. Sens Actuators B 61:92-99

52. Currie MJ, Mapel JK, Heidel TD, Goffri S, Baldo MA (2008) High-efficiency organic solar concentrators for photovoltaics. Science 321(5886):226-228

53. Dawson WR, Kropp JL (1969) Radiationless deactivation and anomalous fluorescence of singlet 1,12-benzperylene. J Phys Chem 73(no. 6): 1752-1758

54. Del Bianco A, Baldini F, Bacci M, Klimant I, Wolfbeis OS (1993) A new kind of oxygen-sensitive transducer based on an immobilized metallo-organic compound. Sens Actuators B 11:347-350

55. DeRosa MC, Hodgson DJ, Enright GD, Dawson B, Evans CEB, Crutchley RJ (2004) Iridium luminophore complexes for unimolecular oxygen sensors. J Am Chem Soc 126(24):7619-7626

56. Djurovich PI, Murphy D, Thompson ME, Hernandez B, Gao R, Hunt PL, Selke M (2007) Cyclometalated iridium and platinum complexes as singlet oxygen photosenitizers: quantum yields, queching rates and correlation with electronic strucures. Dalton Trans 34:3763-3770

57. Dmitriev RI, Ropiak HM, Ponomarev GV, Yashunsky DV, Papkovsky DB (2011) Cell-penetrating conjugates of coproporphyrins with oligoarginine peptides: rational design and application for sensing intracellular O2. Bioconjugate Chem 22 (12):2507-2518

58. Dmitriev RI, Zhdanov AV, Ponomarev GV, Yashunski DV, Papkovsky DB (2010) Intracellular oxygen-sensitive phosphorescent probes based on cell-penetrating peptides. Anal Biochem 398(1):24-33

59. Donckt EV, Camerman B, Vandeloise (1996) Fibre-optic oxygen sensor based on luminescence quenching of a $\mathrm{Pt}(\mathrm{II})$ complex embedded in polymer matrices. Sens Actuators B 32:121-127

60. Douglas P, Eaton K (2002) Response characteristics of thin film oxygen sensors, $\mathrm{Pt}$ and $\mathrm{Pd}$ octaethylporphyrins in polymer films. Sens Actuators B 82(2-3):200-208

61. Draxler S, Lippitsch ME, Klimant I, Kraus H, Wolfbeis OS (1995) Effects of polumer matrices on the time-resolved luminescence of a ruthenium complex quenched by oxygen. J Phys Chem 99:3162-3167

62. Dremel B, Li S-Y, Schmid R (1992) On-line determination of glucose and lactate concentrations in animal cell culture based on fibre optic detection of oxygen in flow-injection analysis. Biosens Bioelecron 7(2):133-139

63. Dunphy I, Vinogradov SA, Wilson D (2002) Oxyphor R2 and G2: phosphors for measuring oxygen by oxygen-dependent quenching of phosphorescence. Anal Biochem 310(2):191-198

64. Eastwood D, Gouterman M (1970) Porphyrins: XVIII. Luminescence of (Co), (Ni), Pd, Pt complexes. J Mol Spectrosc 35(3):359-375

65. Erskine RW, Field BO (1976) Reversible oxygenation. Struc Bond 28:1-50

66. Esipova TV, Karagodov A, Miller J, Wilson DF, Busch TM, Vinogradov SA (2011) Two New "protected" oxyphors for biological oximetry: properties and application in tumor imaging. Anal Chem 83(22):8756-8765

67. Fabricius-Dyg J, Mistlberger G, Staal M, Borisov SM, Klimant I, Kühl M (2012) Imaging of surface O2 dynamics in corals with magnetic micro optode particles. Mar Biol 159(7):1621-1631

68. Feng N, Xie J, Zhang D (2010) Synthesis, characterization, photophysical and oxygen-sensing properties of a novel europium(III) complex. Spectrochim Acta A 77(1):292-296
69. Fercher A, Borisov SM, Zhdanov AV, Klimant I, Papkovsky DB (2011) Intracellular O2 sensing probe based on cell-penetrating phosphorescent nanoparticles. ACS Nano 5(7):5499-5508

70. Filatov MA, Cheprakov AV (2011) The synthesis of new tetrabenzo- and tetranaphthoporphyrins via the addition reactions of 4,7-dihydroisoindole. Tetrahedron 67(19):3559-3566

71. Finikova OS, Aleshchenkov SE, Brñas RP, Cheprakov AV, Carroll PJ, Vinogradov SA (2005) Synthesis of symmetrical tetraaryltetranaphtho[2,3]porphyrins. J Org Chem 70(12):4617-4628

72. Finikova OS, Cheprakov AV, Carroll PJ, Vinogradov SA (2003) Novel route to functionalized tetraaryltetra[2,3]naphthaloporphyrins via oxidative aromatization. J Org Chem 68:7517-7520

73. Finikova OS, Cheprakov AV, Vinogradov SA (2005) Synthesis and luminescence of soluble meso-unsunbstituted tetrabenzo- and tetranaphtho[2,3]porphyrins. J Org Chem 70:9562-9572

74. Finikova OS, Lebedev AY, Aprelev A, Troxler T, Gao F, Garnacho C, Muro S, Hochstrasser RM, Vinogradov SA (2008) Oxygen microscopy by two-photon-excited phosphorescence. ChemPhysChem 9(12):1673-1679

75. Fischer JPWF (2010) A novel planar optode setup for concurrent oxygen and light field imaging: application to a benthic phototrophic community. Limnol Oceanogr Meth 8:254-268

76. Fischer LH, Borisov SM, Schaeferling M, Klimant I, Wolfbeis OS (2010) Dual sensing of pO2 and temperature using a waterbased and sprayable fluorescent paint. Analyst 135:1224-1229

77. Fischer LH, Stich MIJ, Wolfbeis OS, Tian N, Holder E, Schäferling M (2009) Red- and green-emitting iridium(III) complexes for a Dua barometric and temperature-sensitive paint. Chem Eur J 15:1085710863

78. Fujiwara Y, Amao Y (2004) Novel optical oxygen sensing material: 1-pyrenedecanoic acid and perfuorodecanoic acid chemisorbed onto anodic oxidized aluminium plate. Sens Actuators B 99:130-133

79. Ge X, Hanson M, Shen H, Kostov Y, Brorson KA, Frey DD, Moreira AR, Rao G (2006) Validation of an optical sensor-based high-throughput bioreactor system for mammalian cell culture. J Biotechnol 122(3):293-306

80. Gernot TJ, Klimant I, Wittmann C, Heinzle E (2003) Integrated optical sensing of dissolved oxygen in microtiter plates: a novel tool for microbial cultivation. Biotechnol Bioeng 81(7):829-836

81. Ghosh RN, Askeland PA, Kramer S, Loloee R (2011) Optical dissolved oxygen sensor utilizing molybdenum chloride cluster phosphorescence. Appl Phys Lett 98:221103-3

82. Ghosh RN, Baker GL, Ruud C, Nocera D (1999) Fiber-optic oxygen sensor using molybdenum chloride cluster luminescence. Appl Phys Lett 75(19):2885-2887

83. Gillanders RN, Tedford MC, Crilly PJ, Bailey RT (2005) A composite thin film optical sensor for dissolved oxygen in contaminated aqueous environments. Anal Chem Acta 545:189-194

84. Glud RN, Kühl MRN (1999) Heterogeneity of oxygen production and consumption in a photosynthetic microbial mat as studied by planar optodes. J Phycol 35:270-279

85. Glud RN, Ramsing NB, Gundersen JK, Klimant I (1996) Planar optrodes: a new tool for fine scale measurements of two dimensional O2 distribution in bethic communities. Mar Ecol Prog Ser 140:217-226

86. Glud RN, Tengberg A, Kühl M, Hall POJ, Klimant I (2001) An in situ instrument for planar $\mathrm{O} 2$ optode measurements at benthic interfaces. Limnol Ocenogr 46(8):2073-2080

87. Guo L, Ni Q, Li J, Zhang L, Lin X, Xie Z, Chen G (2008) A novel sensor based on the porous plastic probe for determitation of dissolved oxygen in seawater. Talanta 74:1032-1037

88. Haitao J, Huilin Y, Fan L, Yang L (2012) Fabrication and performances of an optical sensor system constructed by a novel $\mathrm{Cu}$ (I) complex embedded on silica matrix. J Lumin 132:198-204 
89. Hanson MA, Ge X, Kostov Y, Brorson KA, Moreira AR, Rao G (2007) Comparisons of optical $\mathrm{pH}$ and dissolved oxygen sensors with traditional electrochemical probes during mammalian cell culture. Biotechnol Bioeng 97(4):833-841

90. Hanson K, Tamayo A, Diev VV, Whited MT, Djurovich PI, Thompson ME (2010) Efficient dipyrrin-centered phosphorescence at room temperature from bis-cyclometalated iridium(III) dipyrrinato complexes. Inorg Chem 49(13):6077-6084

91. Hartmann P, Leiner MJP, Lippitsch ME (1995) Luminescence quenching behavior of an oxygen sensor based on a $\mathrm{Ru}(\mathrm{II})$ complex dissolved in polystyrene. Anal Chem 67(1):88-93

92. Hartmann P, Ziegler W, Holst G, Lübbers DW (1997) Oxygen flux fluorescence lifetime imaging. Sens Actuators B 38:110-115

93. He H, Fraatz RJ, Leiner MJP, Rehn MM, Tusa JK (1995) Selection of silicone polymer matrix for optical gas sensing. Sens Actuators B 29:246-250

94. Higgins C, Wencel D, Burke CS, MacCraith BD, McDonagh C (2007) Novel hybrid optical sensor materials for in-breath O2 analysis. Analyst 133:241-247

95. Holst G, Grundwald B (2001) Luminescence lifetime imaging with transparent oxygen optodes. Sens Actuators B 74:78-90

96. Holst G, Kohls O, Klimant I, König B, Kühl M, Richter T (1998) A modular luminescence lifetime imaging system for mapping oxygen distribution in biological samples. Sens Actuators B 51:163-170

97. Imasaka T, Ishibashi K, Ishibashi N (1982) Time-resolved fluorimetry with a sub-nanosecond dye laser source for the determination of polynuclear aromatic hydrocarbons after separation by highperformance liquid chromatography. Anal Chim Acta 142:1-12

98. Jensen ST, Kühl M, Glud RN, Jørgensen BB, Prieme A (2005) Oxic microzones and radial oxygen loss from roots of Zostera marina. Mar Ecol Prog Ser 293:49-58

99. Jones PF (1968) On the use of phosphorescence quenching for determining permeabilities of polymeric films to gases. J Polym Sci B Polym Lett 6(7):487-491

100. Kautsky H (1939) Quenching of luminescence by oxygen. Trans Faraday Soc 35:216-219

101. Kellner K, Liebsch G, Klimant I, Wolfbeis OS, Blunk T, Schulz MB, Göpferich A (2002) Determination of oxygen gradients in engineered tissue using a fluorescent sensor. Biotechnol Bioeng 80(1):73-83

102. Khalil G, Gouterman M, Ching S, Costin C, Coyle L, Gouin S, Green E, Sadilek M, Wan R, Yearyean J, Zelelow B (2002) Synthesis and spectroscopic characterization of $\mathrm{Ni}, \mathrm{Zn}, \mathrm{Pd}$ and $\mathrm{Pt}$ tetra(pentafuorophenyl)porpholactone with comparison to $\mathrm{Mg}$, $\mathrm{Zn}, \mathrm{Y}, \mathrm{Pd}$ and Pt metal complexes of tetra(pentafuorophenyl)porphine. J Porphyrins Phthalocynines 6:135-145

103. Klimant I, Belser P, Wolfbeis OS (1994) Novel metal-organic ruthenium(II) diimin complexes for use as longwave excitable luminescent oxygen probes. Talanta 41(6):985-991

104. Klimant I, Kühl M, Glud R, Holst G (1997) Optical measurement of oxygen and temperature in microscale: strategies and biological applications. Sens Actuators B 38(1-3):29-37

105. Klimant I, Meyer V, Kühl M (1995) Fiberoptic oxygen microsensors, a new tool in aquatic biology. Limnol Oceanogr 40:1159-1165

106. Klimant I, Ruckruh F, Liebsch G, Stangelmayer A, Wolfbeis OS (1999) Fast response oxygen micro-optodes based on novel soluble ormosil glasses. Mikrochim Acta 131(1):35-46

107. Klimant I, Wolfbeis OS (1995) Oxygen-sensitive luminescent materials based on silicone-soluble ruthenium diimine complexes. Anal Chem 67:3160-3166

108. Knopp JA, Longmuir IS (1972) Intracellular measurement of oxygen by quenching of fluorescence of pyrenebutyric acid. Biochim Biophys Acta 279:393-397

109. Kober EM, Caspar JV, Lumpkin RS, Meyer TJ (1986) Application of the energy gap law to excited-state decay of osmium(II)- polypyridine complexes: calculation of relative nonradiative decay rates from emission spectral profiles. J Phys Chem 90(16):37223734

110. Kocincova AS, Nagl S, Arain S, Krause C, Borisov SM, Arnold M, Wolfbeis OS (2008) Multiplex bacterial growth monitoring in 24-well microplates using a dual optical sensor for dissolved oxygen and pH. Biotechnol Bioeng 100(no. 3):430-438

111. Kolle C, Gruber W, Trettnak WBK, Dolezal C, Reininger F (1997) Fast optochemical sensor for continuous monitoring of oxygen in breath-gas analysis. Sens Actuators B 38-39:141-149

112. König B, Kohls O, Holst G, Glud RN, Kühl M (2005) Fabrication and test of sol-gel based planar oxygen optodes for use in aquatic sediments. Mar Chem 97:262-276

113. Koo Y-EL, Cao Y, Kopelman R, Koo SM, Brasuel M, Philbert MA (2004) Real-time measurements of dissolved oxygen inside live cells by organically modified silicate fluorescent nanosensors. Anal Chem 76(9):2498-2505

114. Koren K, Borisov SMKI (2012) Stable optical oxygen sensing materials based on click-coupling of fluorinated platinum(II) and palladium (II) porphyrins - a convenient way to eliminate dye migration and leaching. Sens Actuators B 169:173-181

115. Koren K, Borisov SM, Saf R, Klimant I (2011) Strongly phosphorescent iridium(III)-porphyrins - new oxygen indicators with tuneable photophysical properties and functionalities. Eur J Inorg Chem 2011(no. 10):1531-1534

116. Koren K, Dmitriev RI, Borisov SM, Papkovsky DB, Klimant I (2012) Complexes of IrIII-octaethylporphyrin with peptides as probes for sensing cellular O2. ChemBioChem 13(8):11841190

117. Köse ME, Crutcheley RJ, DeRosa MC, Ananthakrishnan N, Reynolds JR, Schanze KS (2005) Morphology and oxygen sensor response of luminescent Ir-labeled poly(dimethylsiloxane)/polystyrene polymer blend films. Langmuir 21:8255-8262

118. Kostov Y, Harms P, Pilato RS, Rao G (2000) Ratiometric oxygen sensing: detection of dual-emission ratio through a single emission filter. Analyst 125(6):1175-1178

119. Kuhl Y, Cohen T, Dalsgaard B, Jorgensen B, Reversbech NP (1995) Microenvironment and photosynthesis of zooxanthellea in scleractinian corals studied with microsensors for $\mathrm{O} 2, \mathrm{pH}$ and light. Mar Ecol Prog Ser 117:159-172

120. Kühl G, Larkum AWD, Ralph P (2008) Imaging of oxygen dynamics within the endolithic algal community of the massive coral porites lobata. J Phycol 44:541-550

121. Kühl M, Polerecky L (2008) Functional and structural imaging of phototrophic microbial communities and symbioses. Aquat Microb Ecol 53:99-118

122. Kunkely H, Vogler A (1990) Photoluminescence of platinum complex [PtII(4,7-diphenyl-1,10-phenanthroline)(CN)2] in solution. J Am Chem Soc 112(14):5625-5627

123. Lai S-W, Hou Y-J, Che C-M, Pang H-L, Wong K-Y, Chang CK, Zhu N (2004) Electronic spectroscopy, photophysical properties, and emission quenching studies of an oxydatively robust perfuorinated platinum porphyrin. Inorg Chem 43:3724-3732

124. Lakowicz JR (2006) Principle of fluorescence spectroscopy. Springer, Baltimore

125. Lakowicz JR, Berndt K (1991) Lifetime-selective fluorescence imaging using a RF phase sensitive camera. Rev Sci Instrum 62:1727-1734

126. Lamansky S, Djurovich P, Murphy D, Abdel-Razzaq F, Lee H-E, Adachi C, Burrows PE, Forrest SR, Thompson ME (2001) Highly phosphorescent bis-cyclometalated iridium complexes: synthesis, photophysical characterization, and use in organic light emitting diodes. J Am Chem Soc 123(18):4304-4312

127. Larkum A, Koch E, Kühl M (2003) Diffusive boundary layers and photosynthesis of teh epilithic algal community of coral reefs. Mar Biol 142:1073-1082 
128. Larsen M, Borisov SM, Grundwald B, Klimant I, Glud RN (2011) A simle and inexpensive high resolution color ratiometric planar optode imaging approach: application to oxygen and $\mathrm{pH}$ sensing. Limnol Oceanogr Meth 9:348-360

129. Law G-L, Pal R, Palsson LO, Parker D, Wong K-L (2009) Responsive and reactive terbium complexes with an azaxanthone sensitiser and one naphthyl group: applications in ratiometric oxygen sensing in vitro and in regioselective cell killing. Chem Commun 47:7321-7323

130. Lebedev AY, Cheprakov AV, Sakadzic S, Boas DA, Wilson DF, Vinogradov SA (2009) Dendritic phosphorescent probes for oxygen imaging in biological systems. ACS Appl Mater Interfaces 1 (6): 1292-1304

131. Lecoq J, Parpaleix A, Roussakis E, Ducros M, Houssen YG, Vinogradov SA, Charpak S (2011) Simultaneous two-photon imaging of oxygen and blood flow in deep cerebral vessels. Nat Med 17(7):893-898

132. Lee S-K, Okura I (1997) Optical sensor for oxygen using a porphyrin-doped sol-gel glass. Analyst 122:81-84

133. Lee S-K, Okura I (1997) Porphyrin-doped sol-gel glass as a probe for oxygen sensing. Anal Chem Acta 342:181-188

134. Lee S-K, Okura I (1997) Photostable optical oxygen sening material: platinum tetrakis(pentafluorophenyl)porphyrin immobilized in polystyrene. Anal Comm 34:185-188

135. Lee Y-EK, Ulbrich EE, Kim G, Hah H, Strollo C, Fan W, Gurjar R, Koo S, Kopelman R (2010) Near infrared luminescent oxygen nanosensors with nanoparticle matrix tailored sensitivity. Anal Chem 82(20):8446-8455

136. Li X, Rosenzweig Z (1997) A fiber optic sensor for rapid analysis of bilirubin in serum. Anal Chim Acta 353:263-273

137. Li L, Walt DR (1995) Dual-analyte fiber-optic sensor for the simultaneous and continuous measurement of glucose and oxygen. Anal Chem 67(20):3746-3752

138. Li S, Zhao X (2011) Oxygen sensing nanofibers doped with redemitting Eu(III) complex: synthesis, characterization, machanism, and sensing performance. Synth Met 161:737-742

139. Liebsch G, Klimant I, Frank B, Holst G, Wolfbeis OS (2000) Luminescence lifetime imaging of oxygen, $\mathrm{pH}$, and carbon dioxide distribution using optical sensors. Appl Spectrosc 54(4):548559

140. Liebsch G, Klimant I, Wolfbeis OS (1999) Luminescence lifetime temperature sensing based on sol-gels and poly(acrylonitrile)s dyed with ruthenium metal-ligand complexes. Adv Mater 11 (15): 1296-1299

141. Lin C-T, Böttcher M, Creutz C, Sutin N (1976) Mechanism of the quenching of the emission of substituted polypyridineruthenium (II) complexes by Iron(III), chromium(III) and europium(III) ions. J Am Chem Soc 98:6536-6544

142. Lippitsch ME, Pusterhofer J, Leiner MJP, Wolfbeis OS (1988) Fibre-optic oxygen sensor with the fluorescence decay time as the infomation carrier. Anal Chim Acta 205:1-6

143. Liu Y, Guo H, Zhao J (2011) Ratiometric luminescent molecular oxygen sensors based on uni-luminophores of C[caret] $\mathrm{N} \mathrm{Pt(II)(a-}$ cac) complexes that show intense visible-light absorption and balanced fluorescence/phosphorescence dual emission. Chem Comm 47(41):11471-11473

144. Liu Y-M, Pereoro-Garcia R, Valencia-Gonzalez MJ, Diaz-Gracia ME, Sanz-Medel A (1994) Evaluation of some immobilized room-temperature phosphorescent metal chelates as sensing materials for oxygen. Anal Chem 66:836-840

145. Liu X, Sun W, Zou L, Xie Z, Li X, Lu C, Wang L, Cheng Y (2012) Neutral cuprous complexes as ratiometric oxygen gas sensors. Dalton Trans 41(4):1312-1319

146. Lo L-W, Koch CJ, Wilson DF (1996) Calibration of oxygendependent quenching of the phosphorescence of Pd-meso-tetra (4-carboxyphenyl)porphine: a phosphor with general application for measuring oxygen concentration in biological systems. Anal Biochem 236:153-160

147. MacCraith BD, Mc Donagh CM, O'Keffe G, Keyes ET, Vos JG, O'Kelly B, McGilp JF (1993) Fibre optic oxygen sensor based on fluorescence quenching of evanescent-wave excited ruthenium complexes in sol-gel derived porous coatings. Analyst 118:385-388

148. Mack J, Asano Y, Kobayashi N, Stillman MJ (2005) Application of MCD spectroscopy and TD-DFT to a highly non-planar porphyrinoid ring system. New insights on red-shifted porphyrinoid spectral bands. J Am Chem Soc 127(50):17697-17711

149. Mak CSK, Pentlehner D, Stich M, Wolfbeis OS, Chan WK, Yersin H (2009) Exceptional oxygen sensing capabilities and triplet state properties of $\operatorname{Ir}(\mathrm{ppy}-\mathrm{NPh} 2) 3$. Chem Mater 21 (11):2173-2175

150. Marazuela MD, Moreno-Bondi MC (1998) Determination of choline-containing phospholipids in serum with a fiber-optic biosensor. Anal Chim Acta 374(1):19-29

151. Mayr T, Borisov SM, Abel T, Enko BWK, Mistlberger G, Klimant I (2009) Light harvesting as a simple and versatile way to enhance brightness of luminescent sensors. Anal Chem 81:6541-6545

152. McDonagh C, Bowe P, Mongey KMBD (2002) Characterization of porosity and sensor response times of sol-gel-derived thin films for oxygen sensor application. J Non-Cryst Solids 306:138-148

153. McDonagh C, Burke CS, MacCraith BD (2008) Optical chemical sensors. Chem Rev 108(2):400-422

154. Mcevoy AK, McDonagh C, MacCraith BD (1997) Optimization of sol-gel-derived silica films for optical oxygen sensing. J SolGel Sci Technol 8:1121-1125

155. McLaurin EJ, Greytak AB, Bawendi MG, Nocera DG (2009) Two-photon absorbing nanocrystal sensors for ratiometric detection of oxygen. J Am Chem Soc 131:12994-13001

156. McLean TM, Moody JL, Waterland MR, Telfer SG (2012) Luminescent rhenium(I)-dipyrrinato complexes. Inorg Chem $51: 446-455$

157. Medina-Castillo AL, Fernandez-Sanchez JF, Klein C, Nazeeruddin MK, Segura-Carretero A, Fernandez-Gutierrez A, Graetzel M, Spichiger-Keller UE (2007) Engineering of efficient phosphorescent iridium cationic complex for developing oxygen-sensitive polymeric and nanostructured films. Analyst 132(9):929-936

158. Meier RJ, Schreml S, Wang X-d, Landthaler M, Babilas P, Wolfbeis OS (2011) Simultaneous photographing of oxygen and $\mathrm{pH}$ in vivo using sensor films. Angew Chem Int Ed 50(no. 46):10893-10896

159. Meier B, Werner T, Klimant I, Wolfbeis OS (1995) Novel oxygen sensor material based on a ruthenium bipyridyl complex encapsulated in zeolite Y: dramatic differences in the efficiency of luminescence quenching by oxygen on going from surface-adsorbed to zeolite-encapsulated fluorophores. Sen Actuators B 29:240-245

160. Millikan GA (1942) The oximeter, an instrument for measuring continuously the oxygen saturation of arterial blood in man. Rev Sci Instr 13(10):434-444

161. Mills A (1999) Response characteristics of optical sensors for oxygen: a model based on a distribution in [small tau]oand kq. Analyst 124(9):1309-1314

162. Mills A, Lawrie K, Bardin J, Apedalie A, Skinner GA, O’Rouke C (2012) An O2 smart plastic film for packaging. Analyst 137:106-112

163. Mills A, Lepre A, Theobald BRC, Slade E, Murrer BA (1997) Use of luminescent gold compounds in the design of thin-film oxygen sensors. Anal Chem 69:2842-2847

164. Mills A, Thomas M (1997) Fluorescence-based thin plastic film ion-pair sensors for oxygen. Analyst 122:63-68

165. Mills A, Tommons C, Bailey RT, Crilly P, Tedford MC (2011) Thin-film oxygen sensors using a luminescent polynuclear gold (I) complex. Anal Chem Acta 702:269-273 
166. Mingoarranz FJ, Moreno-Bondi MC, Garcia-Fresnadillo D, de Dios C, Orellana G (1995) Oxygen-sensitive layers for optical fibre devices. Mikrochim Acta 121:107-118

167. Mitsubayashi K, Kon T, Hashimoto Y (2003) Optical bio-sniffer for ethanol vapor using an oxygen-sensitive optical fiber. Biosens Bioelectron 19(3):193-198

168. Morin AM, Xu W, Demas JN, DeGraff BA (2000) Oxygen sensors based on quenching of tris-(4,7-diphenyl-1.10-phenanthroline)ruthenium(II) in fluorinated polymers. J Fluoresc 10:7-12

169. Nagl S, Baleizao C, Borisov SM, Schäferling M, Barberan MN, Wolfbeis OS (2007) Optical sensing and imaging of trace oxygen with record response. Angew Chem Int Ed 46:2317-2319

170. Napp J, Behnke T, Fischer L, Würth C, Wottawa M, Katschinski DM, Alves F, Resch-Genger U, Schäferling M (2011) Targeted luminescent near-infrared polymer-nanoprobes for in vivo imaging of tumor hypoxia. Anal Chem 83:9039-9046

171. Neugebauer U, Pellegrin Y, Devocelle M, Forster RJ, Signac W, Moran N, Keyes TE (2008) Ruthenium polypyridyl peptide conjugates: membrane permeable probes for cellular imaging. Chem Commun 42(42):5307-5309

172. Niedermair F, Borisov SM, Zenkl G, Hofmann OT, Weber H, Saf R, Klimant I (2010) Tunable phosphorescent NIR oxygen indicators based on mixed benzo- and naphthoporphyrin complexes. Inorg Chem 49(no. 20):9333-9342

173. Nock V, Blaikie RJ, David T (2008) Patterning, integration and characterization of polymer optical oxygen sensors for microfluidics devices. Lab Chip 8:1300-1307

174. O'Riordan TC, Zhdanov AV, Ponomarev GV, Papkovsky DB (2007) Analysis of intracellular oxygen and metabolic responses of mammalian cells by time-resolved fluorometry. Anal Chem 79 (24):9414-9419

175. Okazaki T, Imasaka T, Ishibashi N (1988) Optical-fiber sensor based on the second-harmonic emission of a near-infrared semiconductor laser as light source. Anal Chim Acta 209:327-331

176. Opitz N, Graf H-J, Lübbers DW (1988) Oxygen sensor for the temperature range 300 to $500 \mathrm{~K}$ based on fluorescence quenching of indicator-treated silicone rubber membranes. Sens Actuators 13(2):159-163

177. Papkovsky DB (1995) New oxygen sensors and their application to biosensing. Sens Actuators B 29(1-3):213-218

178. Papkovsky DB, Olah J, Troyanovsky IV, Sadovsky NA, Rumyantseva VD, Mironov AF, Yaropolov AI, Savitsky AP (1992) Phosphorescent polymer films for optical oxygen sensors. Biosens Bioelectron 7(3):199-206

179. Papkovsky DB, Ponomarev GV, Trettnak W, O'Leary P (1995) Phosphorescent complexes of phorphyrin ketones: optical properties and application to oxygen sensing. Anal Chem 67:4112-4117

180. Park EJ, Reid KR, Tang W, Kennedy RT, Kopelman R (2005) Ratiometric fiber optic sensors for the detection of inter- and intracellular dissolved oxygen. J Mater Chem 15(27-28):2913-2919

181. Pasic A, Koehler H, Klimant I, Schaupp L (2007) Miniaturized fiber-optic hybrid sensor for continuous glucose monitoring in subcutaneous tissue. Sens Actuators B 122:60-68

182. Pasic A, Koehler H, Schaupp L, Pieber T, Klimant I (2006) Fiberoptic flow-through sensor for online monitoring of glucose. Anal Bioanal Chem 386(5):1293-1302

183. Peterson JI, Fitzgerald RV, Buckhold DK (1984) Fiber-optic probe for in vivo measurement of oxygen partial pressure. Anal Chem 56(1):62-67

184. Polerecky L, Lott C, Weber M (2008) In situ measurement of gross photosynthesis using a microsensor-based light-shade shift method. Limnol Oceanogr Meth 6:373-383

185. Pollack M, Pringsheim P, Terwoord D (1944) A method for determining small quantities of oxygen. J Chem Phys 12 (7):295-299
186. Puklin E, Carlson B, Gouin S, Costin C, Green E, Ponomarev S, Tanji H, Gouterman M (2000) Ideality of pressure-sensitive paint. I. Platinum tetra(pentafluorophenyl)porphine in fluoroacrylic polymer. J Appl Polym Sci 77:2795-2804

187. Roberts L, Lines R, Reddy S, Hay J (2011) Investigation of polyviologens as oxygen indicators in food packaging. Sens Actuators B 152:63-67

188. Rogers JE, Nguyen KA, Hufnagle DC, McLean DG, Su W, Gossett KM, Burke AR, Vinogradov SA, Pachter R, Fleitz PA (2003) Observation and interpretation of annulated porphyrins: studies on the photophysical properties of meso-tetraphenylmetalloporphyrins. J Phys Chem A 107(51):11331-11339

189. Röösli S, Pretsch E, Morf WE, Tsuchida E, Nishide H (1997) Selective optical response to oxygen of membranes based on immobilized cobalt(II) porphyrins. Anal Chim Acta 338:119-125

190. Rosenow TC, Walzer K, Leo K (2008) Near-infrared organic light emitting diodes based on heavy metal phthalocyanines. J Appl Phys 103(no. 4):043105

191. Rozhkov VV, Khajehpour M, Vinogradov SA (2003) Luminescent $\mathrm{Zn}$ and Pd tetranaphthaloporphyrins. Inorg Chem 42(14):42534255

192. Rumsey WL, Vanderkooi JM, Wilson DF (1988) Imaging of phosphorescence: a novel method for measuring oxygen distribution in perfused tissue. Science 241(4873):1649-1651

193. Sacksteder L, Demas JN, DeGraff BA (1993) Design of oxygen sensors based on quenching of luminescent metal complexes: effect of ligand size on heterogeneity. Anal Chem 65(23):3480-3483

194. Sacksteder L, Lee M, Demas JN, DeGraff BA (1993) Long-lived, highly luminescent rhenium(I) complexes as molecular probes: intra- and intermolecular excited-state interactions. J Am Chem Soc 115(18):8230-8238

195. Sakadzic S, Roussakis E, Yaseen MA, Mandeville ET, Srinivasan VJ, Arai K, Ruvinskaya S, Devor A, Lo EH, Vinogradov SA, Boas DA (2010) Two-photon high-resolution measurement of partial pressure of oxygen in cerebral vasculature and tissue. Nat Meth 7(9):755-759

196. Schäferling $M$ (2012) The art of fluorescence imaging with chemical sensors. Angew Chem Int Ed Engl 51(15):3532-3554

197. Schaffar BPH, Wolfbeif OS (1990) A fast responding fibre optic glucose biosensor based on an oxygen optrode. Biosens Bioelectron 5(2):137-148

198. Schmälzlin E, van Dongen JT, Klimant I, Marmodee B, Steup M, Fisahn J, Geigenberger P, Löhmannsröben H-G (2005) An optical multifrequency phase-modulation method using microbeads for measuring intracellular oxygen concentration in plants. Biophys $\mathrm{J}$ 89:1339-1345

199. Schneider K, Schütz V, John G, Heinzle E (2010) Optical device for parallel online measurement of dissolved oxygen and $\mathrm{pH}$ in shake flask cultures. Bioprocess Biosyst Eng 33(5):541-547

200. Schreml S, Meier RJ, Wolfbeis OS, Maisch T, Szeimies RM, Landthaler M, Regensburger J, Santarelli F, Klimant I, Babilas P (2011) 2D luminescence imaging of phystiological wound oxygenation. Exp Dermatol 20(7):550-554

201. Schrenkhammer P, Wolfbeis OS (2008) Fully reversible optical biosensors for uric acid using oxygen transduction. Biosens Bioelectron 24:994-999

202. Schröder CR, Polerecky L, Klimant I (2007) Time-resolved pH/ pO2 mapping with luminescent hybrid sensors. Anal Chem 79 (1):60-70

203. Severinghaus JW, Honda Y (1987) History of blood gas analysis. VII. Pulse oximetry. J Clin Monit 3:135-138

204. Shaw G (1967) Quenching by oxygen diffusion of phosphorescence emission of aromatic molecules in polymethyl methacrylate. Trans Faraday Soc 63:2181-2189

205. Smith CS, Branham CW, Marquardt BJ, Mann KR (2010) Oxygen gas sensing by luminescence quenching in crystals of $\mathrm{Cu}$ 
(xantphos)(phen)+complexes. J Am Chem Soc 132:1407914085

206. Smith CS, Mann KR (2012) Exceptionally long-lived luminescence from $[\mathrm{Cu}(\mathrm{I})$ (isocyanide)2(phen) $]+$ complexes in nanoporous crystals enables remarkable oxygen gas sensing. J Am Chem Soc 134(21):8786-8789

207. Sommer JR, Farley RT, Graham KR, Yang Y, Reynolds JR, Xue J, Schanze KS (2009) Efficient near-infrared polymer and organic light-emitting diodes based on electrophosphorescence from (tetraphenyltetranaphtho[2,3]porphyrin)platinum(II). ACS Appl Mater Interfaces 1(2):274-278

208. Songzhu L, Xiangting D, Jinxian W, Guixia L, Wenshen Y, Roukun J (2010) Fabrication of Eu(III) complex doped nanofibrous membrane and their oxygen-sensitive properties. Spectrochim Acta A 77:885-889

209. Spellane PJ, Gouterman M, Kim AAS, Liu YC (1980) Porphyrins 40. Electronic spectra and four-orbital energies of free-base, zinc, copper, and palladium tertrakis(perfluorophenyl)porphyrins. Inorg Chem 19:386-391

210. Steiner MS, Duerkop A, Wolfbeis OS (2011) Optical methods for sensing glucose. Chem Soc Rev 40(9):4805-4839

211. Steunenberg P, Ruggi A, van den Berg NS, Buckle T, Kuil J, Fijs WB, Velders AH (2012) Phosphorescence imaging of living cells with amino acid-functionalized tris(2-phenylpyridine)iridium(III) complexes. Inorg Chem 51(no. 4):2105-2114

212. Stich MI, Borisov SM, Henne U, Schäferling M (2009) Read-out of multiple optical chemical sensors by means of digital color cameras. Sens Actuators B 139(1):204-207

213. Stubenrauch K, Sandholzer M, Niedermair F, Waich K, Mayr T, Klimant I, Trimmel G, Slugove C (2008) Poly(norbornene)s as matrix materials for platinum tetrakis(pentafuorophenyl)porphyrin based optica oxygen sensors. Eur Polym J 44:2558-2566

214. Thévenot DR, Toth K, Durst RA, Wilson GS (2001) Electrochemical biosensors: recommended definitions and classification. Biosens Bioelectron 16:121-131

215. Thomas P, Halter M, Tona A, Raghavan SR, Plant AL, Forry S (2009) A noninvasive thin film sensor for monitoring oxygen tension during in vitro cell culture. Anal Chem 81(22):9239-9246

216. Tian Y, Shumway BR, Meldrum DR (2010) A New crosslinkable oxygen sensor covalently bonded into poly(2-hydroxyethyl methacrylate)-co-polyacrylamide thin film for dissolved oxygen sensing. Chem Mater 22(6):2069-2078

217. Trettnak W, Kolle C, Reininger F, Dolezal C, O’Leary P (1996) Miniaturized luminescence lifetime-based oxygen sensor instrumentation utilizing a phase modulation technique. Sens Actuators B 35-36:506-512

218. Trettnak W, Leiner MJP, Wolfbeis OS (1988) Optical sensors. Part 34. Fibre optic glucose biosensor with an oxygen optrode as the transducer. Analyst 113(10):1519-1523

219. Tusa JK, He H (2005) Critical care analyzer with fluorescent optical chemosensors for blood analytes. J Mater Chem 15(2728):2640-2647

220. Van Houten KA, Walters KA, Schanze KS, Pilato RS (2000) Study of the heterocyclic-substituted platinum-1,2-enedithiolate 3ILCT excited states by transient absorption spectroscopy. J Fluoresc 10(1):35-40

221. Vasil'ev VV, Borisov SM (2002) Optical oxygen sensors based on phosphorescent water-soluble platinum metals porphyrins immobilized in perfluorinated ion-exchange membrane. Sensors Actuators B 82(no. 2-3):272-276

222. Vasil'ev VV, Borisov SM, Chubarova YO, Rumyantseva VD (2003) Dimerization, aggregation, and luminescent properties of palladium(II) and platinum(II) complexes with meso-tetrakis(4carboxyphenyl)porphyrin. Russ J Inorg Chem 48(no. 3):385-390

223. Vogel A, Venugopalan V (2003) Mechanisms of pulsed laser ablation of biological tissues. Chem Rev 103(2):577-644
224. Voraberger HS, Kreimaier H, Biebernik K, Kern W (2001) Novel oxygen optrode withstanding autoclavation: technical solutions and performance. Sens Actuators B 74:179-185

225. Wang X, Chen H, Zhou T, Lin Z, Zeng J, Xie Z, Chen X, Wong K, Chen G, Wang X (2009) Optical colorimetric sensor strip for direct readout glucose measurement. Biosens Bioelectron 24 (12):3702-3705

226. Wang Y, Li B, Zhang L, Zuo Q, Li P, Zhang J, Su Z (2011) Highperformance oxygen sensors based on EuIII complex/polystyrene composite nanofibrous memabranes prepared by electrospinning. Chem Phys Chem 12:349-355

227. Wang Z, McWilliams AR, Evans CEB, Lu X, Chung S, Winnik MA, Manners I (2002) Covalent attachment of RuII phenanthroline complexes to polythionylphosphazenes: the development and evaluation of single-component polymeric oxygen sensors. Adv Funct Mater 12(6-7):415-419

228. Wang X, Meier RJ, Link M, Wolfbeis OS (2010) Photographing oxygen distribution. Angew Chem Int Edit 49(29):4907-4909

229. Wang XF, Uchida T, Coleman DM, Minami S (1991) A two dimensional fluorescence lifetime imaging system using a gated image intesifier. Appl Spectrosc 45:360-366

230. Wang X, Zhou T, Chen X, Wong K, Wang X (2008) An optical biosensor for the rapid determination of glucose in human serum. Sens Actuators B 129(2):866-873

231. Wenzhöfer F, Glud RN (2004) small-scale spatial and temporal variability in coastal benthic $\mathrm{O} 2$ dynamics: effects of fauna activity. Limnol Oceanogr 49(5):1471-1481

232. Werner T, Klimant I, Huber C, Krause C, Wolfbeis OS (1999) Fiber optic ion-microsensors based on luminescence lifetime. Mikrochim Acta 131(1):25-28

233. Wilhem S, Wolfbeis O (2011) Irreversible sensing of oxygen ingress. Biosens Actuators B 153:199-204

234. Wolfbeis OS (2006) Fiber-optic chemical sensors and biosensors. Anal Chem 78(12):3859-3874

235. Wolfbeis OS, Leiner PMJ, Posch HE (1986) A new sensing material for optical oxygen measurement, with the indicator embedded in an aqueous phase. Mikrochim Acta 90(5):359-366

236. Wolfbeis OS, Oehme I, Papkovskaya N, Klimant I (2000) Sol-gel based glucose biosensors employing optical oxygen transducers, and a method for compensating for variable oxygen background. Biosens Bioelectron 15:69-76

237. Wolfbeis OS, Posch HE, Kroneis HW (1985) Fiber optical fluorosensor for determination of halothane and/or oxygen. Anal Chem 57:2556-2561

238. Woods RJ, Scypinski S, Cline LJ (1984) Transient digitizer for the determination of microsecond luminescence lifetimes. Anal Chem 56(8):1395-1400

239. Wu XJ, Choi MMF (2003) Hydrogel network entrapping cholesterol oxidase and octadecylsilica for optical biosensing in hydrophobic organic or aqueous micelle solvents. Anal Chem 75:4019-4027

240. Wu XJ, Choi MMF (2004) An optical glucose biosensor based on entrapped-glucose oxidase in silicate xerogel hybridised with hydroxyethyl carboxymethyl cellulose. Anal Chim Acta 514 (2):219-226

241. Wu XJ, Choi MMF (2004) Spongiform immobilization architecture of ionotropy polymer hydrogel coentrapping alcohol oxidase and horseradish peroxidase with octadecylsilica for optical biosensing alcohol in organic solvent. Anal Chem 76(15):4279-4285

242. Wu XJ, Choi MMF, Wu XM (2004) An organic-phase optical phenol biosensor coupling enzymatic oxidation with chemical reduction. Analyst 129(11):1143-1149

243. Wu X, Choi MMF, Xiao D (2000) A glucose biosensor with enzyme-entrapped sol-gel and an oxygen-sensitive optode membrane. Analyst 125(no. 1):157-162

244. Wu W, Wu W, Ji S, Guo H, Song P, Han K, Chi L, Shao J, Zhao J (2010) Tuning the emission properties of cyclometalated 
platinum(II) complexes by intramolecular electron-sink/arylethynylated ligands and its application for enhanced luminescent oxygen sensing. J Mater Chem 20(43):9775-9786

245. Xavier MP, Garcia-Fresnadillo D, Moreno-Bondi MC, Orellana G (1998) Oxygen sensing in nonaqueous media using porous glass with covalently bound luminescence $\mathrm{Ru}(\mathrm{II})$ complexes. Anal Chem 70:5184-5189

246. Xiang H, Zhou L, Feng Y, Cheng J, Wu D, Zhou X (2012) Tunable fluorescent/phosphorescent platinum(II) porphyrinfluorene copolymers for ratiometric dual emissive oxygen sensing. Inorg Chem 51(9):5208-5212

247. Xiao D, Choi MMF (2002) Aspartame optical biosensor with bienzyme-immobilized eggshell membrane and oxygensensitive optode membrane. Anal Chem 74(4):863-870

248. Xie K, Zhang X-W, Huang L, Wang Y-T, Lei Y, Rong J, Qian CW, Xie Q-L, Wang Y-F, Hong A, Xiong S (2011) On-line monitoring of oxygen in TubeSpin, a novel, small-scale disposable bioreactor. Cytotechnology 63(4):345-350

249. Xu H, Aylott JW, Kopelman R, Miller TJ, Philbert MA (2001) A real-time ratiometric method for the determination of molecular oxygen inside living cells using sol-gel-based spherical optical nanosensors with applications to Rat C6 glioma. Anal Chem 73 (17):4124-4133

250. Xu W, Kneas KA, Demas JN, DeGraff BA (1996) Oxygen sensors based on luminescence quenching of metal complexes: osmium complexes suitable for laser diode excitation. Anal Chem 68(15):2605-2609

251. Xu W, McDonough RC, Langsdorf B, Demas JN, DeGraff BA (1994) Oxygen sensor based on luminescence quenching: Interactions of metal complexes with the polymer supports. Anal Chem 66:4133-4141
252. Xu W, Schmidt R, Whaley M, Demas JN, DeGraff BA, Karikari EK, Farmer BL (1995) Oxygen sensors based on luminescence quenching: interations of pyrene with the polumer supports. Anal Chem 67:3172-3180

253. Yingkui L (2011) High performance oxygen sensing nanofibrous membranes of Eu(III) complex/polystyrene prepared by electrospinning. Spectrochim Acta A 79:356-360

254. Yoshihara T, Yamaguchi Y, Hosaka M, Takeuchi T, Tobita S (2012) Ratiometric molecular sensor for monitoring oxygen levels in living cells. Angew Chem Int Ed 51:4148-4151

255. Zanzotto A, Szita N, Boccazzi P, Lessard P, Sinskey AJ, Jensen KF (2004) Membrane-aerated microbioreactor for highthroughput bioprocessing. Biotechnol Bioeng 87(2):243-254

256. Zhang G, Chen J, Payne SJ, Kooi SE, Demas JN, Fraser CL (2007) Multi-emissive difluoroboron dibenzoylmethane polylactide exhibiting intense fluorescence and oxygen-sensitive room-temperature phosphorescence. J Am Chem Soc 129:8942-8943

257. Zhang S, Hosaka M, Yoshihara T, Negishi K, Iida Y, Tobita S, Takeuchi T (2010) Phosphorescent light-emitting iridium complexes serve as a hypoxia-sensing probe for tumor imaging in living animals. Cancer Res 70(11):4490-4498

258. Zhang G, Palmer GM, Dewhirst MW, Fraser CL (2009) A dualemissive-materials design concept enables tumour hypoxia imaging. Nat Mater 8:747-751

259. Zhujun Z, Seitz WR (1986) Optical sensor for oxygen based on immobilized hemoglobin. Anal Chem 58(1):220-222

260. Zuo Q, Li B, Zhang L, Wang Y, Liu Y, Zhang J, Chen Y, Guo L (2010) Synthesis, photophysical and oxygen-sensing properties of a novel Eu3+ complex incorporated in mesoporous MCM-41. J Solid State Chem 183:1715-1720 